University of Michigan Law School

University of Michigan Law School Scholarship Repository

Articles

Faculty Scholarship

2000

\title{
Michigan's Minority Graduates in Practice: The River Runs through Law School
}

Richard O. Lempert

University of Michigan Law School, rlempert@umich.edu

David L. Chambers

University of Michigan Law School, dcham@umich.edu

Terry K.Adams

University of Michigan, tkadams@umich.edu

Available at: https://repository.law.umich.edu/articles/1479

Follow this and additional works at: https://repository.law.umich.edu/articles

Part of the Law and Race Commons, Legal Education Commons, and the Legal Profession Commons

\section{Recommended Citation}

Lempert, Richard O. "Michigan's Minority Graduates in Practice: The River Runs through Law School." D. L. Chambers and T. K. Adams, co-authors. Law \& Soc. Inquiry 25, no. 2 (2000): 395-505.

This Article is brought to you for free and open access by the Faculty Scholarship at University of Michigan Law School Scholarship Repository. It has been accepted for inclusion in Articles by an authorized administrator of University of Michigan Law School Scholarship Repository. For more information, please contact mlaw.repository@umich.edu. 
"FROM THE TRENCHES AND TOWERS"

Law School Affirmative Action: An Empirical Study

\title{
Michigan's Minority Graduates in Practice: The River Runs Through Law School
}

\author{
Richard O. Lempert, David L. Chambers, and Terry K. Adams
}

This paper reports the results of a 1997-98 survey designed to explore the careers of the University of Michigan Law School's minority graduates from the classes of 1970 through 1996, and of a random sample of Michigan Law School's white alumni who graduated during the same years. It is to date the most detailed quantitative exploration of how minority students fare after they graduate from law school and enter law practice or related careers. The results reveal that almost all of Michigan Law School's minority graduates pass a bar exam and go on to have careers that appear successful by conventional measures. In particular, the survey indicates that minority graduates (defined so as to include graduates with African American, Latino, and Native American backgrounds) are no less successful than white graduates, whether success is measured by the log of current income, self-reported satisfaction, or an index of service contributions. Also, although an admissions index that combines LSAT scores and undergraduate grade-point average is a significant predictor of law school grades, it does not predict career success on any of our three outcome measures. Michigan is a highly selective law school; our results may not generalize to people who have graduated from other law schools.

Richard O. Lempert is Francis A. Allen professor of law and professor of sociology, University of Michigan. David L. Chambers is Wade H. McCree Jr. professor of law, University of Michigan. Terry K. Adams is senior research associate, University of Michigan Law School, and senior survey specialist, Institute for Social Research, University of Michigan. Work on this study was supported by the Cook Funds of the University of Michigan Law School and by the Russell Sage Foundation's appointment of Richard Lempert as a Visiting Scholar for the academic year 1998-99. We would like to thank Katherine Barnes and Lisa Kahraman for their help with the statistical analyses, Karl Monsma for his statistical advice, and Karin Garver for the many drafts of the manuscript and the tables that she typed. Too many people advised us on the design of the study or commented on earlier versions of this manuscript for us to thank them all by name, but we are very grateful to them, and the study and this paper have been improved substantially due to their criticisms. 
As teachers, we enjoy hearing news of our former students. They call us on the phone from time to time. They seek us out at reunions. They tell us about themselves and about other classmates we both knew. They also appear in our alumni magazines and occasionally in the newspapers. From all this, we develop a general impression of what our students are doing with their lives - a memory bank of upbeat stories of achievement and satisfaction and disheartening stories of overwork and disenchantment. Many of us develop such general impressions and stories about groups of our studentsour women graduates, our graduates of color.

Until recently very little was known beyond anecdote and impression about the careers of the many cohorts of students of color who have been admitted to the nation's colleges and professional schools under various race-conscious admissions programs. ${ }^{1}$ For one important group of students of color, this gap has recently been filled. In 1998, William Bowen, the former president of Princeton, and Derek Bok, the former president of Harvard, published their survey study of the graduates of 28 selective colleges and universities. In The Shape of the River: Long-Term Consequences of Considering Race in College and University Admissions, Bowen and Bok document that attending a selective undergraduate institution has profound benefits for black students admitted under race-conscious admissions programs (Bowen and Bok 1998). This study of graduates of the University of Michigan Law School is a natural extension of Bowen and Bok's project as it seeks to document the effects of what, for many of Bowen and Bok's graduates, is the next bend in the "river," attendance at an elite professional school. ${ }^{2}$

Law schools seek to admit students who will not only do well in law classes but also go on to have productive careers. The University of Michigan, for example, looks for students likely to become "esteemed practitioners, leaders of the American bar, significant contributors to legal scholarship and/or selfless contributors to the public interest." It expects that all those it admits will, "have a strong likelihood of succeeding in the practice of law and contributing in diverse ways to the well-being of others" (University of Michigan Law School Faculty Admissions Policy, 24 April 1992, p.1). Other law schools have similar aspirations for the students they admit. Our research is, we believe, the first systematic examination of minority and white law school graduates aimed at learning the degree to which they

1. Several studies have been done of doctors, focusing mainly on whether physicians of color were more likely than white physicians to serve patients of color. These studies generally find a link between physician race and patient race (Keith et al. 1986; Komaromy et al.1996; Moy and Bartman 1995; but see Davidson and Lewis 1997).

2. Between about a third and a half of those students entering Michigan in recent years are graduates of one of the 28 schools that Bowen and Bok studied, and many additional students come from schools like those that Bowen and Bok studied, but that were not included in their sample (e.g., Berkeley, Brown, Cornell, and Harvard). 
succeed in these ways and whether factors that are weighed in admissions decisions predict post-law school success.

This study looks at the post-graduation performance of minority alumni of the University of Michigan Law School starting with the graduating class of 1970, the first Michigan Law School class with more than 10 minority graduates. We use the terms minority admittees, minority alumni, minority students, and minority graduates to refer to members of three groups-blacks, Native Americans, and Latinos-whose race or ethnicity has, since 1966, been considered in the Law School's admissions process. One result of this process has been to enroll and graduate increasing numbers of black, Latino, and Native American students-about 300 in the 1970s, nearly 400 in the 1980s, and nearly 400 between 1990 and 1996, the last graduation year included in the study. By looking at the post-law school performance of these graduates, we-like Bowen and Bok-seek to inform the current debate about the wisdom of admissions policies that take race and ethnicity into account in admissions. But two important points must be made in this regard, especially since the University of Michigan Law School is currently being sued over its admission policies.

First, the admissions policy and practices of the Law School have changed considerably over the period from 1970 to the present. In particular, in 1992 the faculty adopted a new admissions policy that reflected the faculty's evolving thinking about the broad value within the law school of many sorts of diversity - of which racial and ethnic diversity is one important part. We have not attempted to capture any effects of these recent changes in admissions practices in our analyses, and only one of the 27 classes in our sample was admitted under the new procedures. This study is also not concerned with the historical motivation of the Law School for its consideration of race and ethnicity in admissions. It simply documents some results of that practice over time.

Second, unlike Bowen and Bok, we do not attempt in this article to identify which minority graduates would and would not have been admitted to the Law School if race and ethnicity had not been taken into account. Across the 27 classes included within the study, the Law School has considered race and ethnicity in varying ways in the admissions process. Some of the minority graduates we study would have been admitted to the law school under a so-called race-blind admissions program, but for a considerably larger number, race or ethnicity was a factor favoring their admission. Our study does not seek to differentiate among these groups, in part because, as the reader shall see, we have found little correlation between the numerical entry credentials that Michigan considers-undergraduate grade point average (UGPA) and Law School Admissions Test (LSAT) scoreson the one hand and any of our measures of achievement after law school on the other. 
Bowen and Bok surveyed graduates of 28 selective colleges and universities. With the cooperation of the schools in their sample, they were able to link application credentials and school records with questionnaire data from alumni of these schools. They focused primarily on students who graduated from their sample schools in 1976 and 1989, but for some purposes they used national samples of college graduates as well. Bowen and Bok found that although black graduates of the schools they studied received lower undergraduate grades than their white counterparts, as might have been expected from their lower Scholastic Aptitude Test scores, and had somewhat lower graduation rates, the overall picture of how the black students fared after graduation was one of substantial accomplishment. A central conclusion of their work is that the black students in their sample benefited substantially from being able to obtain elite undergraduate educations. Contrary to the suggestion made by some critics of affirmative action that black students would do better if they attended less selective schools where many white students had admissions credentials like their own, Bowen and Bok found that, even after controlling for SAT scores, the general pattern was that the more selective the institution attended, the more likely a black student was to graduate (Bowen and Bok 1998, 61), to look back with fondness on his or her undergraduate experience $(1998,199)$ and to do well after graduation. ${ }^{3}$

Our study is in many ways like the Bowen and Bok study. Like theirs, this study focuses on race-conscious affirmative action in admissions to elite higher education. Bowen and Bok chose elite schools of necessity, for only the more selective undergraduate institutions need to make race-conscious admissions decisions to ensure substantial ethnic diversity on campus. But, as Bowen and Bok point out, virtually every law school in the country is selective. Michigan generally receives at least 10 applications for every place in a class. Also, like Bowen and Bok, we use mail surveys and link respondents' answers to admissions credentials and indicators of success in school. We seek, as they did, to measure concrete indicators of postschool success, like income, as well as more obviously subjective measures, like expressed career satisfaction. We are also each concerned with how the graduates we study serve their communities. Our analytic strategies are also similar, and our results, as we shall see, are mutually reinforcing.

The major differences between our study and the Bowen and Bok study is that they focus on undergraduate education, while we look at education for the legal profession; and they look at graduates of 28 schools, while we look only at the graduates of one. These differences mean that they can generalize across schools and use school selectivity as a variable while we

3. Students at the more selective institutions among the 28 schools they studied were more likely to get professional or doctoral degrees $(1998,114)$, and they tended to earn more money at midcareer $(1998,143)$. 
cannot; but we have been able to look in greater depth than they at persons who enter a single profession, the jobs they take within that profession, and how they do in their jobs. Statistically, we have no basis for claiming that the results from our survey, which is limited to Michigan graduates, will generalize to graduates from any of the country's other law schools. Nonetheless, we have substantial reason to believe that the post-law school experiences and accomplishments of the minority graduates of at least 10 to 15 of the nation's most prestigious law schools will be similar to those of the graduates we study. Michigan is like most other high-prestige law schools in the quality of the students it admits, the educational opportunities it offers, and the jobs its graduates take. We are less confident that outcomes like those we describe will characterize graduates of schools not in this small group of elite law schools, but they may. Many fine law schools not at the top of the prestige hierarchy attract excellent students, give them fine educations, and supply national as well as local markets with young lawyers.

Our study also differs from Bowen and Bok's in that they focus solely on black alumni, while we provide information about black, Latino, and Native American graduates, the three groups of alumni who, as law school applicants, were eligible for affirmative-action consideration on the basis of their race or ethnicity. In this paper, we generally do not report on the three groups separately. Numerically, black alumni predominate, constituting two-thirds of the minority respondents to the survey. ${ }^{4}$ The three groups do not differ significantly along most of the career dimensions we discuss. They work in similar settings, earn similar incomes, and report similar levels of satisfaction. Where significant differences do exist, we report them either in the text or in footnotes. In a few places, we also discuss our students of Asian heritage, who are not part of either our minority or white samples. ${ }^{5}$

In most of our tables we divide our respondents into cohorts according to graduation decade. This is done primarily because many markers of success change with time from graduation, but also because the situation of minority students at Michigan and the conditions of law practice have

4. Our minority respondents included 360 black alumni (66.1\%), 106 Latino alumni (28.1\%), and 32 Native American alumni (5.9\%).

5. Alumni of Asian heritage are excluded from most analyses for several reasons. They were present only in small numbers until the 1990s; as a group, they were not ordinarily considered in Michigan's pre-1992 minority admissions program; and their status with respect to factors that distinguish the white and minority graduates we study is somewhat ambiguous. As applicants they typically had LSAT scores and UGPAs comparable with Michigan's white students, and as law students their grade point averages were similar to those of white students and higher than the averages of most other minority students. Nonetheless, they were a visible ethnic minority at Michigan Law School and in the city of Ann Arbor, and they remain a visible minority in the world of law practice. Also some Asian alumni report the kinds of experiences and strains that are associated with minority status. Their small numbers preclude a separate examination of Asians before the 1990 s, and their potential vulnerability to the strains minority group members face counsels against including them with the group of white students. 
changed over time. Not only are decade markers convenient divisions, but they also seem to capture effects associated with these changes, as there are often substantial differences in the responses of alumni who graduated in the different decades. We did not examine other possible graduation year breaks to see if using them would make differences starker. In our regression analyses, we pool respondents from the three decades and capture timelinked changes with the continuous variable "years since graduation."

\section{A NOTE ON GENDER}

Our group of minority respondents contains a higher proportion of women $(37.5 \%)$ than our group of white respondents $(24.2 \%)$, reflecting the fact that there have been proportionately more women among the minority students who have attended Michigan than among the white students who have gone there. The gender difference between whites and minorities potentially means that some of the data we present might be misleading. Apparent differences between white and minority graduates might reflect differences between men and women rather than differences associated with ethnicity, and tables showing no differences might reveal differences if the gender composition of our groups of white and minority graduates was the same.

Because of these possibilities, when we present regression analyses, we include a control for gender. Moreover, as a general check on whether gender might qualify the apparent influence of minority status, we examined 84 regression equations in which the independent variables entered sequentially were years since graduation, age entering law school, minority status, gender, and the interaction of gender and minority status. ${ }^{6}$ The dependent variables include most variables that figure in the tables that follow. In no instance did the inclusion of gender in an equation change the prior significance of minority status. If minority status was a significant predictor of a dependent variable before gender was included in the regression equation, it remained a significant predictor after gender was included. If minority status was not a significant predictor of a dependent variable, controlling for gender did not change this situation. However, adding a control for the gender/ minority-status interaction effect did, in a few instances, affect the significance of the minority status variable. In these cases, apparent differences between minorities and whites seem to reflect the special situation of white or minority men or women, rather than an ethnicity-related difference that exists regardless of gender. We note in the text or footnotes the few instances in which differences that appear associated with minority status

6. We used both OLS and logistic regression, depending on the nature of the dependent variable. 
seem largely due to the responses of just the women or just the men among minority or white respondents.

Although in places we suggest explanations for our findings and discuss their possible implications, our focus is not on unraveling causes for the relationships we find. This article is largely descriptive. But since we are describing what no one has seen before, we hope it will be of interest.

\section{CAPSULE SUMMARY}

The core of our study concerns the careers of Michigan Law School's alumni. Nearly all of Michigan's minority alumni are admitted to practice law in at least one state. They take initial jobs and hold current jobs in every area of the legal profession. They make somewhat different career choices than white alumni, as they are more likely than white alumni to begin their careers in government or other public service or public interest jobs and somewhat less likely than white alumni to begin their careers or to work today in the private practice of law. ${ }^{7}$ Still, private practice is the most common setting of work for Michigan's minority alumni and, in large numbers, they are associates and partners in firms of all sizes. All Michigan alumni are disproportionately likely to serve same-race clients, so minority alumni provide, on average, considerably more service to minority clients than white alumni do. Among those Michigan graduates who enter the private practice of law, minority alumni tend to do more pro bono work, sit on the boards of more community organizations, and do more mentoring of younger attorneys than white alumni do.

By any of our study's measures Michigan's minority alumni are, as a group, highly successful in their careers. Although, as a group, they entered Michigan with lower LSAT scores and lower UGPAs than other students, in their jobs immediately after law school and in their jobs today, Michigan's minority alumni are professionals fully in the mainstream of the American economy. They are well represented in all sectors of the legal profession. They are successful financially, leaders in their communities, and generous donors of their time to pro bono work and nonprofit organizations. Most are happy with their careers, and minority alumni respond no differently than white alumni when asked about overall career satisfaction. LSAT scores and UGPA scores, two factors that figure prominently in admissions decisions, correlate with law school grades, but they seem to have no relationship to success after law school, whether success is measured by earned income, career satisfaction, or service contributions. If admission to

7. In this paper, when we use the terms "private practice of law" or, more simply, "private practice" we are referring only to those attorneys who are in solo law practice or are employees or members of private-sector for-profit law firms. 
Michigan had been determined entirely by LSAT scores and UGPA, most of the minority students who graduated from Michigan would not have been admitted even though the measures that would have worked to exclude them seem to have virtually no value as predictors of post-law school accomplishments and success.

\section{METHODS}

This analysis is based on the responses to a seven-page questionnaire mailed in late 1997 and early 1998 to 2,144 members of the Michigan Law School classes of 1970-96. Because until recently minority law students have been a relatively small fraction of Michigan's student body, we sent questionnaires to all living minority alumni we could identify but to only a sample of white alumni. ${ }^{8}$ In sampling white alumni, we oversampled alumni with lower grade-point averages to better allow us to assess the implications of lower grades for job placement and performance. Tabular comparisons of white and minority alumni, except where noted, use weighted data for the white sample so that the percentage figures for white alumni are like those we would have found had our sample of white alumni been a simple random sample. Except where noted, significance tests take account of this weighting. In the regression analyses that conclude this study, we use unweighted data, but we often control separately for final law school grade point averages (LSGPAs). A methodological appendix available from the authors provides more detail on our sampling procedures and the weights we use to reconstitute our white sample.

In drafting the questionnaire, we were particularly interested in issues pertaining to ethnicity, but we wanted to avoid conveying the impression that we were seeking answers of any particular sort. For this reason we entitled the questionnaire "Professional Development Survey," and of the 90 questions we asked, only 13 related to race or ethnicity (such as ethnicity of coworkers and clients), and all of these questions were embedded in a context in which we were also asking about gender and, usually, other matters. A cover letter from Michigan's dean that accompanied the questionnaire made no mention of race and asked for cooperation in a study of our graduates' careers. Nowhere in either the questionnaire or the cover letter did we ask about or refer to admissions policies or to affirmative action. The cover letter did list an advisory panel in which minority alumni were disproportionately represented, ${ }^{9}$ and some recipients of the questionnaire may have

8. We actually mailed a total of 2,204 questionnaires. We do not in this paper use the responses to the 60 questionnaires that were sent to Michigan minority alumni who graduated before 1970 .

9. Ten of the twenty advisory committee members listed on the letter that accompanied our questionnaire were minorities, and nine of these ten were Michigan alumni. We had such 
inferred that we were particularly interested in issues relating to ethnicity or affirmative action. However, no respondent suggested this connection in the space we provided for additional comments, and the responses to this survey by minority and white alumni are much like the responses to similar questions in the Law School's annual alumni surveys, which have never had a significant focus on ethnic backgrounds.

\section{Response Rates}

We received responses to our questionnaire from $51.4 \%$ of the minority alumni in our sample and from $61.9 \%$ of white alumni who were mailed the survey. ${ }^{10}$ Among Asian graduates, who have been present in substantial numbers only in recent years, the response rate was $59.1 \%$. Response rates of minority and white alumni, the two groups that get most of our attention, are closer in each succeeding decade, and among graduates of the 1990s, the difference in response rates is not statistically significant. Tables 1 and 2 present these data and also indicate the separate response rates for black, Latino and Native American alumni. The minority alumni category, as we have noted, includes Native Americans, Latinos, and blacks.

Response rates for all groups are at levels commonly reported by those doing mail surveys. Nevertheless, we are concerned about the biases potentially introduced by nonresponse and the difference between the response rates of minority alumni and white alumni. There are obvious reasons why our respondents might differ from our nonrespondents in ways that are relevant to our study. It is plausible to suppose that responses are less likely from alumni who (1) have been relatively unsuccessful in their careers, (2) felt alienated from law school when they were students, (3) are now working in jobs far removed from the practice of law, (4) cannot be traced to good addresses, and (5) were exceptionally busy when they received our question-

a high proportion of minority members on this committee because we thought their implicit sponsorship would enhance minority graduate response rates. Also, we realized that few if any minority-group members would know the ethnicity of every listed minority-group member, so the prevalence of minorities on the advisory committee would probably appear less to most respondents than it in fact was. The advisory committee knew about the focus of our survey, and all the alumni who were minority graduates received the survey to fill out. However, only six of the nine advisory committee members responded. These respondents, who were asked to be advisory committee members because of their prominence and success, had no need to distort their careers to enhance the apparent success of minorities who graduated from the University of Michigan Law School. They had only to respond, yet had one more committee member not responded, their response rate would have been like that for all minorities. In addition, one white member of the advisory committee was sampled at random and returned a questionnaire.

10. A dozen respondents are excluded from our analyses because we could not link their questionnaire responses to their law school records. In eight cases this was because they had cut the ID \# labels from their questionnaires prior to returning them, and in the remaining cases it was because of a mix-up in affixing ID labels when the questionnaires were sent out. 
TABLE 1

Response Rates, by Ethnicity and Minority Status

\begin{tabular}{lrc} 
Ethnicity & n & $\begin{array}{c}\text { Proportion Returning } \\
\text { Questionnaires }\end{array}$ \\
\hline Black & 704 & $51.1 \%$ \\
Latino & 297 & $51.5 \%$ \\
Native American & 59 & $54.2 \%$ \\
All Minority & 1,060 & $51.4 \%$ \\
White & 935 & $61.9 \%$ \\
Asian & 149 & $59.1 \%$ \\
\hline
\end{tabular}

naire and reminders. Given our interest in career success and data which indicate that Michigan's white and minority graduates have similarly high achievements, what most concerns us is the first source of bias-the possibility that those who are least successful in practice are least likely to have responded. If responses are biased in this way, we will be overstating the accomplishments of both whites and minorities and, more important, overstating the accomplishments of minorities relative to whites, since minorities responded at a lower rate. The next three possibilities are concerns primarily because they may be associated with relatively unsuccessful

\section{TABLE 2}

\section{Response Rates, by Minority Status and Graduation Decade}

\begin{tabular}{lcc}
\hline Graduation Decade & Minority Alumni & White Alumni \\
\hline $1970 \mathrm{~s}^{* * *}$ & $48.7 \%$ & $64.4 \%$ \\
$1980 \mathrm{~s}^{* *}$ & $(300)$ & $(413)$ \\
& $50.5 \%$ & $60.4 \%$ \\
$1990 \mathrm{~s}$ & $(378)$ & $(346)$ \\
& $54.5 \%$ & $59.1 \%$ \\
& $(382)$ & $(176)$ \\
\hline
\end{tabular}

$* * p<.01 * * * p<.001$

NOTE Numbers in parentheses are the total number of respondents giving valid responses in the category and not the number represented by the percentage figures in a cell. Except as otherwise noted, this is true of subsequent tables as well, except that in subsequent tables (but not in table 1 or this one) the percentage figures for whites, unless otherwise noted, are weighted to indicate the proportion of people who would have been expected to be in the cell had we not disproportionately sampled whites with low grade point averages. Indicators of statistical significance in this and other tables, unless otherwise noted, indicate differences within decades between minority and white students. Where the data for whites are weighted, the significance tests are based on the weighted data to avoid giving undue influence to whites with low grade point averages. Using weighted data indicates that had we sampled randomly, we could have expected the decade-specific white response rates shown in this table to be between $2.9 \%$ and $.7 \%$ higher than what they in fact were. The significance levels of the differences between white and minority response rates by decades would have remained the same. 
careers. Because being busy is often an aspect of career success, the fifth possibility, that nonrespondents were busier than respondents, is less a concern unless it contributes more to white nonresponse than to minority nonresponse.

We devoted considerable attention to evaluating the likely existence and magnitude of nonresponse bias, particularly bias that would overstate the accomplishments of minorities relative to whites. We discuss what we did in more detail in a methodological appendix available on request from the authors. Here we briefly summarize the results of our investigations and explain why, though we can't discard entirely the possibility of sample bias, we think it is slight enough that it does not substantially distort the picture our data paint. ${ }^{11}$

First, we know that nonresponse is not largely attributable to unemployment or employment outside the practice of law. We were able to find a current place of employment in private practice, business, government or public interest work for $70 \%$ of our minority nonrespondents and $73 \%$ of the white nonrespondents. ${ }^{12} \mathrm{We}$ also are certain that among these nonrespondents are a great many high-earning persons. For example, of the 174 minority graduates we know to be working currently in firms of more than 50 lawyers, a group that among our respondents reports very high earnings, $41 \%$ were nonrespondents.

Second, a multivariate analysis was consistent with the hypothesis that most nonresponse results from factors that are randomly related to the variables that concern us. Using Multiple Classification Analysis (MCA), we regressed response status on demographic variables (e.g., ethnicity, gender),

11. Our effort to evaluate possible nonresponse bias was aided considerably by our access to law school records for all those in our sample. These allowed us to identify the ethnicity, gender, numerical entry credentials, and law school grades of our nonrespondents. In addition, for everyone in our sample, we independently sought to identify a current work setting and current status at work (e.g., partner, associate), and for those in law firms, the number of other attorneys in the firm. We did so by making use of not only Michigan Law School's address lists, but also Martindale-Hubbell and other online lists and directories of lawyers as well as bar directories from many states. For those in our original sample, we were able to acquire information about work settings from one of these non-questionnaire sources for $87 \%$ of the minority alumni and $90 \%$ of the white alumni. The result is that our information on current employment is to a large extent independent of the tendencies of sample alumni to keep the law school informed about their current addresses.

12. Our inability to find a current place of employment for nonrespondents by consulting the sources cited in note 11 , above, does not mean that the nonrespondents for whom we could not find jobs for were unemployed or employed outside the practice of law. Consulting the same sources, we were similarly unable to find current sources of employment for 134 of our respondents. Their responses indicate that $40 \%$ were engaged in the practice of law with an additional $13 \%$ in law-related jobs such as judge or law teacher and $15 \%$ in nonlaw positions as business executives or managers. Only one respondent indicated that he/she was unemployed, and an additional $13 \%$ chose not to indicate their current occupation. Moreover, $85 \%$ of these respondents indicated that they had practiced law at some time in their careers, and $70 \%$ had spent at least half their careers in law practice. Only $11 \%$ of these respondents indicated they had never practiced law. 
and such possible correlates of career success as job status (e.g., partner, associate, judge), job organization (e.g., law firm, federal government, legal services), law school grade-point average (LSGPA) and whether we could find recent work and home addresses for those in our sample. Despite the richness of these variables, we were able to explain only $9.3 \%$ of adjusted response variance in the full sample. ${ }^{13}$ Among minorities the same model explains $8.3 \%$ of the adjusted variance, and among whites $8.6 \%$ of the adjusted variance in response is explained. ${ }^{14}$

Third, those who did not respond had only slightly lower grades than those who did. When LSGPA is regressed on time since graduation (to control for grade inflation and the possibility that people who have been out longer will be harder to find) and whether a person in our sample responded, knowing whether a person responded uniquely explains only $1 \%$ of the variance in LSGPA among minorities and $1.6 \%$ of the variance among whites. Controlling for time since graduation, the average minority nonrespondent has an LSGPA .077 lower (on a scale that ranges between 2.0 and 4.5 ) than the average minority respondent, and the average white nonrespondent has a GPA .122 lower than that of the average white respondent. ${ }^{15}$ Not only are these differences small, but among respondents, law school grades do relatively little to explain various measures of post-law school accomplishment and success.

Fourth, among respondents there is little evidence that the amount of prodding needed to elicit responses relates to post-law school achievement, which is consistent with there being little relationship between not responding at all and post-law school achievement. Knowing whether a person responded to our original questionnaire only after a second or third reminder does not add significantly, for either whites or minorities, to the amount of variance explained by regression models we shall later present when the log of income or a service index is dependent. But among minorities, responders after one reminder have significantly lower satisfaction index scores than those who responded without a reminder. The difference is small, however (2.1 points on a 56-point scale). Moreover, those who needed two reminders have higher satisfaction scores than those who

13. Explained variance $\left(R^{2}\right)$ in MCA is computed in a manner mathematically equivalent to the comparable computation in ordinary least-squares regression with dummy predictor variables: explained sum of squares divided by total sum of squares. The adjusted explained variance $\left(R_{\text {adj }}^{2}\right)$ is computed from $R^{2}$ with an adjustment factor for the number of cases $(n)$, number of predictor variables $(p)$, and sum of categories of all predictor variables (c): $\mathrm{R}_{\text {adj }}^{2}=1-\left(1-\mathrm{R}^{2}\right)((\mathrm{n}-1) /(\mathbf{n}+\mathrm{p}-\mathrm{c}-1))$

14. When the data for whites are weighted to remove the effect of oversampling whites with low LSGPAs, our model explains $9.7 \%$ of the adjusted variance in responding among whites and $10.1 \%$ of the adjusted variance in the full sample.

15. Without the control for time since graduation, the average minority nonrespondent's LSGPA is .094 lower than that of the average minority respondent, and the average white nonrespondent's LSGPA is .113 lower than that of the average white respondent. 
needed only one. Also, when we look separately at the components of our satisfaction index, the difference across response waves is small and statistically insignificant for income satisfaction, although income is often taken as a marker of career success.

Fifth, among whites and minorities the amount of prodding needed does not relate to graded law school performance. When final LSGPA is regressed separately for whites and minorities on years since graduation and the two response wave variables, neither second-or third-wave respondents differ significantly from first-wave respondents in their law school GPAs.

Finally, the response rates of minorities and whites are closest and do not differ significantly for 1990s graduates. Thus it appears that at least for recent graduates in the early part of their careers, response bias is not a likely explanation for similarities or differences in career paths and accomplishments. It is, of course, the experience of recent graduates that most directly relates to the longer-term implications for individuals and society of Michigan's current minority admissions program.

We conclude from our bias checks that, as suggested by their slightly lower law school grades, those who didn't respond to our survey may, on average, be slightly less successful in some aspects of their careers than those who did respond, but if they are, the difference is likely to be too small to be a serious concern. Moreover, there is no evidence that minority nonrespondents have fared worse in their careers relative to minority respondents than white nonrespondents have fared relative to white respondents. Although a higher proportion of whites than minorities responded, our data provide little reason to believe that this response rate difference greatly affects comparisons between the two groups.

\section{Approach to Analysis}

With respect to many of the variables we investigate, we compare the performance of minority alumni with the performance of white alumni. We do this not because we regard differences between these groups as intrinsically important, but because it is often unclear what the normative or expected performance of Michigan Law School graduates might be. For example, we can report that the average minority graduate of the 1970s who is in private practice devotes about 137 hours a year to pro bono work, but without looking at white alumni we have no way of knowing whether 137 hours is a particularly large or small time commitment for a Michigan graduate who has been out of school at least 18 years. At the same time, devoting 137 hours a year to pro bono activity, the equivalent of three solid weeks of work, shows substantial effort and success in giving back to the community regardless of what white alumni do. Thus we can get a good sense of how minority alumni are doing by just looking at the data that pertain to them. 
The fact that, as we shall see, white private practitioners who graduated in the 1970s devote less time to pro bono work (an average of about 94 hours a year) than their minority counterparts does not increase the contribution that minority alumni are making or render the pro bono contributions of Michigan's white alumni insubstantial.

In order to gain a sense of what is typical for Michigan graduates, we use, for the most part, data from white alumni only in the comparisons we draw. Whites are the largest single ethnic group who attend Michigan Law School and, unlike Asians, who are also not part of the minority subsample, whites ordinarily don't have to cope, either in school or afterwards, with the destructive pressures resulting from ethnic prejudice that may bear on racial or ethnic minority group members. Asian alumni are present in such small numbers, especially before 1990 , and are for the most part so similar to white alumni in law school performance and career choices, that including them in the comparison group would not substantially change the similarities and contrasts that comparisons of white with minority alumni reveal.

Finally, we should point out that, except as explicitly noted, our data for all cohorts focus on the current (as of the time our questionnaire was answered) views and activities of Michigan Law School's alumni. In reading about the views and situations of graduates of the 1970s, 1980s, and 1990s, and about some of the marked differences between them, it is easy to slip into thinking that the differences we identify are differently dated, but most of the differences noted in the report are differences that exist today ${ }^{16}$ in the activities and attitudes of our respondents, although linked to the time respondents graduated. Many differences we see between graduates of different decades are, we believe, genuine cohort effects, meaning that we do not expect graduates of the 1980s and 1990s to look like graduates of the 1970s when they have been out of law school as long as the 1970s graduates have been. Some differences between cohorts, however, are to a large degree maturation effects, such as the high likelihood that graduates of the 1970s working in private law firms will be partners rather than associates. On variables like attaining partnership status, we expect the figures from later cohorts to change as their members age and their careers progress. Ordinarily, only common sense allows us to distinguish cohort from maturation effects or to estimate their likely relative importance in settings where both may be operating.

16. When we use words like today or use the present tense to describe our respondents' situations and attitudes, we mean to be describing matters not as of the time we write but as of late 1997 and early 1998, the time our respondents filled out their questionnaires. 


\section{THE LAW SCHOOL EXPERIENCE}

Although most of our survey questions inquired about post-law school experiences, we begin by looking at several items that ask about the law school experience, since our respondents' legal educations set the stage for everything that followed, and we are interested in what our respondents thought they took from it.

TABLE 3

Alumni Reporting Satisfaction with Aspects of Law School Experience, by Minority Status and Graduation Decade

\begin{tabular}{rllll}
\hline & \multicolumn{5}{c}{ Aspect of Experience } \\
\cline { 2 - 5 } & Intellectual & $\begin{array}{c}\text { Career } \\
\text { Training }\end{array}$ & Social & $\begin{array}{c}\text { Overall } \\
\text { Satisfaction }\end{array}$ \\
\hline 1970s & & & & \\
MA & $82.1 \% *$ & $75.2 \%$ & $45.8 \%$ & $69.0 \%+$ \\
& $(145)$ & $(145)$ & $(144)$ & $(142)$ \\
WA & $89.7 \%$ & $71.8 \%$ & $50.8 \%$ & $77.4 \%$ \\
$1980 s$ & $(266)$ & $(266)$ & $(266)$ & $(265)$ \\
MA & $85.3 \%$ & $63.7 \%$ & $47.9 \%$ & $70.7 \%$ \\
& $(191)$ & $(190)$ & $(190)$ & $(188)$ \\
WA & $81.8 \%$ & $66.7 \%$ & $55.8 \%$ & $72.4 \%$ \\
1990 s & $(208)$ & $(208)$ & $(207)$ & $(204)$ \\
MA & $84.1 \%$ & $60.3 \%$ & $56.1 \%$ & $69.5 \%$ \\
& $(207)$ & $(204)$ & $(205)$ & $(203)$ \\
WA & $89.5 \%$ & $52.2 \%$ & $65.9 \%$ & $80.0 \%$ \\
& $(103)$ & $(103)$ & $(103)$ & $(103)$ \\
\hline
\end{tabular}

$+p<.1 * p<.05$

NOTES MA $=$ minority alumni; WA $=$ white alumni. Percentages are the proportions of respondents giving a response of 5,6 , or 7 on a scale, where $1=$ very unsatisfactory and $7=$ very satisfactory.

Table 3 indicates, by minority status and graduation decade, the proportion of respondents who reported general satisfaction with their law school experience along four dimensions: intellectually, as career training, socially, and overall. Respondents are considered to be satisfied if they gave responses of 5, 6, or 7 on a 7 -point scale ranging from very unsatisfactory to very satisfactory. ${ }^{17}$ Table 3 reveals substantial similarity in how minority

17. On our questionnaire the coding was reversed. A score of 1 was "very satisfactory" and a score of 7 was "very unsatisfactory." In analyzing the data we reversed the coding of some items so that higher scores always indicate greater satisfaction. Henceforth, we shall not explicitly note when this was done. 
and white alumni look back on their law school careers. Satisfaction with law school overall is, in retrospect, prevalent, with $69 \%$ or more of the respondents from both groups in all decades giving scores on this measure of 5 or above. White alumni in the 1990-96 cohort are the most satisfied group, and white alumni overall tend to be slightly more satisfied with their law school experience than minority alumni. The difference between white and minority alumni on the proportion reporting overall satisfaction is only marginally significant among graduates of the 1970 s and not statistically significant in any other cohort. ${ }^{18}$ However, even if the differences in reported satisfaction are real, they are quite small. This is even clearer if we look at average law school satisfaction scores rather than at the percentage of respondents giving higher scores. Using this measure, the difference in average satisfaction scores between the white and minority graduates of the 1970s is less than 4 on the 7-point scale (data not in table). ${ }^{19}$

Regression analysis confirms the suggestion that there is little difference between the overall law school satisfaction scores of whites and minorities $^{20}$ and also indicates that what differences exist, are largely attributable to the tendency of whites to have higher grades. Controlling for LSGPA, minority graduates report greater overall satisfaction with law school, and the difference is highly significant $(p<.001)$. This is because male minority graduates report having been more satisfied with law school than white males and females when grades are controlled. Minority females are similar to white males and females when grades are taken into account, but they report substantially lower satisfaction levels than white males and females and minority males when grades are not taken into account.

18. While there are no significant differences in overall satisfaction with law school between whites and minorities as a whole among the graduates of the 1980s and 1990s, there were differences among the minority graduates. As a group, Latino graduates of the $1980 \mathrm{~s}$ were more satisfied with their law school experience overall than were black graduates, a difference of .5 on the 7 -point scale, $p<.05$. For the classes of the 1990 s, overall satisfaction was virtually identical for the two groups. Few Latinos graduated in the 1970 s.

19. On these variables and other variables we measure on 7-point scales, there is always a high correlation between the proportion of respondents in a group giving scores of 5,6, or 7 and the average scores of groups of respondents. Ordinarily we report only the proportion of respondents giving scores of 5 or above, as we find this figure intuitively more meaningful than mean scores. Where mean score differences shed light on or qualify the picture painted by proportions, we report them in the text, though we do not present them in tables.

20. The model we used is the model described in the text at note 6 , with LSGPA added after the effects of the other variables have been taken into account. Until LSGPA is entered into the model, differences between minorities and whites are not significant. Because of the skewness in overall satisfaction scores, we confirmed the OLS results described in this paragraph using logistic regression after recoding overall satisfaction scores so that ratings of 1-4 equaled 0 and ratings of 5-7 equaled 1 . As with OLS, there was no significant minority status difference until LSGPA was added to the model. Then minorities showed themselves to be more satisfied, largely because of the scores of minority men ( $p$ value of interaction term < .001.) The results are the same if overall satisfaction is recoded so that only scores of 6 and 7 count as 1 . 
Looking at the specific dimensions of satisfaction, we see that for both white and minority students, satisfaction with law school is greatest on the intellectual dimension, followed by satisfaction with law school as career training. In general, both white and minority graduates recall the social aspects of law school as less satisfying than the other dimensions, although the minority and white graduates of the 1990s report considerably more satisfaction with the social aspects of law school than do graduates of the earlier decades. Minority alumni report taking as much intellectual satisfaction from the challenge of law school as their white counterparts, and are as satisfied as their white counterparts with law school as career training. Only with respect to social satisfaction do minority alumni lag behind their white counterparts in all cohorts, but the lag is not statistically significant. ${ }^{21}$

Table 4 presents data on how alumni, looking back, regard the value of four aspects of their legal education to their law school classroom experience: the faculty's ability as teachers, the faculty's ability as scholars, being called on in class, and the intellectual abilities of their classmates. The table indicates the proportion of students by minority status and graduation decade who, when asked to rate the value of these aspects to their classroom experience, gave ratings of 5,6 , or 7 on a 7 -point scale, where 1 is "none" and 7 is "a great deal."

With the exception of being called on in class, the bulk of respondents in all time periods see considerable value in the contributions made by these factors to their law school classroom experience. White and minority alumni do not differ significantly in the value they place on the faculty's abilities as teachers. ${ }^{22}$ White alumni in the 1970-79 cohort think they got more out of being called on in class than minority alumni do. ${ }^{23}$ Particularly striking is the difference between Latinos and others in the perceived value of being called on in the $1970-79$ cohort. While $44 \%$ of white students and

21. The effect seems largely due to the very low social satisfaction scores of minority women. In a full sample regression, a significant negative effect of minority status on social satisfaction disappears once the interaction of minority status and gender is taken into account.

22. Whether or not one controls for grades, women as a group place a significantly higher value on faculty scholarship than men, but if we look at the four groups formed by the interaction of race and gender, we see that minority men place the highest value on faculty scholarship as a contributor to their classroom experience. White males value it the least. This suggests that belonging to a legally protected minority may enhance appreciation of faculty scholarship. A possible reason is that female and minority students are particularly appreciative of the role that legal scholarship played in making the case for the protection of women and minorities. Another possible reason is that they are aware of the connection between a law school's prestige and the scholarship of its faculty, and count on the prestige of a Michigan degree to open doors into once largely closed areas of law practice.

23. Of the various aspects of the classroom experience about which we inquired, belief about the value of being called on in class was the only one that related strongly to overall satisfaction with law school. Those who thought being called on contributed little or nothing to their classroom experience reported substantially lower than average overall satisfaction, while those who report that being called on contributed considerably to their classroom experience report substantially higher than average satisfaction. 


\section{TABLE 4}

Alumni Placing Considerable Value on Various Aspects of Their Legal Education to Their Classroom Experience, by Minority Status and Graduation Decade

\begin{tabular}{rllll}
\hline & \multicolumn{5}{c}{ Aspect of Law School } \\
\cline { 2 - 5 } & $\begin{array}{c}\text { Faculty as } \\
\text { Teachers }\end{array}$ & $\begin{array}{c}\text { Faculty as } \\
\text { Scholars }\end{array}$ & $\begin{array}{c}\text { Being Called } \\
\text { On }\end{array}$ & $\begin{array}{c}\text { Classmates' } \\
\text { Abilities }\end{array}$ \\
\hline $1970 s$ & & & & \\
MA & $72.9 \%$ & $61.8 \%^{* *}$ & $31.5 \% *$ & $62.1 \% *$ \\
& $(144)$ & $(144)$ & $(143)$ & $(145)$ \\
WA & $76.7 \%$ & $45.4 \%$ & $44.0 \%$ & $73.8 \%$ \\
& $(260)$ & $(260)$ & $(262)$ & $(263)$ \\
$1980 s$ & & & & $68.8 \%$ \\
MA & $66.3 \%$ & $58.4 \% *$ & $39.4 \%$ & $(189)$ \\
& $(190)$ & $(190)$ & $(188)$ & $74.1 \%$ \\
WA & $72.4 \%$ & $47.8 \%$ & $39.8 \%$ & $(207)$ \\
$1990 s$ & $(207)$ & $(207)$ & $(207)$ & $65.5 \% *$ \\
MA & $65.5 \%$ & $56.9 \%$ & $41.7 \%$ & $(206)$ \\
& $(203)$ & $(204)$ & $(206)$ & $80.9 \%$ \\
WA & $70.7 \%$ & $51.3 \%$ & $52.0 \%$ & $(101)$ \\
& $(100)$ & $(101)$ & $(100)$ & \\
\hline
\end{tabular}

$* p<.05 * * p<.01$

Note Percentages are proportions of respondents giving a response of 5,6 , or 7 on a scale of contributions to the classroom experience, where $1=$ none, and $7=$ a great deal.

$33 \%$ of black students gave responses of 5 or above to the value of being called on in class, only $14.3 \%$ of Latinos gave a response of 5 or above, and no Latino gave a response of 7. (Data not presented in table.) This may be because the law school's minority admissions program admitted only small numbers of Latino students during the 1970s. Anecdotal evidence suggests that being part of a very small but visible minority can put tremendous burdens on students. They may regard themselves as "tokens" and feel the quality of their answers have implications for how all their fellow ethnics will be regarded. In the 1980 s, Latino students began to enter the school in more substantial numbers. Among graduates of that decade, there is no difference between white and Latino alumni in their recollections of the value of being called on in class.

Finally, while most white and minority students regard the intellectual abilities of their classmates as having made important contributions to their classroom experience, white graduates of the 1970s and 1990s are signifcantly more likely than minority alumni to value highly this aspect of Michigan Law School's strength. But as in the prior table, even though some 
TABLE 5A

Alumni Placing Considerable Value on the Contributions of Diversity to Their Classroom Experience, by Diversity Aspect, Minority Status, and Graduation Decade

\begin{tabular}{rlll}
\hline & \multicolumn{3}{c}{ Aspect of Diversity } \\
\cline { 2 - 4 } & $\begin{array}{c}\text { Ideological } \\
\text { Diversity }\end{array}$ & $\begin{array}{c}\text { Gender } \\
\text { Diversity }\end{array}$ & $\begin{array}{c}\text { Ethnic } \\
\text { Diversity }\end{array}$ \\
\hline 1970 s & & & \\
MA & $63.2 \%^{* * *}$ & $61.8 \%^{* * *}$ & $65.0 \%^{* * *}$ \\
WA & $(144)$ & $(144)$ & $(143)$ \\
& $35.8 \%$ & $26.5 \%$ & $24.8 \%$ \\
1980s & $(262)$ & $(260)$ & $(260)$ \\
MA & $58.7 \%$ & $58.7 \% * * *$ & $60.6 \% * * *$ \\
& $(189)$ & $(189)$ & $(188)$ \\
WA & $51.3 \%$ & $40.7 \%$ & $32.5 \%$ \\
$1990 s$ & $(204)$ & $(206)$ & $(205)$ \\
MA & $60.5 \%$ & $59.0 \%+$ & $57.3 \%$ \\
& $(205)$ & $(205)$ & $(206)$ \\
WA & $59.3 \%$ & $46.0 \%$ & $50.0 \%$ \\
& $(101)$ & $(101)$ & $(100)$ \\
\hline
\end{tabular}

$+p<.1 \quad * * * p<.001$

Note Percentages are proportions of respondents giving a response of 5,6 , or 7 on a scale of contributions to the classroom experience, where $1=$ none, and $7=$ a great deal.

differences between minority and white alumni on this measure are statistically significant, not much should be made of them, for they don't represent substantial differences in judgments. ${ }^{24}$

Table 5A indicates respondents' retrospective views of the value of different kinds of diversity to their classroom experience. Here, more than with respect to other aspects of the law school experience, white and minority alumni differ in their response patterns. Minority alumni in all decades see ideological, gender, and ethnic diversity within the classroom as having been more important to their classroom experiences than white alumni do. Differences are highly significant across all three types of diversity for those graduating in the 1970s and for gender and ethnic diversity among gradu-

24. The statistical significance of some differences, like the difference between the value white and minority alumni attribute to their classmates' intellectual abilities, disappears if one looks at mean scores rather than at the proportion of respondents giving high scores, and no difference in average ratings of the importance of classmates' intellectual abilities is greater than .4 or about $7 \%$ of the range of a 7 -point scale. The difference that does exist is due to the low value that minority women place on their classmates' intellectual abilities. The ratings of minority men are statistically indistinguishable from the ratings of whites. 
ates of the 1980s. White and minority alumni of the 1990 s are more similar in how important they think the kinds of diversity were to their classroom experience. Looking at mean scores (data not in table) confirms the importance of these differences in the proportions giving high scores. In three of the significant relationships, the averages for minority and white alumni differ by more than a scale point, and all the significant differences involve differences in average scores of .6 of a scale point $(10 \%$ of the possible range) or more.

TABLE 5B

White Alumni Placing Considerable Value on the Contributions of Diversity to Their Classroom Experience, by Diversity Aspect, Gender, and Graduation Decade

\begin{tabular}{|c|c|c|c|}
\hline & \multicolumn{3}{|c|}{ Aspect of Diversity } \\
\hline & $\begin{array}{c}\text { Ideological } \\
\text { Diversity }\end{array}$ & $\begin{array}{c}\text { Gender } \\
\text { Diversity }\end{array}$ & $\begin{array}{c}\text { Ethnic } \\
\text { Diversity }\end{array}$ \\
\hline \multicolumn{4}{|l|}{$1970 \mathrm{~s}$} \\
\hline Men & $\begin{array}{l}33.3 \% \\
(230)\end{array}$ & $\begin{array}{l}21.5 \% * * \\
(229)\end{array}$ & $\begin{array}{l}20.3 \% * * \\
(230)\end{array}$ \\
\hline Women & $\begin{array}{l}51.5 \% \\
(32)\end{array}$ & $\begin{array}{l}57.4 \% \\
(31)\end{array}$ & $\begin{array}{l}53.8 \% \\
(30)\end{array}$ \\
\hline \multicolumn{4}{|l|}{$1980 \mathrm{~s}$} \\
\hline Men & $\begin{array}{l}43.0 \% * * \\
(133)\end{array}$ & $\begin{array}{l}30.2 \% * * * \\
(133)\end{array}$ & $\begin{array}{l}23.5 \% * * \\
(133)\end{array}$ \\
\hline Women & $\begin{array}{l}67.0 \% \\
(71)\end{array}$ & $\begin{array}{l}60.0 \% \\
(73)\end{array}$ & $\begin{array}{l}49.4 \% \\
(72)\end{array}$ \\
\hline \multicolumn{4}{|l|}{$1990 \mathrm{~s}$} \\
\hline Men & $\begin{array}{l}60.8 \% \\
(64)\end{array}$ & $\begin{array}{l}44.9 \% \\
(64)\end{array}$ & $\begin{array}{l}48.6 \% \\
(64)\end{array}$ \\
\hline Women & $\begin{array}{l}56.7 \% \\
(37)\end{array}$ & $\begin{array}{l}47.7 \% \\
(37)\end{array}$ & $\begin{array}{l}52.3 \% \\
(36)\end{array}$ \\
\hline $\begin{array}{r}\quad * * p<. \\
\text { Note } \mathrm{P} \\
\text { contribution } \\
\text { for significan }\end{array}$ & $\begin{array}{l}1 \\
\text { proportions c } \\
\text { om experienc }\end{array}$ & $\begin{array}{l}\text { iving a resp } \\
\text { ne, and } 7= \\
\text { pes of diver }\end{array}$ & $\begin{array}{l}7 \text { on a scale of } \\
\text { fferences tested }\end{array}$ \\
\hline
\end{tabular}

But these figures disguise a more nuanced story. Table 5B breaks down white responses by gender. We see that the difference between the value that white and minority graduates place on diversity in the 1970s and 1980s cohorts is due largely to the views of white male law students. The proportion of white women who believe that ethnic, gender, and ideological diversity were important to the value of their classroom experience is close to the proportion of minority alumni who feel this way. Until we get to the graduates of the 1990 s, however, fewer than $25 \%$ of white male respondents feel 
that the value of their classroom experience was substantially enhanced by ethnic diversity. Only among graduates of the 1990s does this change. Gender differences among whites disappear, and about one in two white male students believes that ethnic diversity added considerably to the value of his classroom experience.

To some degree the gender differences we see in table $5 \mathrm{~B}$ reflect differences in the political attitudes of men and women, both when they answered our questionnaire and when they were law students. Although our questionnaire contained no political-attitude items, they have been included on surveys that Michigan's graduates receive during the fifth and fifteenth years after their graduation. The sample of white alumni who answered our survey should be much like those who have responded to these alumni surveys; indeed, we expect that most of our respondents have been Alumni Survey respondents since the motivations to respond to each survey are similar. ${ }^{25}$

No matter when they graduated, women responding to the Alumni Survey report more liberal political views than men, both at the time of the survey and when asked to recollect their views while in law school. ${ }^{26}$ Thus, the women in our survey may place higher values on diversity than the men because recollecting diversity as valuable accords more with women's current political attitudes and/or, with respect to ethnic diversity, because their attitudes in law school made them more receptive than men to arguments minorities made in class and to out-of-class associations with minority law students.

Regardless of how the dynamic works, political attitude is unlikely to explain all the gender-associated differences in the perceived value of ethnic or other diversity. Changing political views seem particularly unlikely to explain the dramatic increase in the value that white male alumni of the 1990 s, as compared to white male alumni of earlier decades, place on ethnic and other kinds of diversity as aspects of the classroom experience. Alumni Survey data from the classes of 1990 and 1991 indicate that white male

25. A problem with using the Michigan Alumni Survey data for our purposes is that except for the classes most recently surveyed, the attitude items may not report current views. To the extent political attitudes change with age, the Alumni Survey data for some of the classes we examine may differ, most likely in a liberal direction, from what would have been reported in our survey (which we call the Professional Development Survey, or PDS) had we included political attitude items. Nevertheless, data from the alumni surveys can help us evaluate the possibility that political attitudes explain the gender effect in table $5 \mathrm{~B}$ and, more important, the marked change in the attitudes of white males who graduated from Michigan in the 1990 s.

26. On a 7-point scale running from very liberal to very conservative, the proportion of women characterizing their political views today as very liberal (scores of 1 or 2 ) is usually about twice the proportion of men with such views, and the smaller proportion reporting themselves as very conservative (scores of 6 or 7 ) is among women about half of what it is among men. Women also remember their political attitudes as students as more liberal than men remember theirs, and both, as groups, report having had somewhat more liberal attitudes as students than they report having today. 
graduates from these classes are currently about as conservative politically as white male graduates of the 1980 s or perhaps a bit more so, and that while in law school, they were more conservative, as a group, than 1980s white male alumni. ${ }^{27}$ Yet $49 \%$ of the white male respondents in our survey from the classes of 1990 and 1991 give ratings of 5, 6, or 7 when asked about how valuable ethnic diversity was to their classroom experience, a proportion almost the same as what we see when we look at all 1990s white male graduates. By contrast only $23.5 \%$ of 1980 s white male alumni place such a high value on ethnic diversity. ${ }^{28}$

If increasingly liberal political attitudes cannot explain the 1990s upsurge in the value white males place on ethnic diversity, what does explain it? We tentatively offer two hypotheses. First, we suggest that the change in how white males assess the classroom value of diversity reflects the fact that Michigan's ethnic diversity was greater in the 1990s than it was in the two preceding decades. The proportion of Michigan graduates who were black, Latino, or Native American rose from $7.6 \%$ of all students in the 1970 s, to $10.2 \%$ in the 1980 s, to $15.4 \%$ in the first seven years of the 1990 s. Moreover, Asians began entering Michigan Law School in substantial numbers in the 1990s, further enhancing visible ethnic diversity. This increase may have made Michigan's white male students more aware of the classroom contributions of those with different ethnic backgrounds, and it may also be that the presence of larger numbers of minorities resulted in issues being raised that would not have been voiced in the classroom at an earlier time. Increased minority enrollment is also likely to have increased interaction

27. We only have Alumni Survey data for the classes of 1990 and 1991 in usable form, but these data have the virtue of being collected close to the time of our own survey and are likely to be a good proxy for the current views of our respondents from these classes. The current political attitudes of white males in the classes of 1990 and 1991 as measured in the Alumni Survey are not much different from the attitudes held by white male alumni of earlier decades. Only $20.4 \%$ of these alumni said they were currently very liberal (scores of 1 or 2 on a 7 -point scale), and $17.2 \%$, a higher proportion than in any of the other groups we look at, considered themselves very conservative (scores of 6 or 7 on a 7 -point scale). By way of comparison, in the 1982-89 cohort, for which we also only have five-year data, $21.5 \%$ of respondents rated themselves as very liberal when they filled out the Alumni Survey, and $10.9 \%$ saw themselves as very conservative. For data on the views of the classes of 1980 and 1981 , see note 28 , below.

28. It does not appear that this difference can be explained simply by the fact that 1980 s alumni have been out of school longer than 1990 and 1991 alumni and so may have grown more politically conservative. We can see this by looking at alumni who graduated in 1980 and 1981 and so participated in the 15-year Alumni Survey at the same time the 1990 and 1991 alumni were participating in the 5 -year Alumni Survey. The white male alumni of a decade earlier have $6.7 \%$ fewer strong conservatives than the $1990-91$ group and $5.8 \%$ fewer strong liberals. The difference in strong conservatives is opposite what one might expect if conservatism increases with age, and the liberal difference is too small to account for the large difference in the educational value that the 1980 s and 1990 s white male graduates we surveyed placed on ethnic (and other) diversity. Moreover, 1980-81 white male graduates are more likely than their 1990-91 counterparts to report having had strong liberal views while in law school ( $39.4 \%$ vs. $29.8 \%)$, and fewer report having had strong conservative views $(8.3 \%$ vs. $17.2 \%$ ) in their law school days. 
between white males and minority students. Consistent with these suggestions, Bowen and Bok $(1998,235)$ found a linear relationship between the percentage of black students in the colleges that furnished graduates for their study and the percentage of the college's 1989 white alumni who reported having known well two or more black students.

Second, we suggest that being in a minority can sensitize a person to both the degree of diversity and the value of minority perspectives. In addition to their greater liberalism, white women had the experience of being in a minority while in law school, and this may be one reason why so many of them, especially graduates of the 1970 s, saw value in ethnic diversity. By contrast, white males, until the decade of the 1990s, constituted a majority of Michigan's law students. But in the 1990s, increased female and minority (including Asian) enrollment meant that white male law students became, for the first time, themselves a minority of the student body. They were more exposed to women and people of color, and the likelihood that most of their friends and associates were fellow white males probably diminished. At the same time, the likelihood of sitting in class next to a person of a different gender or ethnicity, or being assigned to write a brief with, negotiate with, or respond to the views of someone of a different gender or ethnicity went up. We expect that such interactions increase the perceived educational value of diversity. Unlike white female and minority students, who have always been minorities in Michigan's student body, for white male law students it was not until the 1990s that many of their class-related interactions with other law students could not help but cross gender and ethnic lines.

These data are consistent with the claims of some educators that increasing diversity, particularly ethnic diversity, has important educational benefits not just for minority and women students but for white male students as well. Although the correlation we report cannot prove causality, we think we have shown that the correlation between increased ethnic diversity and the increased educational value that the law school's most numerous group, white males, see in diversity cannot be dismissed as simply reflecting differences in the "politically correct" response to questions about the value of diversity. All our respondents, regardless of when they graduated, provided their answers in the context of the same present-day political atmosphere. Moreover, to the extent our respondents are recalling their feelings when they were in law school, opposing affirmative-action programs is probably more acceptable among students today than it was in earlier decades. Finally, the political-attitude data captured by the alumni surveys are inconsistent with a "political correctness" explanation. At least in the classes of 1990 and 1991, we know that a dramatic change in white male attitudes toward the classroom value of ethnic diversity is not mirrored by a marked change in the overall political attitudes of white male alumni. 
Our results are consistent with what Gary Orfield and Dean Whitla report (Orfield and Whitla 1999) in a recent paper that presents the results of a survey of University of Michigan Law School and Harvard Law School students. The survey asked questions about the effects of ethnic diversity in the school and the classroom on students. Using electronic mail as the medium, Orfield and Whitla obtained an $81 \%$ response rate. The white respondents from both schools reported in overwhelming numbers that in law school, but not before, they have several (three or more) close friends of another racial or ethnic background. The draft that has been released does not break down responses to other questions by race, but on every one of a long series of questions about the possible impacts of racial diversity on their experiences, a large majority of the Michigan students reported that they believe the effects of diversity are positive. For example, $72.8 \%$ of the Michigan students believed that racial diversity within the school enhances the way they and others think about problems and solutions in classes, and $73.5 \%$ regarded having students of different races and ethnicities as a "clearly positive" element of their educational experience. ${ }^{29}$ The Orfield and Whitla study complements our findings. Together they provide strong evidence that, in the 1990s, many Michigan Law School students perceived ethnic diversity as adding value to their educational experience.

Table 6 shifts to the benefits after law school of friendships and contacts made at Michigan and with Michigan graduates later as well as the benefits of the "prestige associated with being a University of Michigan Law School graduate." On a scale of 1 to 7, where 1 means "none" and 7 means "a great deal," about $85 \%$ of Michigan's minority alumni reply with scores of 5 or above when asked about the degree to which their career has benefited from "the prestige associated with being a University of Michigan Law School graduate." Lesser proportions point to friends made at Michigan ( $22.5 \%$ to $30.8 \%$ depending on graduation decade) or Michigan contacts $(17.3 \%$ to $19.8 \%$ ) made after graduation as important to their subsequent careers, but a significant minority of Michigan's minority alumni believe they benefited from these byproducts of a Michigan education as well. ${ }^{30}$ Minority alumni graduating in the 1970 s and 1980 s are more prone than white alumni graduating during these decades to think that their Michigan education benefited their careers in the ways we asked about. There are no statistically significant differences in the 1990-96 cohort. Regardless of cohort or minority status, the prestige of having attended the University of

29. An additional $17 \%$ believed it a "moderately positive" element. Fewer than $1 \%$ of respondents considered it had no value whatsoever.

30. Regression analyses indicate that in the full sample, minorities are significantly more likely than whites to feel they benefited from friends made at Michigan and contacts with Michigan alumni after graduation. Gender does not significantly affect responses to either the friends or contacts item, but minority males are more likely than minority females or whites of either sex to report that friends made at Michigan were important to their subsequent careers. 
TABLE 6 Alumni Reporting Considerable Career Benefits From Attending Michigan,
by Type of Benefit, Minority Status, and Graduation Decade

\begin{tabular}{rlll}
\hline & \multicolumn{3}{c}{ Type of Benefit } \\
\cline { 2 - 4 } & $\begin{array}{c}\text { Friends Made at } \\
\text { Michigan }\end{array}$ & $\begin{array}{c}\text { Contacts Made } \\
\text { Through Michigan }\end{array}$ & Prestige of Michigan \\
\hline 1970s & $30.8 \% * * *$ & $19.2 \%^{* *}$ & $86.1 \% * * *$ \\
MA & $(146)$ & $(146)$ & $(144)$ \\
WA & $13.4 \%$ & $7.8 \%$ & $71.6 \%$ \\
& $(266)$ & $(266)$ & $(260)$ \\
$1980 s$ & $22.5 \%+$ & $17.3 \% *$ & $85.2 \% *$ \\
MA & $(191)$ & $(191)$ & $(189)$ \\
& $14.8 \%$ & $9.6 \%$ & $75.0 \%$ \\
WA & $(209)$ & $(208)$ & $(205)$ \\
1990s & $29.5 \%$ & $19.8 \%$ & $85.3 \%$ \\
MA & $(207)$ & $(207)$ & $(204)$ \\
& $29.7 \%$ & $16.4 \%$ & $79.9 \%$ \\
WA & $(104)$ & $(104)$ & $(104)$ \\
& & & \\
\hline
\end{tabular}

$+p<.1^{*} p<.05^{* *} p<.01^{* * *} p<.001$

NOTE Percentages are proportions of respondents giving answers of 5,6 or 7 to questions regarding the importance to their careers of friends and contacts made at Michigan and of the prestige associated with being a Michigan Law School graduate where $1=$ none, and $7=$ a great deal.

Michigan Law School is associated with greater career benefits than friends made at Michigan or alumni contacts after graduation.

A regression model of the full sample confirms that minorities place a higher value on the prestige of a Michigan Law School degree than whites do and that white women place a higher value on Michigan's prestige than white men do. ${ }^{31}$ It appears that those with reason to feel that their demographic status is likely to hamper their career chances place a special value on the way in which a high-prestige law degree can open up career opportunities. If Michigan's graduates are correct in their perceptions, attending prestigious law schools like the University of Michigan has higher career returns to women and minorities than it does to white men.

31. The model is the one described in the text at note 6 . The results do not change if LSGPA is also controlled. The gender effect is qualified by a significant gender/minoritystatus interaction effect. Minority women see the same career value in the prestige of a Michigan degree as minority men; they do not place a higher value on school prestige because they are women. 
When the Supreme Court ordered the University of Texas Law School desegregated in 1950 (Sweatt v. Painter, 339 U.S. 629 [1950]) it held that "separate but equal" could not justify segregated professional education because the prestige and "connection" benefits of attending a state's leading law school could not be duplicated in an all-black law school; even if the state were to invest as much money in the black school as was invested in the white one. Our data suggest that Michigan alumni would agree with the Supreme Court. White and minority graduates believe they benefited from attending an elite law school in ways they might not have benefited from attending a less prestigious one. The benefits appear as particularly important to graduates with demographic characteristics that, regardless of their talents, once would have barred them from many of the nation's highest status legal positions (Smigel 1969) and even today may make them more vulnerable than white males to invidious stereotyping and discrimination.

\section{Educational Debt}

Table 7 reports responses to this question: "When you completed law school, how much contractually enforceable debt resulting from attending college and law school did you have?" Across the decades, the debts of both minorities and whites have risen greatly in nominal dollars, in constant 1996 dollars, and in probable debt payments as a proportion of first-year earnings. Table 7 also reveals that, in every decade, a much higher proportion of minorities than whites have left law school with educational debt, and in every decade, the debts of minority students are much higher than the debts of white students. ${ }^{32}$ Michigan's minority students simply come to law school, on average, from families with fewer economic resources than its white students.

By the classes of 1995 and 1996, over half the minority graduates finished law school with educational debts of at least $\$ 70,000$. Based on their reported first-year earnings and the common level of debt payments that have to be made each year for each $\$ 1,000$ in loans, it is probable that over half the minority graduates of these classes with debts had to spend more than $15 \%$ of their first-year incomes making the payments due on them. That is a substantial burden that is likely to weigh most heavily on those who take initial employment in government, legal services, or other relatively low-paying public interest settings. The claim by some critics of affirmative action that most minority students are, on account of their

32. Among the graduates of the 1990 s but not in earlier decades, Latino students with debt finished law school with significantly higher debt in constant 1996 dollars than black students with debt (a mean of $\$ 71,555 \mathrm{v}$. a mean of $\$ 61,192, p<.01$.) As table 7 reports, white students with debt had an average debt in constant 1996 dollars of $\$ 52,665$, significantly lower than either Latinos or blacks. 


\section{TABLE 7}

\section{Mean Educational Debt and Debt/Earnings by Minority Status and Graduation Decade}

\begin{tabular}{|c|c|c|c|c|}
\hline & $\begin{array}{l}\text { Proportion with } \\
\text { Debt on } \\
\text { Graduating from } \\
\text { Law School }\end{array}$ & $\begin{array}{c}\text { Mean Debt of } \\
\text { Those with } \\
\text { Debt }\end{array}$ & $\begin{array}{l}\text { Mean Debt in } \\
1996 \text { Dollars for } \\
\text { Those with } \\
\text { Debt }\end{array}$ & $\begin{array}{c}\text { Mean Annual } \\
\text { Debt Payments } \\
\text { As a \% of } 1 \text { st- } \\
\text { year Earnings } \\
\text { for Those with } \\
\text { Debt }\end{array}$ \\
\hline \multicolumn{5}{|l|}{$1970 \mathrm{~s}$} \\
\hline MA & $\begin{array}{l}83.5 \% * * * \\
(127)\end{array}$ & $\begin{array}{l}\$ 12,633 * * * \\
(106 ; \$ 888)^{b}\end{array}$ & $\begin{array}{l}\$ 37,666 * * * \\
(106)\end{array}$ & $\begin{array}{l}7.6 \% * * * \\
(101)\end{array}$ \\
\hline WA & $\begin{array}{l}52.7 \% \\
(251)\end{array}$ & $\begin{array}{l}\$ 9,069 \\
(128 ; \$ 864)\end{array}$ & $\begin{array}{l}\$ 26,345 \\
(128)\end{array}$ & $\begin{array}{l}5.1 \% \\
(124)\end{array}$ \\
\hline \multicolumn{5}{|l|}{$1980 \mathrm{~s}$} \\
\hline MA & $\begin{array}{l}93.5 \% * * * \\
(184)\end{array}$ & $\begin{array}{l}\$ 32,655 * * * \\
(172 ; \$ 1,420)\end{array}$ & $\begin{array}{l}\$ 47,207^{* * *} \\
(172)\end{array}$ & $\begin{array}{l}10.1 \% * * * \\
(162)\end{array}$ \\
\hline WA & $\begin{array}{l}79.5 \% \\
(204)\end{array}$ & $\begin{array}{l}\$ 23,697 \\
(163 ; \$ 1,580)\end{array}$ & $\begin{array}{l}\$ 34,959 \\
(163)\end{array}$ & $\begin{array}{l}6.5 \% \\
(156)\end{array}$ \\
\hline \multicolumn{5}{|l|}{$1990 \mathrm{~s}$} \\
\hline MA & $\begin{array}{l}96.0 \% * * * \\
(201)\end{array}$ & $\begin{array}{l}\$ 59,720 * * * \\
(193 ; \$ 1,708)\end{array}$ & $\begin{array}{l}\$ 65,652 * * * \\
(193)\end{array}$ & $\begin{array}{l}15.1 \% * * * \\
(185)^{\mathrm{c}}\end{array}$ \\
\hline WA & $\begin{array}{l}71.6 \% \\
(101)\end{array}$ & $\begin{array}{l}\$ 48,404 \\
(72 ; \$ 4,210)\end{array}$ & $\begin{array}{l}\$ 52,665 \\
(72)\end{array}$ & $\begin{array}{l}8.3 \% \\
(71)\end{array}$ \\
\hline
\end{tabular}

$* * * p<.001$

a. Law Access, the principal loan program relied on by law students, expects that most graduates will pay an amount each year toward principal and interest equaling about $10 \%$ of the total of their loans. We calculated the probable debt payments by multiplying the total debt of each student by .10 and then dividing that product by their reported first-year income.

b. The second number in the parenthesis is the standard error of the mean debt.

c. Two outliers with debts exceeding $\$ 80,000$ and incomes of $\$ 1,000$ or less were not included in calculating the figure for this cell.

ethnicity, getting free rides at the expense of their white counterparts differs sharply from what these data tell us.

\section{WORK AFTER LAW SCHOOL}

Six of the seven pages of our questionnaire dealt with the experiences of Michigan's graduates after they finished law school. We asked respondents questions about their first jobs, their current jobs, and the overall shape of their careers. We also asked about dimensions of career satisfaction, partnership status and income, pro bono work, and service and other activities apart from their jobs. In the next two sections we look at these aspects of the careers of Michigan Law School's graduates. 


\section{Bar Passage and First Jobs}

Ninety-six percent of the minority students and $98.5 \%$ of the white students who entered Michigan between 1983 and 1992 graduated from Michigan with the J.D. degree. ${ }^{33}$ In launching their careers, law students face two immediate challenges. The first is to pass a bar exam, and the second (usually met by Michigan students before they graduate) is to find a job.

TABLE 8

Bar Passage Rates, by Minority Status and Graduation Decade

\begin{tabular}{cll}
\hline & \% Bar Members & $\begin{array}{c}\text { \% Bar Members, } \\
\text { Two or More States }\end{array}$ \\
\hline 1970 s & & \\
MA & $98.5 \%$ & $37.2 \%$ \\
WA & $(137)$ & $(137)$ \\
1980s & $97.9 \%$ & $39.6 \%$ \\
MA & $(256)$ & $(256)$ \\
WA & $95.1 \% * *$ & $32.6 \%+$ \\
$1990 s$ & $(184)$ & $(184)$ \\
MA & $99.3 \%$ & $43.2 \%$ \\
& $(202)$ & $(202)$ \\
WA & $96.1 \%$ & $26.5 \% *$ \\
& $(204)$ & $(204)$ \\
& $97.5 \%$ & $40.0 \%$ \\
\hline
\end{tabular}

$+p<.1^{*} p<.05 * * p<.01$

As table 8 reveals, almost all minority alumni who responded to our survey passed a bar exam after graduation. Overall, $96.3 \%$ have been admitted to the bar of at least one state, and many have been admitted in two or more states. We do not know how many, if any, of the $3.7 \%$ who have not joined a bar (19 individuals out of 525 responding minority graduates) attempted to pass a bar examination and failed and how many, if any, chose employment from the beginning that did not require bar membership. We do know that as a group these 19 view their nonlaw careers today with high satisfaction (somewhat higher, in fact, than the respondents who are bar

33. Among both minorities and whites most of those who entered but did not graduate from Michigan were in academic good standing when they left, some to enter other law schools and some to pursue other careers. We were unable to get graduation data broken down by race for classes entering before 1983 . 
members), and two-thirds of them report that their legal training is of "great value" to them in their current employment. (For comparison, the proportion of white graduates who have ever been admitted to the bar is $98.3 \%$.)

\section{TABLE 9}

Proportions of Alumni Securing Judicial Clerkships, by Minority Status and Graduation Decade

\begin{tabular}{rrr}
\hline & n & Proportion Taking Clerkship \\
\hline $1970 s$ & & \\
MA & 144 & $8.3 \%+$ \\
WA & 260 & $13.3 \%$ \\
$1980 s$ & & \\
MA & 189 & $10.6 \%+$ \\
WA & 206 & $16.2 \%$ \\
$1990 s$ & & \\
MA & 205 & $18.1 \%$ \\
WA & 104 & $23.8 \%$ \\
\hline
\end{tabular}

$+p<.1$

The other task, finding initial employment, often has two stages. Students decide whether to seek a judicial clerkship, commonly a one-year appointment after law school, and then, if they do not seek or find a clerkship, they seek an initial longer-term job with a law firm, business, government agency, or elsewhere. We sought to learn from all respondents whether they took a clerkship and, apart from clerkships, what their first job was.

Overall, $12.8 \%$ of Michigan's minority graduates have taken judicial clerkships. As table 9 reports, the proportion taking clerkships has risen over time from $8.3 \%$ of the minority graduates of the 1970 s to $10.6 \%$ among minority graduates of the 1980 s to $18.1 \%$ of the minority graduates in the 1990-96 cohort. This trend over time among minority alumni is mirrored by white alumni and so seems to reflect a general increase in the interest of Michigan students in judicial clerkships and in their capacity to secure them. Although relatively more white alumni than minority alumni have taken clerkships over the years, the difference is only marginally significant in the 1970 and 1980 cohorts, and not significant among graduates in the 1990 s. ${ }^{34}$

Table 10 displays the first jobs of white and minority graduates, not counting any judicial clerkships, and table 11 indicates the size of the firms

34. We did not ask where clerkships were held and so have no data on the prestige of the clerkships held by minorities and whites. 
TABLE 10

First Jobs of Michigan Alumni by Job Sector, Minority Status, and Graduation Decade

\begin{tabular}{|c|c|c|c|c|c|c|}
\hline & \multicolumn{6}{|c|}{ First-Job Sector } \\
\hline & $\mathbf{n}$ & $\begin{array}{l}\text { Private } \\
\text { Practice }\end{array}$ & Business & Government & $\begin{array}{l}\text { Legal Services } \\
\text { or } \\
\text { Public Interest }\end{array}$ & Other $^{1}$ \\
\hline \multicolumn{7}{|l|}{$1970 s^{2}$} \\
\hline MA & 145 & $31.7 \%$ & $10.3 \%$ & $29.7 \%$ & $17.9 \%$ & $10.3 \%$ \\
\hline WA & 260 & $68.7 \%$ & $5.6 \%$ & $15.2 \%$ & $5.3 \%$ & $5.2 \%$ \\
\hline \multicolumn{7}{|l|}{$1980 s^{3}$} \\
\hline MA & 189 & $72.0 \%$ & $3.7 \%$ & $13.2 \%$ & $6.9 \%$ & $4.2 \%$ \\
\hline WA & 206 & $85.1 \%$ & $2.7 \%$ & $3.7 \%$ & $3.3 \%$ & $5.1 \%$ \\
\hline \multicolumn{7}{|l|}{$1990 s^{4}$} \\
\hline MA & 203 & $69.0 \%$ & $3.0 \%$ & $15.8 \%$ & $3.0 \%$ & $9.4 \%$ \\
\hline WA & 103 & $81.9 \%$ & $2.1 \%$ & $3.0 \%$ & $5.7 \%$ & $7.3 \%$ \\
\hline \multicolumn{7}{|c|}{$\begin{array}{l}1 \text { Includes education, accounting firms, labor unions, etc. } \\
{ }^{2} \chi^{2}=52.1, p<.001 \\
{ }_{3}^{2} \chi^{2}=16.5, p<.01 \\
{ }^{4} \chi^{2}=15.2, p<.01\end{array}$} \\
\hline
\end{tabular}

for those who chose the private practice of law. The pattern of first employment has changed dramatically over time. For the minority graduates of the 1970s, substantially more took initial positions in government, legal services, or public interest work $(47.6 \%)$ than took jobs in private practice (31.7\%). And, of those who took jobs in private practice, almost half took jobs in firms with 10 or fewer lawyers. In the 1980s and 1990s, the proportions of minority alumni taking jobs in firms increased dramatically, reflectirig both a general increase in the size of law firms in the United States and a major change in the jobs minority alumni acquired as firms of all sizes became accessible to them. During the 1980 s, $72 \%$ of Michigan's minority graduates took first jobs in law firms, and fewer than $15 \%$ of them worked in firms with 10 or fewer lawyers. ${ }^{35}$ The picture is similar for graduates of the 1990 s. ${ }^{36}$

Jobs with large private law firms are the most sought after positions by most American law school graduates. Large firms seek young lawyers willing to work long hours to a high standard of quality. Many of the job offers they

35. In the 1980s, more Latinos than blacks took jobs in firms (83\% of Latinos, $64 \%$ of blacks), and more blacks than Latinos took jobs in government or public interest work $(25 \%$ of blacks, $12 \%$ of Latinos).

36. In the 1990 s, unlike the 1980 s (see preceding footnote), more Latinos (27.2\%) than blacks $(15.4 \%)$ took initial jobs in government or public interest work. 
TABLE 11

Firm Size of First Jobs of Alumni Entering Private Practice, by Minority Status and Graduation Decade

\begin{tabular}{|c|c|c|c|c|c|c|}
\hline & \multicolumn{6}{|c|}{ Number of Lawyers } \\
\hline & $\mathbf{n}$ & $1-10$ & 11.50 & $51-100$ & $101-150$ & $151+$ \\
\hline \multicolumn{7}{|l|}{$1970 s^{1}$} \\
\hline MA & 45 & $46.7 \%$ & $31.1 \%$ & $11.1 \%$ & $2.2 \%$ & $8.9 \%$ \\
\hline WA & 159 & $25.5 \%$ & $39.5 \%$ & $19.7 \%$ & $6.4 \%$ & $9.0 \%$ \\
\hline \multicolumn{7}{|l|}{$1980 s^{2}$} \\
\hline MA & 134 & $14.9 \%$ & $20.1 \%$ & $21.6 \%$ & $10.4 \%$ & $32.8 \%$ \\
\hline WA & 168 & $10.6 \%$ & $26.8 \%$ & $18.0 \%$ & $11.6 \%$ & $33.1 \%$ \\
\hline \multicolumn{7}{|l|}{$1990 s^{3}$} \\
\hline MA & 140 & $14.3 \%$ & $20.7 \%$ & $12.9 \%$ & $16.4 \%$ & $35.7 \%$ \\
\hline WA & 84 & $9.3 \%$ & $8.4 \%$ & $18.4 \%$ & $8.2 \%$ & $55.9 \%$ \\
\hline \multicolumn{7}{|c|}{$\begin{array}{l}{ }^{1} \chi^{2}=8.3, p<.1 \\
\chi^{2}=5.1, \text { not sig. } \\
{ }^{3} \chi^{2}=16.6, p<.01\end{array}$} \\
\hline
\end{tabular}

extend are to students whose abilities they know firsthand because they have observed them as summer clerks. These firms pay high salaries and are seen as stepping stones to other desirable positions. About $45 \%$ of minority graduates in the $1980 \mathrm{~s}$ and more than $50 \%$ of minority graduates in the 1990s secured first jobs with firms employing more than 100 lawyers, and most of these graduates were in firms with 150 lawyers or more. The employment picture for white graduates changes in much the same way over time. In each decade a higher proportion of white graduates than minority graduates took first jobs in large firms $(100+$ lawyers $)$, and fewer took first jobs in very small firms (1-10 lawyers), but the difference in the overall pattern of first job firm sizes achieves statistical significance only in the 1990-96 cohort.

Law school graduates acquire first jobs in many ways. In recent years, a common mode of entry into law firm jobs, especially in larger law firms, has been to clerk for a firm during the summer and to so impress the firm's partners that a permanent job offer is forthcoming. ${ }^{37}$ Securing summer clerkships turns to different degrees on law school grades, impressions made

37. We did not inquire in the PDS about whether graduates held summer clerkships in the firms that hired them, but a question on the Alumni Survey asks whether the respondent's first job after any clerkship was with a firm he or she had clerked for after the second year of law school. In the classes of 1988 through $1991,75.6 \%$ of minority alumni in firms with more than 50 lawyers reported having had summer clerkships with the first firm that employed them, as did $68.1 \%$ of white alumni. Among alumni working in smaller firms, white alumni were more likely than minority alumni to have clerked for the firm that hired them, so 
in interviews, faculty recommendations, personal connections, and sheer initiative. The fact that minority students tend to have lower law school grade-point averages than white students may lead those law firms interested in hiring minority lawyers to make special efforts to recruit minority students as summer clerks. This gives them an experiential base for deciding whether to extend offers. Law firms may do the same with white students who are more impressive in their interviews than on their transcripts, or who, despite low LSGPAs are attractive for other reasons, like potentially important business connections. This makes sense because the less stellar a student's grades, the more risky hiring her may appear, absent other information about how she is likely to perform. Our data show that minority graduates hired by large law firms have on average lower LSGPAs than the white graduates these firms hire, but this does not necessarily tell us anything about how firms view the relative prospects for success of the minority and white graduates to whom they extend job offers. These judgments may in large measure reflect impressions conveyed during interviews, faculty recommendations, or a summer clerkship experience. Moreover, LSGPA, as we shall see later, seems to have only limited bearing on later career success, and law firms may have some inkling of this.

We would expect those who lack the capacity for large firm work to quit their jobs or be eased out of them relatively soon. For this reason we asked our respondents how many years they worked at their first jobs. The graduates of the 1990s haven't been out long enough for meaningful assessment, but the graduates of the 1980 s are a good group to examine. The minority graduates from the 1980 s who took a first job in a firm with more than 50 lawyers spent an average of 4.1 years at that firm. The whites in our sample who took a job in such a firm spent an average of 4.7 years at the firm. Seventeen percent of minority alumni and $22 \%$ of white alumni spent 7 or more years at their first large firm job. These differences are not great, and they are not statistically significant. They might also be explained by differential satisfaction with large-firm work unrelated to capacity (e.g., if minorities are less comfortable than whites in largely white, business-oriented firms; Wilkins and Gulati 1996) or by the quality of available alternative opportunities (e.g., if competent minority attorneys are more in demand than competent whites). The differences could also be greater than they appear if it is whites who have more competence-unrelated dissatisfaction or have more opportunities elsewhere.

In each of our cohorts, many minority students have taken first jobs in government, and some have taken jobs in legal services offices, public defender offices, or other public-interest settings. Between the 1970s and the 1980 s the numbers of minority students taking first jobs in these public

that overall $60.1 \%$ of both minority and white Alumni Survey respondents in these classes had clerked for the first firm to hire them. 
service settings declined sharply, but in all three decades the proportion of minority students taking first jobs in government has substantially exceeded the numbers of whites taking government jobs, and the proportion entering the legal services/public interest sector is greater for minority alumni among graduates of the 1970s and 1980s, although not among graduates of 1990s. The other major job sector that Michigan Law School's graduates frequently enter is business and finance, often in the offices of corporate counsel of major corporations. There is no substantial difference in the propensities of Michigan's minority and white students to take first jobs in this sector.

\section{CURRENT JOBS}

\section{The Overall Pattern}

Table 12 reports the current jobs of minority and white alumni by graduation decade. For both minority and white graduates, regardless of graduation decade, the private practice of law in firms is by a wide margin the most frequent single setting of work, and in each decade, the proportion of whites in private practice exceeds the proportion of minorities. Overall, about half of all minority alumni and $60 \%$ of white alumni currently work in solo practice or in firms. The gap between whites and minorities is greatest for the graduates of the 1970s, where the proportion of minority alumni in private practice is only two-thirds the proportion of white alumni in private practice. This gap is not due to a diminution over time in the attractiveness of private practice to 1970 s minority graduates, as this cohort is the only decade cohort of white or minority alumni which shows a net movement into private practice since their first jobs. ${ }^{38} \mathrm{We}$ look more closely at those in private practice in the next section.

After private practice, the next most common current work setting for minority graduates is government. About a fifth of the minority alumni responding to our survey work in government today, and regardless of graduation decade, a higher proportion of minority graduates than white graduates

38. Gender is more strongly associated with private practice careers than minority status. Logistic regression indicates that at the mean of the other variables in the model described in the text at note 6 , the odds that a female Michigan graduate is currently in private practice are about half the odds that a male graduate has a current private practice career. However, even though there are proportionately more women among Michigan's minority graduates than among its white graduates, gender explains little of the difference between whites and minorities. Before controlling for gender, the odds that a Michigan minority graduate will have a current career in private practice is .70 of the odds that a white graduate will have a private practice job. After controlling for gender, the relative odds increase to .71 . Controlling for grades, the odds that a minority graduate will have a private practice career increases substantially relative to the odds that a white will have a private practice career (to .87 ), but the odds that a woman will have a private practice career barely changes relative to the odds for men. 
TABLE 12

Current Jobs of Alumni, by Job Sector, Minority Status and Graduation Decade

\begin{tabular}{|c|c|c|c|c|c|c|}
\hline & \multicolumn{6}{|c|}{ Current Job Sector } \\
\hline & $\mathbf{n}$ & $\begin{array}{l}\text { Private } \\
\text { Practice }\end{array}$ & Business & Government & $\begin{array}{l}\text { Legal Services } \\
\text { or } \\
\text { Public Interest }\end{array}$ & Other $^{1}$ \\
\hline \multicolumn{7}{|l|}{$1970 s^{2}$} \\
\hline MA & 138 & $40.6 \%$ & $20.3 \%$ & $22.5 \%$ & $2.2 \%$ & $14.5 \%$ \\
\hline WA & 256 & $60.0 \%$ & $16.3 \%$ & $13.6 \%$ & $0.5 \%$ & $9.7 \%$ \\
\hline \multicolumn{7}{|l|}{$1980 s^{3}$} \\
\hline MA & 178 & $47.2 \%$ & $14.0 \%$ & $18.5 \%$ & $3.9 \%$ & $16.3 \%$ \\
\hline WA & 199 & $53.0 \%$ & $25.3 \%$ & $9.9 \%$ & $3.0 \%$ & $8.9 \%$ \\
\hline \multicolumn{7}{|l|}{$1990 s^{4}$} \\
\hline MA & 202 & $57.9 \%$ & $12.4 \%$ & $20.3 \%$ & $3.5 \%$ & $5.9 \%$ \\
\hline WA & 104 & $67.1 \%$ & $5.2 \%$ & $8.8 \%$ & $2.1 \%$ & $16.8 \%$ \\
\hline \multicolumn{7}{|c|}{$\begin{array}{l}1 \text { Includes education, accounting firms, labor unions, etc. } \\
{ }^{2} \chi^{2}=15.2, p<.01 \\
{ }^{3} \chi^{2}=16.5, p<.01 \\
{ }^{4} \chi^{2}=21.1, p<.001\end{array}$} \\
\hline
\end{tabular}

currently work for government employers. On its face, this pattern of government work echoes the data on initial job choices, which revealed that minority alumni at all points in time were more likely to take first jobs in government than their white counterparts. But among alumni of the 1970s and 1980s, it is not ordinary government work that explains the pattern. In these cohorts a high proportion of the minority alumni in government jobs today work not as attorneys but as judges or appointed or elected officials. A remarkable $13 \%$ of all minority graduates of the 1970 s serve as judges, public officials, or government agency managers (in comparison to $4 \%$ of white alumni); and $5 \%$ of the minority graduates of the 1980 s serve in such positions (compared to no white alumni). These data may help explain the comparatively small proportion of the 1970 s minority graduates currently in private practice. Many who might have had enduring private practice careers may have opted for careers in judicial or political office or law teaching instead. About a third of the re' ttively small number of the 1970s minority graduates who began in private practice are today judges, political office holders or law teachers. By contrast only about $2 \%$ of white alumni 
from this decade with a first job in private practice ended up in one of these careers. $^{39}$

After private practice and government, the next most popular current job sector for minority alumni is business. Over half of Michigan's minority alumni who work for businesses practice law as corporate counsel, and about half the remainder are business executives or managers. The overall propensity of minority alumni to be currently in business careers does not differ substantially from that of white alumni, but there is variation over time. White graduates of the 1980 s and minority graduates of the 1990 s seem to have had a special affinity for business careers. In addition, among those choosing business careers, minority alumni of the 1990s appear relatively more likely than white alumni to be working at Fortune 500 companies (data not shown in table).

About $6 \%$ of Michigan's minority graduates work in the field of education. Most of this group-25 minority graduates in all-are teachers of law. Since our survey focused primarily on those who practice law in some setting, we did not learn much about the professional life of law teacherswhat or where they taught, for example. But the sheer numbers are important. Michigan is among the five or six law schools that provide the largest numbers of law teachers for the nearly 200 American law schools. At the beginning of the 1970s, there were almost no black, Latino, or Native American law teachers at predominantly white law schools in the United States. Together with the minority graduates of the other teacher-producing schools, Michigan's minority graduates have played an important role in bringing minority teachers to the faculties of law schools in the United States. White and minority alumni have similar propensities to choose careers in education, and about the same proportion of those who chose careers in this sector entered law teaching. ${ }^{40}$

Relatively few Michigan alumni, whatever their ethnic background or graduation year, work in legal services or other public-interest positions. But

39. Logistic regression on the full sample confirms the statistical significance and strength of the tendency of minorities to gravitate toward government work. At the mean of the other independent variables in the model the odds that a minority Michigan graduate will be working for government is about 1.9 times the odds that a white Michigan graduate will be (about 1.7 times if LSGPA is controlled). The tendency of women to work for government is even stronger. The relative odds that women, as compared to men, will be currently working in government are more than 2.2:1 regardless of whether grades are controlled. As with private practice, gender does little to qualify the disproportionate tendency of minorities to have government positions.

40. Small numbers mean that one should not make too much of differences in propensities to choose careers in education across decades, but it is interesting to note that differences in the tendencies over time of minority and white alumni to choose careers in education are almost the mirror image of differences in tendencies to choose business careers. Relative to whites, minority graduates of the 1980 s seem to have a special propensity to choose jobs in education and not in business, while among graduates of the 1990s the situation is reversed. 
TABLE 13

Alumni Working as Lawyers in Settings Other Than Private Practice Who are Supervising or Managing Attorneys, by Minority Status and Graduation Decade

\begin{tabular}{rcc}
\hline & $\mathbf{n}$ & $\begin{array}{c}\text { \% Supervising or } \\
\text { Managing Attorney }\end{array}$ \\
\hline $\begin{array}{r}1970 \mathrm{~s} \\
\text { MA }\end{array}$ & 31 & $64.5 \%$ \\
WA & 43 & $63.5 \%$ \\
$1980 \mathrm{~s}$ & & \\
MA & 48 & $25.0 \%$ \\
WA & 50 & $30.9 \%$ \\
$1990 s$ & & $14.3 \% * *$ \\
MA & 49 & $0.0 \%$ \\
WA & 16 & \\
\hline
\end{tabular}

** $p<.01$

in all cohorts, minority alumni are somewhat more prone than white alumni to have careers in this sector.

Table 13 looks at the occupational roles of alumni who practice law in government, businesses, and other nonfirm organizations. We see that, as one would expect, the likelihood of being a supervisory or managing attorney increases with time since graduation. There is no consistent association with minority status, but considering how short a time they have been out, it seems that a remarkably high proportion of minority alumni from the 1990 s $(14.3 \%)$ have attained supervisory roles, given that none of the white alumni from this decade have done so. The difference is statistically significant.

\section{More on the Private Practitioners}

Private practice is the setting in which about half of all Michigan's minority alumni and $65 \%$ of its white alumni work. It is by far the largest employment sector for the school's graduates. Here we look at the private practitioners in somewhat more detail, saying more about the settings in which they work, the colleagues with whom they practice, and the clients they serve. 


\section{TABLE 14}

Firm Sizes of Alumni Currently in Private Practice, by Minority Status and Graduation Decade

\begin{tabular}{|c|c|c|c|c|c|c|}
\hline & \multicolumn{6}{|c|}{ Lawyers in Firm } \\
\hline & $\mathbf{n}$ & $1-10$ & $11-50$ & $51-100$ & $101-150$ & $151+$ \\
\hline \multicolumn{7}{|l|}{$1970 s^{1}$} \\
\hline MA & 56 & $66.1 \%$ & $17.9 \%$ & $5.4 \%$ & $1.8 \%$ & $8.9 \%$ \\
\hline WA & 145 & $38.8 \%$ & $23.6 \%$ & $10.5 \%$ & $6.9 \%$ & $20.1 \%$ \\
\hline \multicolumn{7}{|l|}{$1980 \mathrm{~s}^{2}$} \\
\hline MA & 83 & $47.0 \%$ & $21.7 \%$ & $6.0 \%$ & $6.0 \%$ & $19.3 \%$ \\
\hline WA & 101 & $27.7 \%$ & $21.0 \%$ & $14.1 \%$ & $9.6 \%$ & $27.6 \%$ \\
\hline \multicolumn{7}{|l|}{$1990 s^{3}$} \\
\hline MA & 116 & $25.9 \%$ & $18.1 \%$ & $15.5 \%$ & $9.5 \%$ & $31.0 \%$ \\
\hline WA & 69 & $14.4 \%$ & $19.9 \%$ & $13.5 \%$ & $14.3 \%$ & $37.9 \%$ \\
\hline \multicolumn{7}{|c|}{$\begin{array}{l}1 \chi^{2}=8.1, p<.1 \\
{ }^{2} \chi^{2}=6.6, \text { not sig. } \\
{ }^{3} \chi^{2}=4.5, \text { not sig. }\end{array}$} \\
\hline
\end{tabular}

Table 14 reports firm sizes for those Michigan alumni currently in private practice. These alumni work in firms of all sizes, across the whole spectrum of American law practice. There are, however, major cohort differences. The substantial majority of minority graduates from the 1970s who are in private practice today-over $65 \%$-work alone or in small firms of 10 or fewer lawyers. Of those who graduated in the 1980 s, $47 \%$ are in solo practice or small firms, but nearly a third work in firms of more than 50 lawyers. Among the most recent graduates, only about one-quarter work for firms of 10 or fewer lawyers and over half work in firms of more than 50 lawyers. In part, the size of the current law firms in which minority graduates practice reflects their opportunities and job choices at the time they graduated; in part, it reflects the usual migration of young lawyers from an initial job in a larger firm to a long-term position in a smaller practice setting. It also reflects, as we shall see shortly, considerable movement into and out of the private practice of law.

Among white graduates, the same partnership pattern exists, though among the graduates of the 1970 s proportionately more whites than minority graduates work in firms of larger sizes and proportionately fewer in very small firms or solo practice. Chi-square tests indicate, however, that only in the earliest cohort is there a possibly significant difference in the way that minority and white alumni sort themselves into firms of various sizes. $\mathrm{Mi}$ nority graduates of the 1990 s look the most like their white counterparts with respect to the size of the firms they practice in, and they are considera- 
bly less likely than the minority graduates of prior years to be currently practicing in firms of 10 or fewer lawyers or by themselves.

TABLE 15

Alumni in Private Practice Who Are Partners in Firms, by Minority Status and Graduation Decade

\begin{tabular}{rrc}
\hline & $\mathbf{n}$ & \% Partners in Firms \\
\hline 1970 s & & \\
MA & 56 & $91.1 \%$ \\
WA & 142 & $96.0 \%$ \\
1980 s & & \\
MA & 84 & $72.6 \%$ \\
WA & 99 & $80.0 \%$ \\
1990 s & 116 & $19.0 \%$ \\
MA & 68 & $13.2 \%$ \\
WA & & \\
\hline
\end{tabular}

Table 15 displays the proportion of lawyers currently in private law firms who are partners, excluding a small number of alumni who are "of counsel." We see from this table that almost all minority graduates from the 1970s who work in law firms are partners $(91.1 \%)$ as are over two-thirds of those who graduated in the 1980s. White graduates in these cohorts do even better. No difference in partnership rates is significant, however, and the $7.4 \%$ advantage whites held in the 1980 s exists in large part because minority alumni from the 1980s have been with their firms for a shorter time, on average, than the white graduates (a mean of 6.0 years for minority graduates compared to 7.3 years for white graduates) and because, on average, they graduated more recently from law school (36\% of the minority graduates of the 1980 s, but only $24 \%$ of the white graduates, are from the classes of 1988 or 1989 ).

The next two tables, tables $16 \mathrm{~A}$ and $16 \mathrm{~B}$, depict characteristics of the private practitioners' colleagues within the firms where they work. Table $16 \mathrm{~A}$ presents data on the number and proportion of the other lawyers in their law firms who are graduates of so-called elite law schools (in the words of the questionnaire, "graduates of schools like Berkeley, Harvard, Michigan, and Yale"). Three features of this table stand out. First, Michigan graduates regardless of race tend to work in law firms with substantial proportions of attorneys from other leading law schools-across the decades, an average of about a third or more of the attorneys in respondents' firms. Second, the graduates of the 1990s tend to have a somewhat higher proportion of "elite" law school colleagues than the graduates of the earlier 
TABLE 16A

"Elite" Law School Graduates in the Firms of Alumni in Private Practice, by Minority Status and Graduation Decade

\begin{tabular}{rrrc}
\hline & $\mathbf{n}$ & $\begin{array}{c}\text { Proportion of Elite Law } \\
\text { School Graduates }\end{array}$ & $\begin{array}{c}\text { Mean Number of Elite Law } \\
\text { School Graduates }\end{array}$ \\
\hline $\begin{array}{r}\text { 1970s } \\
\text { MA }\end{array}$ & 41 & & $16.6 * * *$ \\
WA & 109 & $31.6 \%$ & 55.8 \\
$1980 s$ & & & 53.0 \\
MA & 64 & $32.4 \%$ & 61.0 \\
WA & 81 & $41.3 \%$ & $64.2+$ \\
$1990 s$ & 100 & $40.5 \%$ & 92.2 \\
MA & 59 & $46.1 \%$ & \\
WA & & & \\
\hline
\end{tabular}

$+p<.1 * * * p<.001$

NOTE The question asked "[A]bout how many [lawyers in respondents' firms] are from 'elite' law schools (Berkeley, Harvard, Michigan, Yale, etc.)?"

decades, reflecting the higher proportion of more recent graduates working in large firms. And, third, within decades of graduation, minority and white alumni report similar proportions of "elite" law school graduates among the lawyers in their firms. Differences in the proportions are not statistically significant. ${ }^{41}$

Table $16 \mathrm{~B}$ reports on the ethnicity of the other lawyers in the firms where respondents practice. The table shows, for private practitioners of the various ethnic groups, the mean percentage of lawyers of each ethnicity in their firm. Unlike most of our tables, this table does not divide respondents into two groups, minority and white alumni. Rather, it looks separately at each of the major ethnic groups represented in our survey, including Asians, whom we have heretofore not considered. In addition, because the numbers of Latinos, Native Americans, and Asians in firms are small, we group all three decades together. As the table reveals, for members of each ethnic group, a majority of their colleagues in both small (2-10 lawyers) and large firms (more than 50 lawyers) are white. It also reveals that, in large firms,

41. There is a possible selection bias problem here, as a smaller proportion of minority alumni than white alumni have current positions with law firms. It is possible that had as high a proportion of minority alumni as white alumni entered law firms, the additional entrants would not have entered firms with as high a proportion of elite attorneys. Significantly, however, in the 1990-96 cohort, where the proportion of minority alumni in law firms is highest and closest to the proportion of white alumni in firms, the average proportion of elite attorneys in minority respondents' law firms is higher than it is for minority alumni of earlier decades. Similar selection problems may affect some of the other law-firm related variables we examine. 


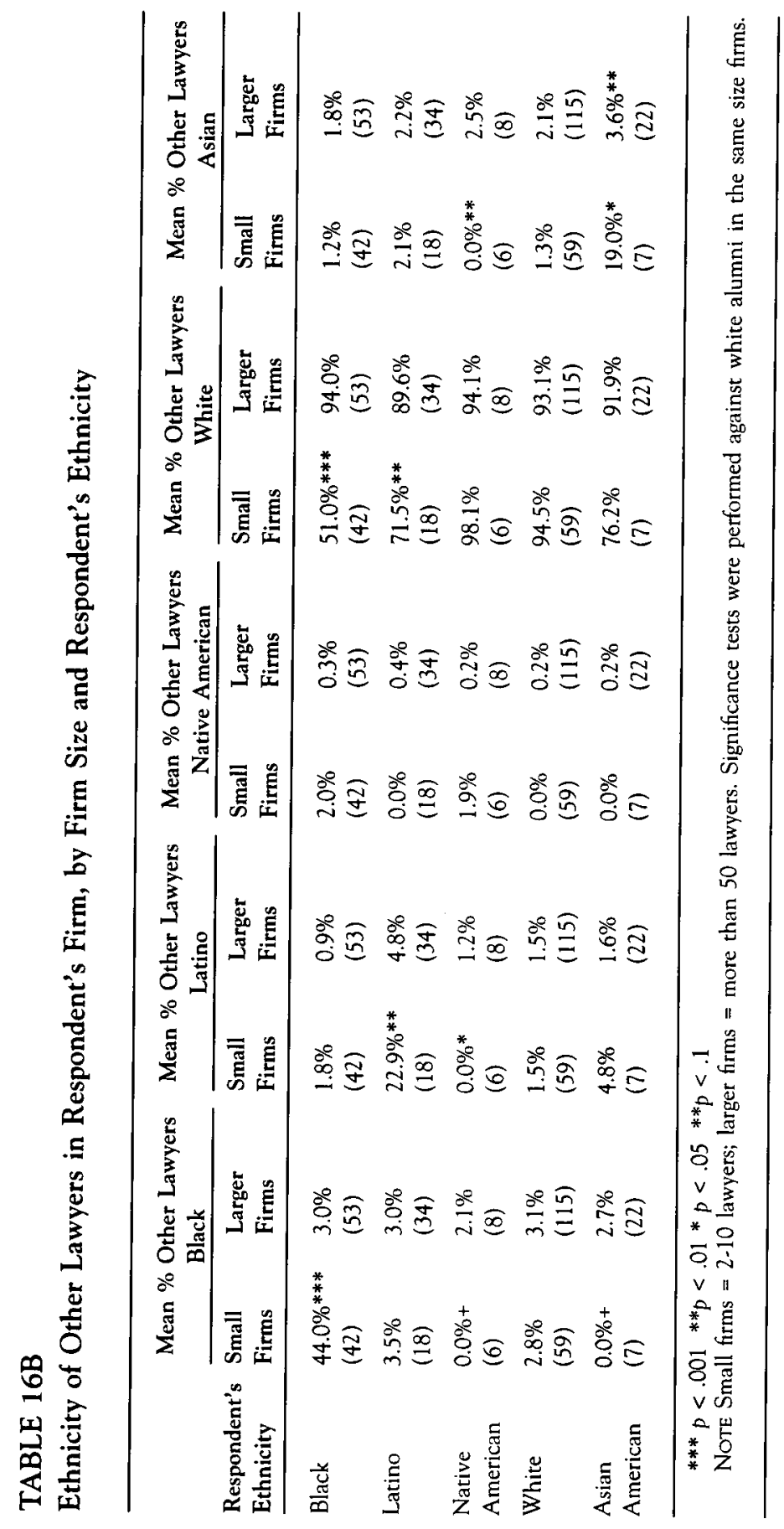


regardless of their ethnicity, respondents tend to have few minority colleagues. Our black graduates in large firms are no more likely than our white graduates to have a substantial proportion of black attorneys among their colleagues. The same is true for Latinos, Native Americans and Asian Americans. This is because the large law firms in this country are overwhelmingly white, so regardless of their ethnicity, Michigan graduates working in large firms have mainly white colleagues. (Much the same is true of midsized firms of 11-50 lawyers [not shown in table]. There too, the overwhelming majority of minority lawyers practice with no or few samerace colleagues.)

A different pattern exists for those practicing in firms of 2 to 10 lawyers. Unlike their counterparts in larger firms, black, Latino, and Asian American lawyers who practice in small firms often have a substantial proportion of fellow ethnics as colleagues. For example, on average $44 \%$ of the colleagues of black private practitioners in small firms are black. (No other ethnic group averages more than $4 \%$ black colleagues.) The $44 \%$ figure is, however, somewhat misleading. Almost none of the black graduates work in small firms where roughly half their colleagues are black. Rather, the average disguises a bimodal distribution: about half the black respondents in small firms have no black colleagues, and about a third have no colleagues who aren't black. But black lawyers are not the most likely to practice only with others of their race. The small-firm lawyers most likely to practice only with same-race colleagues are the whites: $94.5 \%$ of the colleagues of white small-firm attorneys are white, and 71.4 percent of whites in small firms have no colleagues who are black, Latino, Native American, or Asian American.

Tables 17, 18, and 19 look at the clients of the private practitioners. Table 17 shows how the three decades of Michigan alumni in private practice divide their time among different types of individual and organizational clients. We see from the table that collectively both minority and white alumni serve a diverse group of clients, ranging from poor individuals to wealthy corporations. As a broad generalization, whether minority or white, the more recent the graduate, the more likely clients are to be businesses and the less likely they are to be individuals (a pattern that reflects the much greater tendency of recent graduates to work in large firms).

Differences between minority and white alumni in the types of clients served are greatest among 1970s graduates, but in all cohorts, minorities seem more likely than white graduates to serve low- and middle-income individuals, while white alumni are more likely to serve small- and mediumsized businesses. Most differences on these client-served variables are significant or marginally significant. There are no statistically significant differ- 


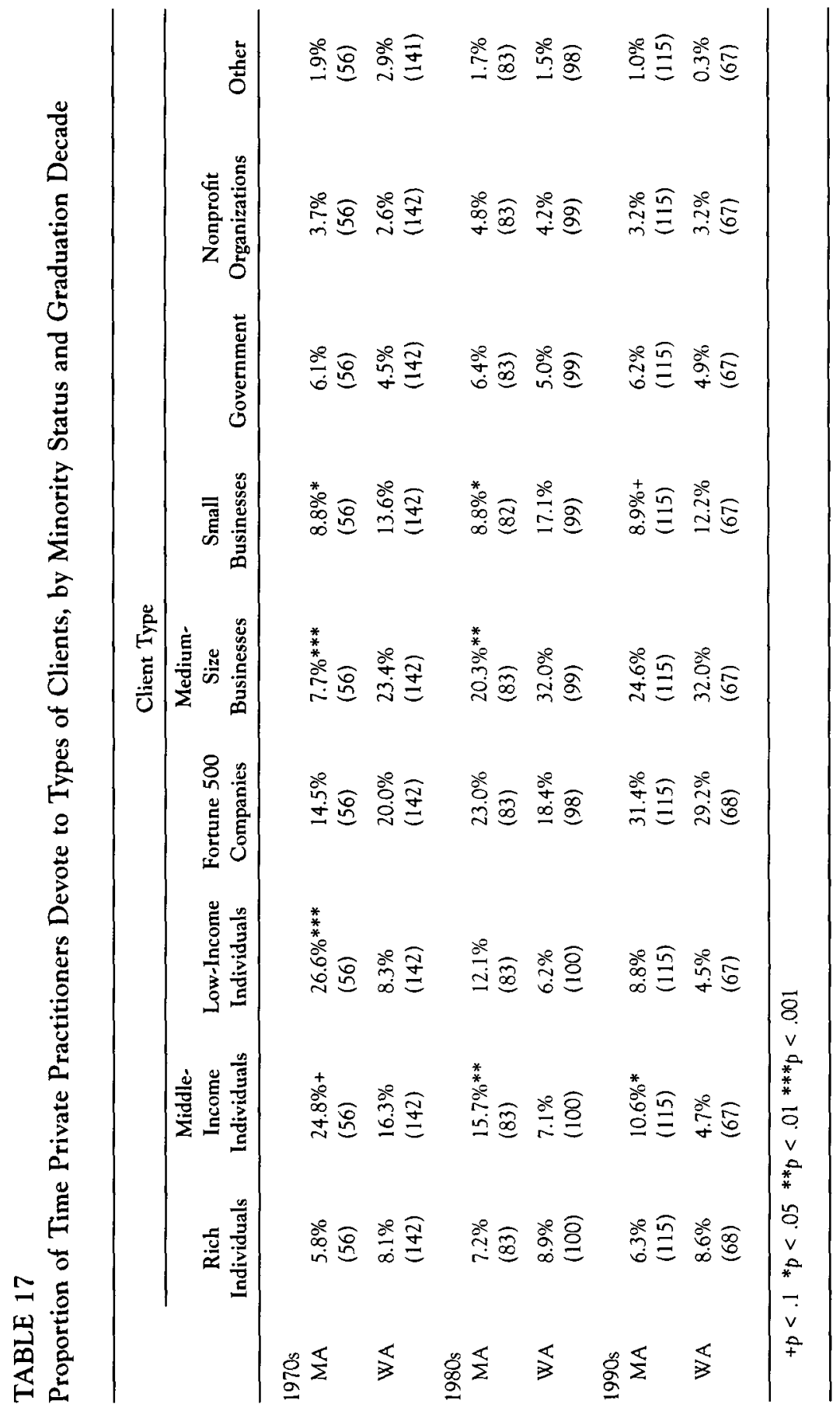


TABLE 18

Ethnicity of Individual Clients of Alumni in Private Practice, by Lawyer Ethnicity, among Alumni Who Spent $20 \%$ or More of Their Time Serving Individual Clients

\begin{tabular}{|c|c|c|c|c|c|}
\hline \multirow[b]{2}{*}{$\begin{array}{l}\text { Alumni } \\
\text { Ethnicity }\end{array}$} & \multicolumn{5}{|c|}{ Client Ethnicity } \\
\hline & Black & Latino & $\begin{array}{c}\text { Native } \\
\text { American }\end{array}$ & White & Asian \\
\hline Black & $\begin{array}{l}53.1 \% * * * \\
(73)\end{array}$ & $\begin{array}{l}5.5 \% \\
(73)\end{array}$ & $\begin{array}{l}0.2 \% \\
(73)\end{array}$ & $\begin{array}{l}39.3 \% * * * \\
(73)\end{array}$ & $\begin{array}{l}1.1 \% * \\
(73)\end{array}$ \\
\hline Latino & $\begin{array}{l}10.9 \% \\
(36)\end{array}$ & $\begin{array}{l}28.9 \% * * * \\
(36)\end{array}$ & $\begin{array}{l}0.6 \% \\
(36)\end{array}$ & $\begin{array}{l}53.0 \% * * * \\
(36)\end{array}$ & $\begin{array}{l}4.8 \% \\
(36)\end{array}$ \\
\hline $\begin{array}{l}\text { Native } \\
\text { American }\end{array}$ & $\begin{array}{l}3.5 \% * * \\
(11)\end{array}$ & $\begin{array}{l}4.7 \% \\
(11)\end{array}$ & $\begin{array}{l}10.9 \% \\
(11)\end{array}$ & $\begin{array}{l}69.9 \% \\
(11)\end{array}$ & $\begin{array}{l}8.2 \% \\
(11)\end{array}$ \\
\hline White & $\begin{array}{l}13.6 \% \\
(130)\end{array}$ & $\begin{array}{l}5.3 \% \\
(129)\end{array}$ & $\begin{array}{l}0.3 \% \\
(129)\end{array}$ & $\begin{array}{l}76.6 \% \\
(130)\end{array}$ & $\begin{array}{l}2.4 \% \\
(128)\end{array}$ \\
\hline Asian & $\begin{array}{l}0.6 \% * * * \\
(10)\end{array}$ & $\begin{array}{l}0.6 \% * * * \\
(10)\end{array}$ & $\begin{array}{l}0.0 \% * * * \\
(10)\end{array}$ & $\begin{array}{l}67.3 \% \\
(10)\end{array}$ & $\begin{array}{l}31.5 \% * * \\
(10)\end{array}$ \\
\hline
\end{tabular}

${ }^{*} p<.05 * * p<.01 * * * p<.001$

NOTE Significance tests were performed against white alumni serving the same ethnic population.

TABLE 19

Ethnicity of Principal Contacts within Organizations Served by Alumni in Private Practice, by Lawyer Ethnicity, for Alumni Who Spent $20 \%$ or More of Their Time Serving Organizational Clients

\begin{tabular}{|c|c|c|c|c|c|}
\hline \multirow[b]{2}{*}{$\begin{array}{l}\text { Alumni } \\
\text { Ethnicity }\end{array}$} & \multicolumn{5}{|c|}{ Ethnicity of Principal Organizational Contact } \\
\hline & Black & Latino & $\begin{array}{c}\text { Native } \\
\text { American }\end{array}$ & White & Asian \\
\hline Black & $\begin{array}{l}24.6 \% * * * \\
(101)\end{array}$ & $\begin{array}{l}2.1 \% \\
(101)\end{array}$ & $\begin{array}{l}0.9 \% \\
(101)\end{array}$ & $\begin{array}{l}72.7 \% * * * \\
(101)\end{array}$ & $\begin{array}{l}1.1 \% * * * \\
(101)\end{array}$ \\
\hline Latino & $\begin{array}{l}3.0 \% \\
(65)\end{array}$ & $\begin{array}{l}9.3 \% * * \\
(65)\end{array}$ & $\begin{array}{l}0.2 \% \\
(65)\end{array}$ & $\begin{array}{l}82.1 \%+ \\
(65)\end{array}$ & $\begin{array}{l}2.2 \% \\
(65)\end{array}$ \\
\hline $\begin{array}{l}\text { Native } \\
\text { American }\end{array}$ & $\begin{array}{l}2.3 \% \\
(13)\end{array}$ & $\begin{array}{l}0.8 \% \\
(13)\end{array}$ & $\begin{array}{l}6.5 \% \\
(13)\end{array}$ & $\begin{array}{l}80.5 \% \\
(13)\end{array}$ & $\begin{array}{l}6.7 \% \\
(13)\end{array}$ \\
\hline White & $\begin{array}{l}3.7 \% \\
(237)\end{array}$ & $\begin{array}{l}1.8 \% \\
(235)\end{array}$ & $\begin{array}{l}0.2 \% \\
(235)\end{array}$ & $\begin{array}{l}88.7 \% \\
(237)\end{array}$ & $\begin{array}{l}3.2 \% \\
(235)\end{array}$ \\
\hline Asian & $\begin{array}{l}1.9 \% * \\
(40)\end{array}$ & $\begin{array}{l}2.0 \% \\
(40)\end{array}$ & $\begin{array}{l}0.1 \% \\
(40)\end{array}$ & $\begin{array}{l}71.9 \% * * * \\
(40)\end{array}$ & $\begin{array}{l}21.6 \% * * * \\
(40)\end{array}$ \\
\hline
\end{tabular}

$+p<.1 * p<.05 * * p<.01 * * * p<.001$

NOTE Significance tests were performed against white alumni serving the same ethnic population. 
ences in the average amount of time that white and minority private practitioners spend on the business of Fortune 500 companies, government agencies, or nonprofit organizations. For both whites and minorities, the proportion of time devoted to the affairs of low- and middle-income individuals seems to reflect substantial cohort effects. Among 1970 s alumni, minorities spend about half their time and whites, about a quarter of their time, on the legal affairs of such clients. In the 1990 cohort, minority alumni are devoting less than $20 \%$ of their time and white alumni, less than $10 \%$ of their time, to such individuals. None of these differences should, however, obscure the larger picture. Minority and white alumni in all decades serve all kinds of clients, and within each group in each cohort, there is substantial variation in the kinds of clients time is devoted to.

The pattern of client service we see among graduates of the $1970 \mathrm{~s}$ is visible but less striking among alumni of the later decades. ${ }^{42}$ By the 1990 s, associations are attenuated to the point where differences between the tendencies of minority and white alumni to devote time to low-income individuals and medium-sized businesses have ceased to be significant.

The next two tables examine the relationship between the ethnicity of lawyers and the ethnicity of the clients they serve. Table 18 looks at the ethnicity of individual clients for lawyers who report spending at least $20 \%$ of their time serving individual clients, and table 19 looks at the ethnicity of the principal contact person at organizations for lawyers who report spending at least $20 \%$ of their time serving organizations (including businesses, governments, and nonprofits). ${ }^{43}$ Again, as with the examination of colleagues in the same firms, we look at each ethnic group separately, and again, because the numbers of some groups, such as Asians and Native Americans, were so small in the earlier decades, we combine the three decades.

For all groups, a high proportion of their individual clients and an even higher proportion of their contacts at organizations are white. That is unsurprising given the numbers and resources of whites in our society. What is striking in the tables is the extent to which the members of each minority ethnic group have individual clients and organizational contacts who are members of their own group. This pattern illustrates well the continuing salience of race in American society and, in particular, in the provision of legal services by private practitioners of law. For the black graduates, our

42. In most respects black and Latino graduates in private practice report similar work settings and experiences, but among the graduates of the 1980 s, black private practitioners spent on average $35.1 \%$ of their time serving low- and middle-income individuals, while Latino private practitioners spent on average $17.5 \%$ of their time serving such clients $(p<.05)$. White private practitioners in the 1980 s averaged $13.3 \%$ of their time serving such clients.

43. We tried to constrain respondents' answers to the items we summarize in this table so that the proportions of different client's represented would total $100 \%$. But because we did not offer the category "other ethnicity" or because of respondents' mistakes in addition, not every row in these tables totals $100 \%$. 
largest minority group, an average of $53.1 \%$ of their individual clients and $24.6 \%$ of their organizational contacts are also black, a vastly higher percentage of black clients than is the case for any other group. Similarly, Asian graduates, who are most like white graduates in UGPAs, LSAT scores, and career choices, have more than 6 times the proportion of Asians among their individual clients and organizational contacts, that white, black, or Latino graduates have.

The strong statistically significant tendency of alumni to disproportionally serve persons of their own race or ethnicity exists among the graduates of each of the three decades examined separately (not shown in tables), but is more pronounced among the graduates of the 1970s than among more recent graduates. The graduates of the 1970 s are more frequently in solo practice and small firms, and it is among solo practitioners and small-firm lawyers that the highest proportion of same-race individual clients and organizational contacts are reported.

As we have noted, lawyers tend to have colleagues of their own ethnicity. The stronger this tendency, the more likely it is that a lawyer's clientele will also consist disproportionately of members of the lawyer's ethnic group. Thus, minority lawyers practicing in minority-dominated firms are more likely to have same-minority clients or organizational client contacts than minority lawyers practicing in white-dominated firms, and whites are more likely to have white clients and client contacts, the smaller the proportion of the firm's lawyers with minority backgrounds. For example, among black lawyers in private practice, the correlation between the percentage of lawyers in their firm who are black and the percentage of individual clients who are black is .55 . The correlation between the percentage of lawyers who are black and the percentage of institutional client contact persons who are black is .59. This relationship loses none of its strength after controlling for size of firm. The same pattern exists between the proportion of Latino lawyers in a firm and the proportions of the firm's clients and client contacts who are Latino. These patterns may exist because the more dominated firms are by lawyers of one ethnic group, the greater their capacity to attract clients from that ethnic group and the less their relative ability to attract clients from other ethnic groups. The pattern could also reflect the preferences of lawyers who could attract clients from any ethnic group or the implications of residential segregation for where lawyers work and where clients seek lawyers.

From one point of view, the strong relationship between the ethnicity of minority lawyers and the ethnicity of their clients is an aspect of the success of Michigan's commitment to train more minority lawyers, for the Michigan program has surely increased the numbers of its graduates providing services to African American and Latino individuals and organizations and to low- and middle-income individuals. From another point of view, 
the implications of the race-linked pattern of client relationships are a discouraging reminder of the continuing deep significance of race in personal and professional relationships in American society. Clients and representatives of organizational clients gravitate toward attorneys of their own ethnic group and vice versa. Clients seek lawyers whom they know personally or by reputation and with whom they expect to be comfortable. Lawyers seek out, as colleagues and clients, people to whom they have access through informal networks and with whom they expect to be comfortable. Color blindness seems not to prevail in the world of law practice, and it seems unlikely to prevail as long as ethnicity plays a major role in structuring opportunities and relationships in the larger society. Medicine is similar. Komaromy et al. (1996) report that even after controlling for the ethnic characteristics of practice locations, black and Hispanic physicians were disproportionately likely to serve patients from their own ethnic groups. Keith et al. (1985), looking at 1985 medical school graduates, found that black, Hispanic, Native American, Asian, and white physicians each tended disproportionately to serve patients of their own ethnic backgrounds. These findings confirm our sense of the importance race has in the establishment of professionalclient relationships.

TABLE 20A

Job Movement, by Minority Status and Graduation Decade: Michigan Alumni with First Job in Sector Who Are Still in the Same Sector

\begin{tabular}{|c|c|c|c|c|c|}
\hline & $\begin{array}{l}\text { Private } \\
\text { Practice }\end{array}$ & $\begin{array}{l}\text { Business/ } \\
\text { Finance }\end{array}$ & Government & $\begin{array}{l}\text { Legal Services/ } \\
\text { Public Interest }\end{array}$ & Other \\
\hline \multicolumn{6}{|l|}{$1970 \mathrm{~s}$} \\
\hline MA & $\begin{array}{l}59 \% \\
(46)\end{array}$ & $\begin{array}{l}40 \% \\
(15)\end{array}$ & $\begin{array}{l}40 \% \\
(43)\end{array}$ & $\begin{array}{l}8 \% \\
(26)\end{array}$ & $\begin{array}{l}20 \% \\
(15)\end{array}$ \\
\hline WA & $\begin{array}{c}71 \% \\
(160)\end{array}$ & $\begin{array}{l}46 \% \\
(18)\end{array}$ & $\begin{array}{l}46 \% \\
(46)\end{array}$ & $\begin{array}{c}1 \% \\
(17)\end{array}$ & $\begin{array}{l}35 \% \\
(19)\end{array}$ \\
\hline \multicolumn{6}{|l|}{$1980 \mathrm{~s}$} \\
\hline MA & $\begin{array}{c}53 \% \\
(136)\end{array}$ & $\begin{array}{c}57 \% \\
(7)\end{array}$ & $\begin{array}{l}24 \% \\
(25)\end{array}$ & $\begin{array}{l}31 \% \\
(13)\end{array}$ & $\begin{array}{c}13 \% \\
(8)\end{array}$ \\
\hline WA & $\begin{array}{l}55 \% \\
(170)\end{array}$ & $\begin{array}{c}77 \% \\
(9)\end{array}$ & $\begin{array}{c}36 \% \\
(7)\end{array}$ & $\begin{array}{c}27 \% \\
(8)\end{array}$ & $\begin{array}{l}26 \% \\
(12)\end{array}$ \\
\hline \multicolumn{6}{|l|}{$1990 \mathrm{~s}$} \\
\hline MA & $\begin{array}{l}72 \% \\
(140)\end{array}$ & $\begin{array}{c}50 \% \\
(6)\end{array}$ & $\begin{array}{l}69 \% * * * \\
(32)\end{array}$ & $\begin{array}{c}33 \% \\
(6)\end{array}$ & $\begin{array}{l}32 \% * \\
(19)\end{array}$ \\
\hline WA & $\begin{array}{l}79 \% \\
(84)\end{array}$ & $\begin{array}{c}24 \% \\
(3)\end{array}$ & $\begin{array}{c}100 \% \\
(3)\end{array}$ & $\begin{array}{c}19 \% \\
(6)\end{array}$ & $\begin{array}{l}71 \% \\
(7)\end{array}$ \\
\hline
\end{tabular}




\section{Career Patterns}

Tables $20 \mathrm{~A}$ and $\mathrm{B}$ look at career trajectories by examining movements from first to current jobs by job sector, graduation decade, and minority status. Table 20A looks at whether our respondents at the time of our survey were working in the same job sector in which they initially worked (after a judicial clerkship, if any). Since the data relate only to first and current jobs, it is an imperfect measure of job changes. People who have not changed job sectors may have changed employers within that sector, and some may have left their initial job sector but returned to it by the time of our questionnaire. Table 20A reveals no important differences between white and minority students in their tendencies to be working at the time of our survey in the same job sector in which they began their careers. In the few cases where the stability proportions differ substantially, the number of people working originally in the sector is so small that the differences have little meaning, although in two cases they are significant. A relatively small proportion of 1970s minority graduates began in the private practice of law, but nothing about the table suggests that these early graduates could not succeed in private practice. We see from table 20B that these 1970s graduates are the only group to show net movement into private practice, and we have already noted that a large proportion of those in this group who left private practice left for the high-prestige alternatives of political office, judging, and teaching. The most noticeable aspect of table $20 \mathrm{~A}$ is how much sector shifting goes on, even during the first few years after law school. At the time of our questionnaire, more than $40 \%$ of our respondents were no longer working in the same practice sector where they began, and no doubt, many additional career moves have occurred within sectors.

Table 20B gives a sense of career moves across sectors, as it presents the number of respondents in a job sector as a proportion of the number who started out there. These proportions capture the net effects of movement both into and out of the various sectors. Where the number having first jobs in a sector is small, these proportions can be quite large, but not much should be made of their absolute magnitude. The direction of movement into or out of a sector is of more interest. Minorities and whites are very much alike. Both have tended to leave jobs in private practice or the legal-services/public-interest sector and to move into jobs in the business/ finance area and, for graduates of the last two cohorts, government. Minority alumni of the 1970s, as we just noted, are the only group to show net movement toward private practice. This reflects, no doubt, the small proportion of minority graduates of this decade who began there. Overall, our data are consistent with the reported derline in the satisfaction of attorneys in private law firms relative to those in other spheres of legal work. Those whose practice careers go back long enough or who entered practice with 
TABLE 20B

Job Movement, by Minority Status and Graduation Decade: Michigan Alumni Currently in Job Sector as a Proportion of Those with First Job in Sector

\begin{tabular}{|c|c|c|c|c|c|}
\hline & $\begin{array}{l}\text { Private } \\
\text { Practice }\end{array}$ & $\begin{array}{l}\text { Business/ } \\
\text { Finance }\end{array}$ & Government & $\begin{array}{l}\text { Legal Services/ } \\
\text { Public Interest }\end{array}$ & Other \\
\hline \multicolumn{6}{|l|}{$1970 \mathrm{~s}$} \\
\hline MA & $\begin{array}{l}127 \% \\
(56)\end{array}$ & $\begin{array}{c}187 \% \\
(28)\end{array}$ & $\begin{array}{l}76 \% \\
(31)\end{array}$ & $\begin{array}{l}13 \% \\
(3)\end{array}$ & $\begin{array}{l}143 \% \\
(20)\end{array}$ \\
\hline WA & $\begin{array}{l}88 \% \\
(145)\end{array}$ & $\begin{array}{c}281 \% \\
(45)\end{array}$ & $\begin{array}{l}88 \% \\
(36)\end{array}$ & $\begin{array}{l}9 \% \\
(2)\end{array}$ & $\begin{array}{l}197 \% \\
(27)\end{array}$ \\
\hline \multicolumn{6}{|l|}{$1980 \mathrm{~s}$} \\
\hline MA & $\begin{array}{l}64 \% \\
(84)\end{array}$ & $\begin{array}{c}357 \% \\
(25)\end{array}$ & $\begin{array}{c}165 \% \\
(33)\end{array}$ & $\begin{array}{c}58 \% \\
(7)\end{array}$ & $\begin{array}{l}414 \% \\
(29)\end{array}$ \\
\hline WA & $\begin{array}{c}62 \% \\
(101)\end{array}$ & $\begin{array}{c}893 \% \\
(50)\end{array}$ & $\begin{array}{c}255 \% \\
(21)\end{array}$ & $\begin{array}{c}95 \% \\
(7)\end{array}$ & $\begin{array}{c}168 \% \\
(20)\end{array}$ \\
\hline \multicolumn{6}{|l|}{$1990 \mathrm{~s}$} \\
\hline MA & $\begin{array}{c}85 \% \\
(117)\end{array}$ & $\begin{array}{c}417 \% \\
(25)\end{array}$ & $\begin{array}{c}125 \% \\
(40)\end{array}$ & $\begin{array}{c}120 \% \\
(6)\end{array}$ & $\begin{array}{l}63 \% \\
(12)\end{array}$ \\
\hline WA & $\begin{array}{l}83 \% \\
(69)\end{array}$ & $\begin{array}{c}256 \% \\
(7)\end{array}$ & $\begin{array}{l}258 \% \\
(9)\end{array}$ & $\begin{array}{l}38 \% \\
(2)\end{array}$ & $\begin{array}{c}231 \% \\
(16)\end{array}$ \\
\hline
\end{tabular}

NOTE Numbers in parentheses are the actual number of respondents currently working in job sector. Percentages are rounded to the nearest whole number. No significance tests were done.

more seniority apparently find the practice experience more satisfying than younger attorneys. As we have seen, almost all 1970s Michigan law graduates are partners if they are in law firms, and as we shall see, their overall satisfaction with their careers is both absolutely high and higher than that of private practitioners who graduated in later decades.

\section{Summary of Work Settings}

To summarize, when we look at the careers of Michigan's minority alumni we see that they are found in substantial numbers in all the major settings where lawyers work: small and large private law firms, government agencies, judgeships, businesses, and legal education. And when we compare the current positions of minority and white alumni, similarities stand out more than differences. Alumni from both groups, regardless of graduation decade, are more likely to be engaged in the private practice of law than in any other occupation. The proportion of private practice lawyers who are solo practitioners decreases markedly for each group with each graduation decade, and the proportion of attorneys practicing in large and very large 
firms increases. Regardless of minority status, graduates of the 1970s working in law firms are almost all partners, and those working as lawyers for nonfirm organizations are likely to have supervisory responsibilities. The biggest difference between the jobs of the minority and white alumni is that minority alumni are substantially more likely than white alumni to work in government. Indeed, among white graduates of the 1970s and 1980s, business, not government, is the second most likely current employer. But the different propensities of minority and white graduates of these decades to hold current jobs in government is because a higher proportion of minority alumni have been elected or appointed to judgeships, political office, or high-level administrative positions and does not reflect a difference in tendencies to work as government attorneys. Turning our attention to the 1990-96 cohort, we see that virtually all current occupation differences between minority and white alumni are substantially diminished compared to earlier decades, and on a number of measures that might be thought to reflect rapid or high achievement, such as partnership status in law firms and supervisory responsibility in nonfirm organizations, the group of most recently graduated minority alumni is doing at least as well as, if not a bit better than, their white counterparts.

\section{SUCCESS AND ACHIEVEMENT}

There are many ways to measure professional success and ability, but none is without its problems. Although some research has attempted to look at lawyer performance in practice, no researcher has yet come up with an acceptable general measure of lawyer competence. We have already, in the preceding section, looked at some indications of success and achievementfor example, persons who have become judges, public officials, or partners in large firms. In this portion of the report, we look at three other measures of success and achievement and indirectly of ability: self-reports of career satisfaction; income from work; and contributions as a citizen/lawyer-that is, serving the legal needs of the public, supporting younger attorneys, and giving back to the community. The latter kinds of contributions are usually not required of lawyers but are expected by the legal profession's aspirational norms.

None of our achievement measures is ideal. All are based on self-reports, and each may be biased toward reporting greater success than has in fact been experienced. For example, most of our respondents report they are more satisfied than dissatisfied with their careers. In worker surveys, findings of self-reported career satisfaction are, however, common, even among those in careers that might appear to many as less rewarding (and certainly far less remunerative) than our respondents' legal careers. It may be that our respondents share a general bias against acknowledging job dissatisfaction or 
that their tendency to report satisfaction with their careers hides considerable dissatisfaction. But, with satisfaction, as with our other measures of achievement, we have no reason to believe that biases that might affect whites differ from those that might affect minorities. If they don't, the validity of the comparisons we draw between whites and minorities will not be affected. Moreover, the fact that the data below reveal few differences between the career satisfaction of whites and minorities is important. If minorities were much less happy with their careers than whites, it would be a sign that something was amiss, and that affirmative action programs for minority applicants were not having some of the long-term effects supporters of these programs intended.

Unfortunately, we have no way of directly measuring competence. We did not observe our respondents in their jobs or test them or seek to learn what other attorneys think of the quality of their work. At best we would expect some of our measures, like income and the previously examined promotion to partnership, to have some positive but unknown association with relative competence and, in the case of those earning high incomes or working as partners, to largely negate the possibility of incompetence.

Finally, there are many dimensions of practice success for which we have no measures. Thus, there is much to be said about practice success that we cannot address. But in employing three measures, we have diverse indicators of success and accomplishment, and a number of the variables we have already examined relate to success or accomplishment on other dimensions. If there are large differences between the success and accomplishments of Michigan's white and minority graduates, we would expect some of our measures to be noticeably affected.

\section{Career Satisfaction}

To learn how satisfied our alumni felt about their careers, we inquired about overall career satisfaction and satisfaction with the following aspects of work: solving problems for specific clients, income, the intellectual challenge of work, the value of one's work to society, relationships with coworkers, and the balance work allows between professional and family life. Table 21 presents measures of overall job satisfaction on a 7-point scale for everyone and separately for those in private practice, government, and business (the three largest sectors of employment). Tables 22 and 23 present data on specific kinds of career satisfaction controlling for whether respondents are in private practice. 
TABLE 21

Michigan Alumni Who Report Being Satisfied with Their Careers Overall, by Minority Status, Practice Setting, and Graduation Decade

\begin{tabular}{rllll}
\hline & \multicolumn{4}{c}{ Practice Sector } \\
\cline { 2 - 5 } & $\begin{array}{l}\text { Private } \\
\text { Practice }\end{array}$ & Government & Business & All Alumni \\
\hline 1970s & & & & \\
MA & $80.4 \%$ & $87.1 \%$ & $64.3 \% *$ & $79.2 \%$ \\
& $(56)$ & $(31)$ & $(28)$ & $(144)$ \\
WA & $79.2 \%$ & $91.0 \%$ & $84.2 \%$ & $81.8 \%$ \\
& $(144)$ & $(36)$ & $(44)$ & $(256)$ \\
$1980 s$ & & & & \\
MA & $70.2 \%$ & $84.8 \%$ & $84.0 \%$ & $75.5 \%$ \\
& $(84)$ & $(33)$ & $(26)$ & $(184)$ \\
WA & $70.7 \%$ & $91.9 \%$ & $88.9 \%$ & $79.4 \%$ \\
& $(101)$ & $(21)$ & $(50)$ & $(202)$ \\
$1990 s$ & & & & $71.2 \%$ \\
MA & $63.2 \%$ & $85.4 \%$ & $68.0 \%+$ & $(205)$ \\
& $(117)$ & $(41)$ & $(25)$ & $76.4 \%$ \\
WA & $71.7 \%$ & $87.8 \%$ & $90.8 \%$ & $(104)$ \\
& $(69)$ & $(10)$ & $(7)$ & \\
\hline
\end{tabular}

$+p<.1 * p<.05$

NOTE Data reflect proportion of respondents giving a rating of 5,6 , or 7 on a scale, where 1 is "very dissatisfied" and 7 is "very satisfied," when asked how satisfied they were with their careers overall.

Table 21 shows that the great majority of minority graduates in all three decades are satisfied overall with their careers and that there is just one statistically significant difference and one marginally significant difference in the overall reported career satisfaction of Michigan's white and minority alumni. Both indicate that whites in the business sector are more satisfied than minorities with their careers. Perhaps the most striking aspect of the table is that both white and minority alumni of all three decades are considerably more likely to report being satisfied with their careers if they work in government rather than in private practice, and among alumni of the 1980s and 1990s, those with business careers are also more likely to report satisfaction than those in private practice. This confirms a general sense in the law school world that the conditions of the private practice of law today have led to considerable dissatisfaction at both the associate and partner level. However, it is important to note that even among those in private practice, a substantial majority of respondents indicate satisfaction with their careers. 
Looking within practice sectors at the various dimensions of satisfaction we inquired about, we see from tables $22 \mathrm{~A}, \mathrm{~B}$, and $\mathrm{C}$ that white and minority graduates present similar satisfaction profiles. Table $22 \mathrm{~A}$ indicates that, in general, those in private practice are most likely to report as satisfying the solving of problems for clients and the intellectual challenge of their work and least likely to report as satisfying the value of their work to society and the balance between their professional and their personal or family life. In only 3 of the 21 comparisons that can be made of minority and white alumni are differences statistically significant. Among 1970s graduates, minority alumni are more likely than white alumni to be satisfied with the social value of their work, and white alumni of the 1990s are more likely than minority alumni to be satisfied with their relationships with coworkers and with their incomes. The last of these differences is surprising because, as we shall see, 1990s minority alumni who are in private practice have slightly higher earnings than their white counterparts. This difference could reflect disposable income differences stemming from differences in the average debt loads of minority and white students. Also, perhaps some minority graduates may suspect they are getting paid less than their white counterparts, even when they are not.

Table $22 \mathrm{~B}$ reports on those in government. We find that both whites and minorities in government are far more satisfied with the social value of their work and the balance of their work and professional lives than those in private practice (table 22A). Among the white graduates of the 1980s and all graduates of the 1990s, however, those in government are much less satisfied with their incomes than those in private practice. Looking within table 22B at the satisfaction of whites and minorities reveals few significant differences on the components of career satisfaction. White graduates from the 1980s with careers in government are much less satisfied with their incomes than similarly situated minority graduates, and white alumni from the 1990 s are more satisfied than minority alumni with the social value of their work and coworker relations, although minority satisfaction levels on these dimensions are high.

Table 22C looks at those working as corporate counsel or in other positions in business. Comparing those working in business with those in private practice (table 22A), we see that patterns of satisfaction are similar, except that, apart from minority alumni of the 1970s, both minorities and whites in business are typically much more satisfied than private practitioners with the balance of work and family. Among just those who work in business, white 1970s graduates and perhaps 1990s graduates are more satisfied overall than minority graduates, and in all decades, they seem more satisfied with their relationships with coworkers. As a general matter, 1990s white alumni in the business sector report very high satisfaction, except when asked about the social value of their work, and more satisfaction than 
minorities, but so few Michigan alumni work in business that sizeable differences between whites and minorities are not always statistically significant.

Table 23, which aggregates the satisfaction data across work sectors, is consistent with what we have already seen. Few of the differences between whites and minorities are significant (minority graduates of the 1970s and 1980 s are more likely to report satisfaction with the social value of their work than white graduates, and white graduates of the 1990s are more likely to report satisfaction with coworkers than minorities).

To summarize, we see from these data that to the extent that career success or achievement is measured by the likelihood a person is satisfied with his or her overall career and with important aspects of it, Michigan's minority alumni are, for the most part, successful in their careers and, on average, as successful as Michigan's white alumni. The differences in the overall satisfaction levels reported by minority and white alumni never approach statistical significance.

\section{Earned Income}

Turning from career satisfaction to income from employment, we see that Michigan's minority alumni do very well. Table 24 presents mean and median incomes of minority and white alumni. The mean job income earned in 1996 by Michigan's minority alumni by cohorts is $\$ 141,419$ for the 1970-79 cohort, $\$ 104,513$ for the $1980-89$ cohort and $\$ 67,865$ for the 1990-96 cohort. Median income levels for the same three cohorts are $\$ 101,500, \$ 85,000$ and $\$ 65,000$ respectively. To put these figures in perspective, the median job income of Michigan's minority alumni who graduated between 1970 and 1979 places them in the top $8 \%$ of total household incomes in the United States without regard to other household income; graduates of the 1980s are in the top 13\% of U.S. household incomes, and graduates of the 1990s, who are at the start of their careers, are already in the top 22\% (U.S. Bureau of the Census 1997). If we add spouse's income and nonjob sources of income to respondent's job income (data not presented), minority graduates from our three cohorts had, by decades, median household incomes in 1996 in the top $3 \%, 7 \%$ and $14 \%$ of all U.S. household incomes. When we look separately at the household incomes of those minority alumni in private practice, we see that their median household income is in the top $2 \%$ of the United States income distribution for graduates of both the 1970s and 1980s and, already, in the top $9 \%$ for graduates of the 1990s. But those minority alumni not in private practice are not doing poorly. They have median household incomes that fall into the top $3 \%, 8 \%$, and $22 \%$ of the U.S. income distribution for graduates of the 1970 s, 1980s and 1990s respectively. Mean incomes are higher still, because of the effects of very high incomes. 


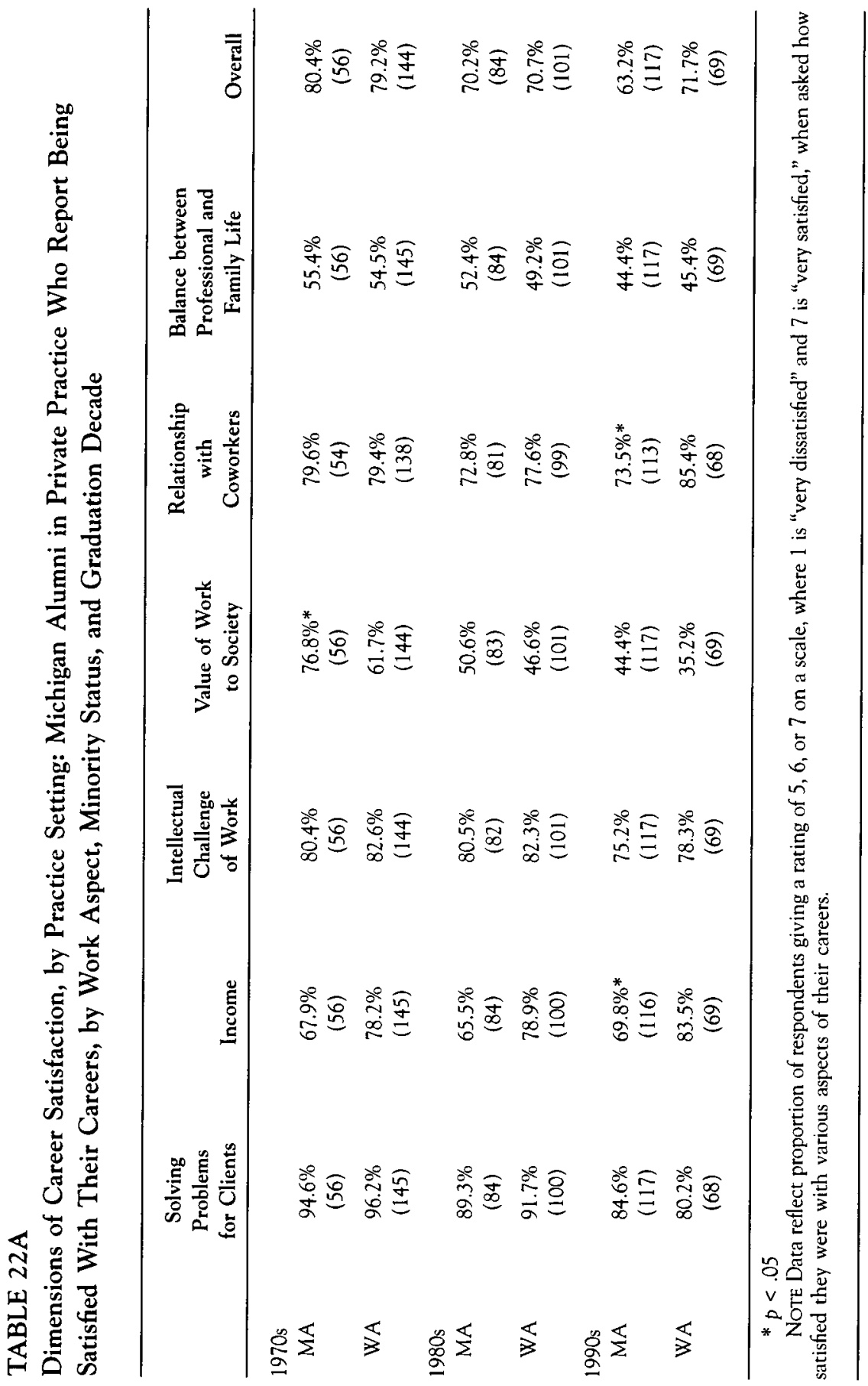




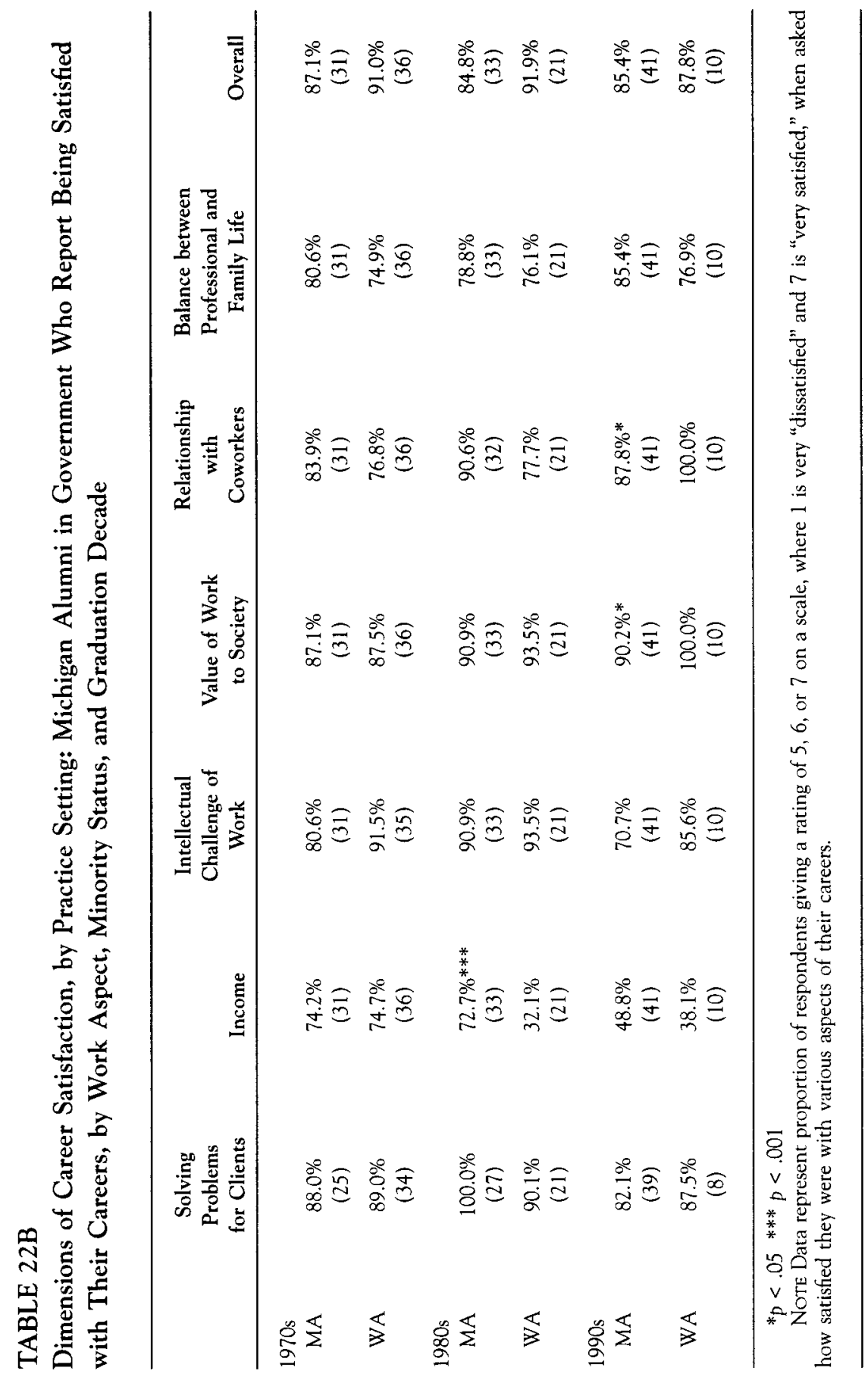




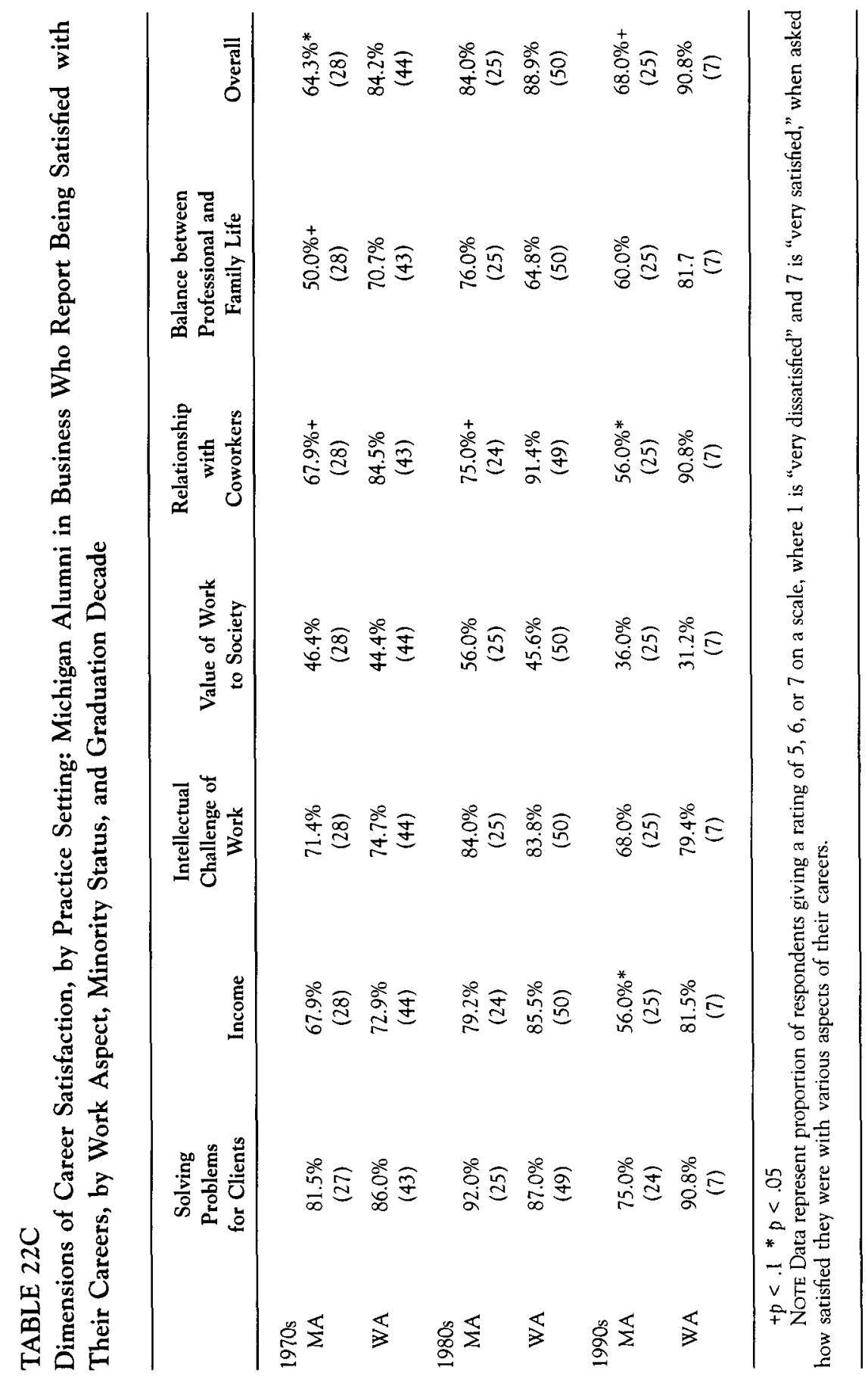




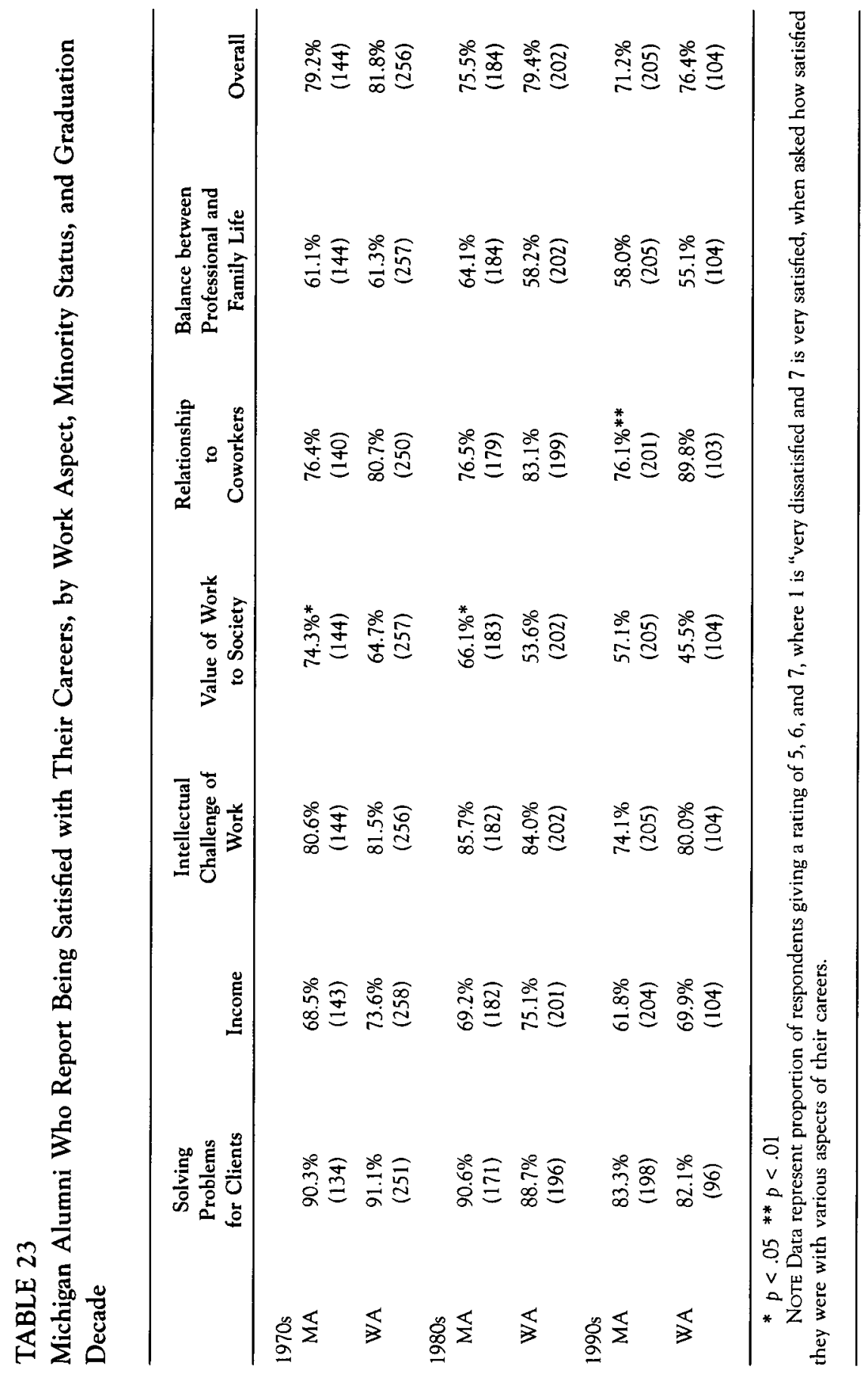




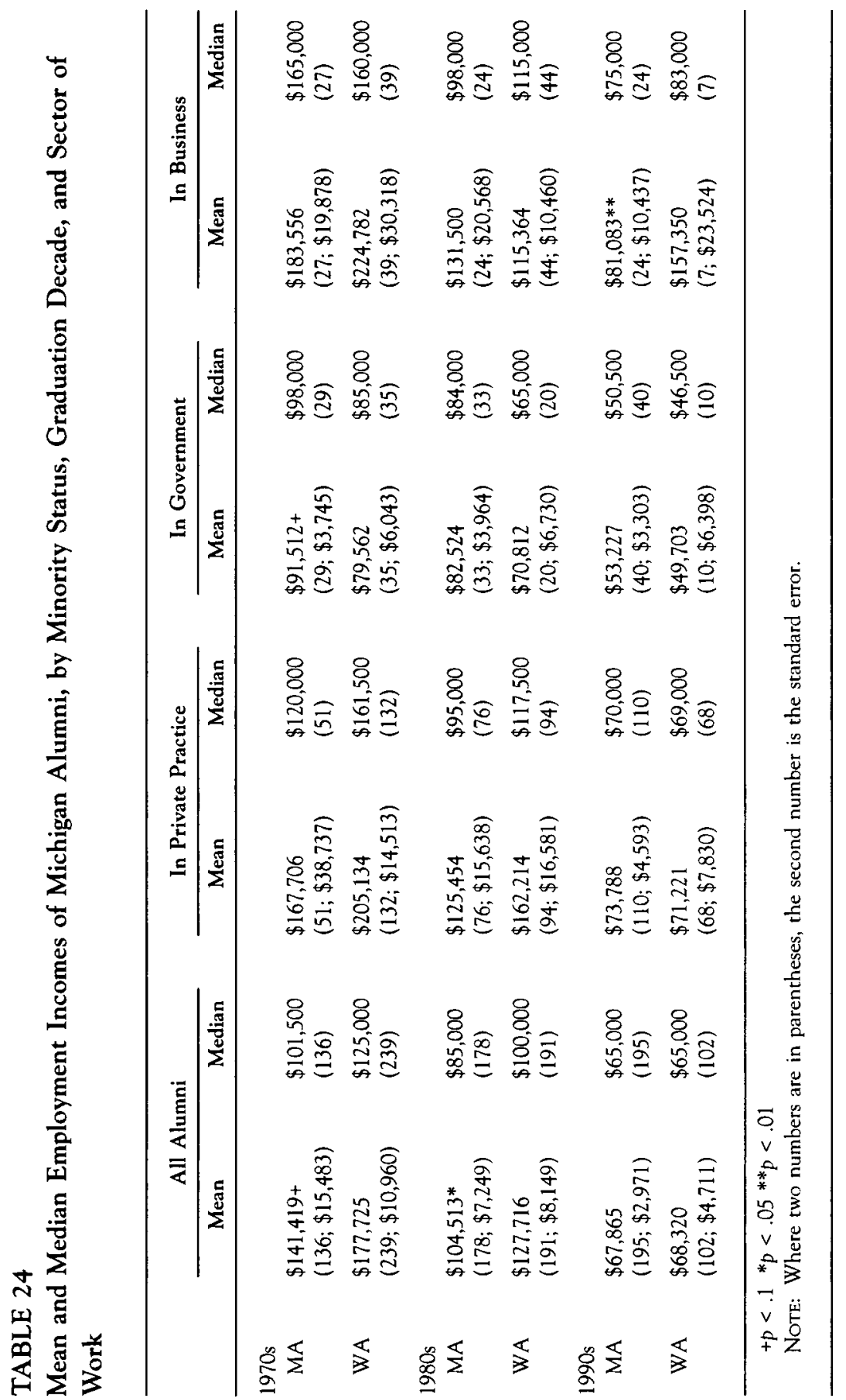


When we look at income by job sector, we see that for both minority and white alumni in all three cohorts, the mean and median job incomes of those in private practice are not consistently higher or lower than the incomes of those in corporate counsel's offices and other business work, and that those in private practice and business have incomes that are always higher, and often substantially higher, than the mean and median incomes of those in government jobs. Among Michigan alumni in private practice, the mean and median incomes of white graduates of the 1970s and 1980s are higher than the mean and median incomes of minority graduates, but the difference in mean income among those who graduated in the 1970s is not statistically significant. For those graduating in the 1990s, the situation changes, and minority alumni have the higher mean income (though the difference is not statistically significant), and by $\$ 1,000$, the higher median income as well. Among government workers, the tendency of minority alumni from the 1970 s to earn more than whites is marginally significant, and among those in business, whites in the 1990s earned significantly more than minorities, but in all other groups there are no significant differences between whites and minorities.

Despite the lack of statistical significance it is tempting to see in the data for private practitioners who graduated in the 1970s and 1980s some evidence that whites are earning more than minorities, for differences in both mean and median incomes favor whites and seem substantial. But it is a mistake to attribute these differences to minority status. Over the period of our study the proportion of minority students in the law school was increasing, and in most classes the group of minority students has contained proportionately more women than the group of white students. When the minority status of those in private practice is entered into an equation that regresses logged income on years since graduation and gender, the minority status coefficient is not statistically significant and, adjusting for degrees of freedom, it adds nothing to the explained variance.

The overarching point is that, to the extent earnings are a mark of success, Michigan's minority alumni are doing well, both absolutely and in comparison to white alumni. What stands out from the tables is not the differences between minorities and whites but the similarities.

\section{Unremunerated Service}

As a final measure of career quality, we look at what are ordinarily unremunerated contributions to the well-being of others. These include such activities as mentoring younger attorneys, serving on the boards of public and private nonprofit organizations, exercising community leadership through political involvement, and providing legal services on a pro bono basis. Tables 25-27 report the relevant data. From these tables it appears 


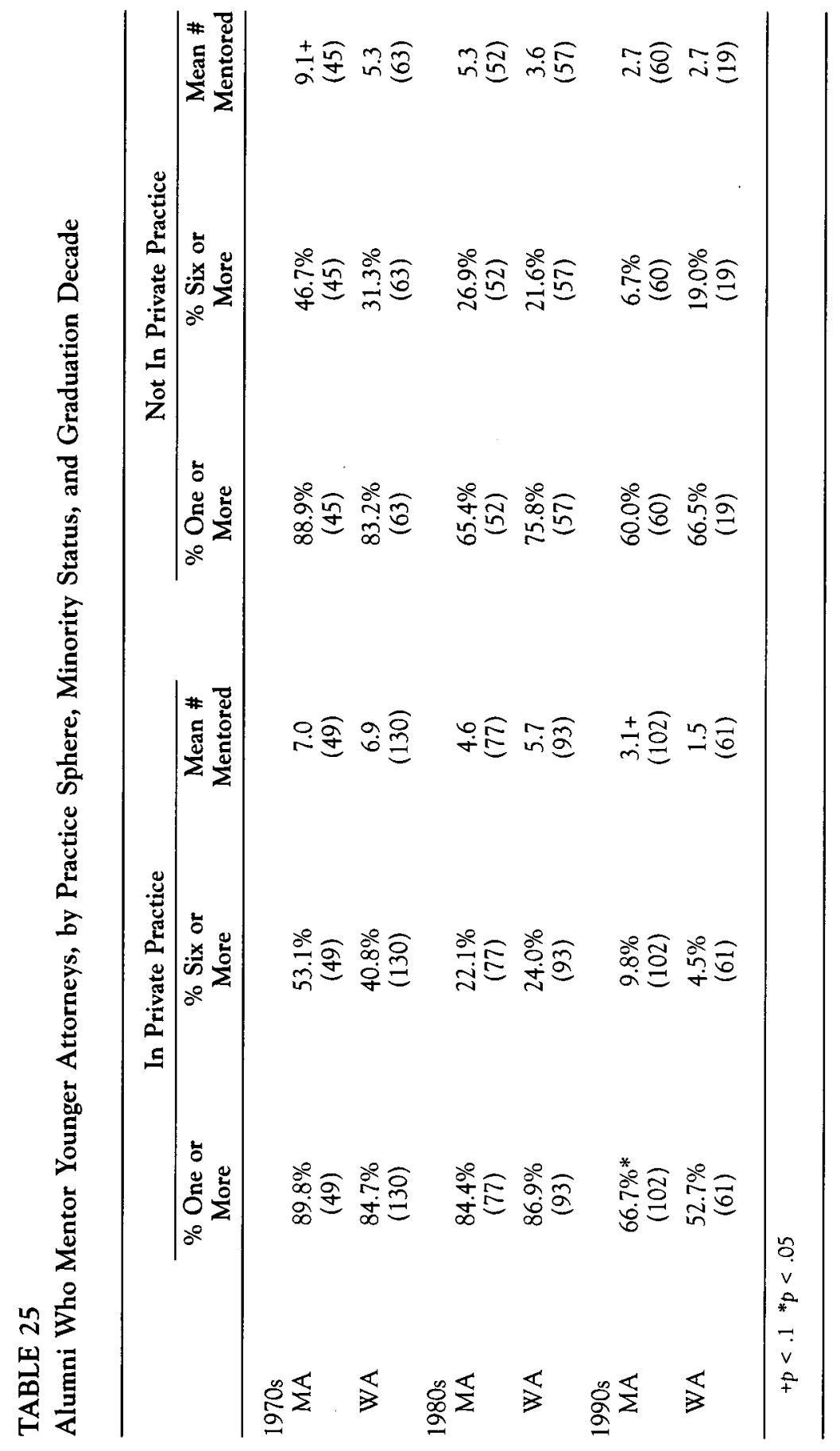


that Michigan's alumni, both white and minority, contribute substantially to the well-being of others, but minority alumni, particularly those who graduated in the 1970s, tend to make more contributions than whites.

\section{Mentoring Younger Attorneys}

We asked on our questionnaire, "For how many younger lawyers have you been an important mentor?" About 9 out of 10 minority graduates from the 1970s who are in private practice report mentoring other attorneys, as do about seven-eighths of the 1980 s minority graduates and two-thirds of the 1990s minority alumni (table 25). More than half the minority alumni of the 1970s, almost one-quarter of the alumni from the 1980s, and about $10 \%$ of the minority alumni from the 1990 s report mentoring six or more fellow attorneys. Mentoring by alumni who practice law but are not in private practice is close to the same level. White attorneys, on average, do somewhat less mentoring of younger attorneys than minority attorneys, but the difference between the mean number of attorneys that minorities and whites mentor is never significant and marginally significant only for private practitioners who graduated in the 1990s, and for graduates of the 1970 s who are not in private practice.

We did not ask about the ethnicity of the mentored attorneys. Thus we cannot tell whether there are attorneys who because of their ethnicity might lack mentors if our respondents were not in practice. It is highly probable that Michigan's minority alumni as a group mentor proportionately more younger minority attorneys than the school's white alumni as a group. This is because we know that, among attorneys practicing in small firms, Michigan's minority alumni are more likely than its white alumni to work in settings where a high proportion of the other attorneys have minority backgrounds, which means they are more likely to encounter younger minority attorneys in need of mentoring (table 16B).

\section{Community Leadership}

Minority graduates also do a large amount of unremunerated public service. Table 26 presents data on nonprofit board membership and political involvement. Among minority alumni, $60 \%$ of the alumni from the 1970 s, $48 \%$ from the 1980 s, and $29 \%$ from the 1990 s serve on the board of at least one civil rights, charitable, religious, or other nonprofit organization. ${ }^{44}$ In the first two cohorts, significantly more minority alumni than white alumni

44. Among the graduates of the $1990 \mathrm{~s}$, but not of the earlier decades, black graduates were somewhat more likely to serve on nonprofit boards than Latino graduates: $33.9 \%$ of the black graduates and $20.2 \%$ of the Latino graduates of the 1990 s served on a nonprofit board ( $p$ $<.05$ ). 
sit on such boards. And about half the minority alumni who serve on one board serve on two or more boards. For both white and minority alumni, nonprofit board membership is most prevalent among those in private practice, but it is also common among those in other sectors.

In a similar manner, as table 26 reveals, Michigan's minority alumni also exercise community leadership through political activity. About $40 \%$ of the minority alumni from the 1970s and a quarter of the minority alumni from the more recent two decades participate in electoral politics or in nonelectoral, issue-oriented politics. Here again, in each decade, minority graduates participate more frequently than whites, but only for the graduates of the 1970 s is the difference statistically significant.

\section{Pro Bono Work}

Michigan's minority alumni do what seems to be an extraordinary amount of pro bono legal work, much more than that reported in other studies of American practitioners in general. ${ }^{45} \mathrm{We}$ asked our respondents how many hours they spent representing individual or organizational clients on a pro bono basis (counting explicit initial agreements only-not post hoc decisions to forgo collection of a previously agreed-upon fee) and how much time they spent doing other law-related work on a pro bono basis (such as serving on a legal services board or bar committee). Table 27 reports these data. As a group, the minority alumni in private practice averaged 75 hours of pro bono representational work and 46 hours of other pro bono work a year. The minority graduates of the 1980s and 1990s average, all told, about 100 hours of pro bono work per year, while minority graduates of the 1970s average 137 hours per year, or about three full weeks of legal work. Minority alumni who practice law in settings other than private practice also engage in pro bono legal work, but they do not devote as much time to pro bono work as their private-practice minority counterparts.

Michigan's white graduates are also very active, contributing an average of 51 hours of representational work and 47 hours of other work per year. Whites in private practice who graduated in the 1970 s or 1990 s devote less time to pro bono work than their minority counterparts, with the difference being statistically significant among graduates of the 1990 s and marginally significant among graduates of the 1970s. Among private practitioner who graduated in the 1980 s, however, it is whites who average more hours of pro bono service, although the difference is not significant. Except among white graduates of the 1990s, minorities and whites in pri-

45. "Recent estimates suggest that most attorneys do not perform significant pro bono work, and that only between ten and twenty percent of those who do are assisting low-income clients. The average for the profession as a whole is less than a half an hour per week" (Rhode 1999). 
vate practice report performing more pro bono work, and often substantially more, than those not in private practice. As one might expect, the difference is particularly marked with respect to legal representation (data not in table). Among those alumni not in private practice, minority graduates of the 1970s and 1980s devote, on average, significantly more time to pro bono work than white graduates. White graduates of the 1990s average substantially more pro bono hours than their minority counterparts, but a high standard error means the difference is not statistically significant.

\section{Summary of Unremunerated Service}

Both absolutely, and in comparison with white alumni, Michigan's minority alumni seem to enjoy remarkable professional success to the extent that success is indicated by "giving back" to the community. The 1970-79 cohort seems particularly noteworthy in this respect. This group of alumni were the pioneers of affirmative action admissions and more likely than later groups to enter a world of law practice in which they encountered significant discrimination (for example, at the start of the decade, many jobs in law firms in the South were closed to them). Today, they report substantially more pro bono involvement, mentoring of other attorneys, and community leadership than the minority alumni of succeeding decades, and the gap between this alumni group and its white counterpart is greater than the gaps in the two succeeding decades. Some of the greater participation may be due to the fact that these attorneys are further advanced in their careers, but it also seems to reflect a genuine cohort effect. On every measure we examine, minority graduates of the 1970s do more than minority graduates of succeeding decades, but white attorneys of the 1970s, who have the same age and experience advantages, do not consistently exceed the activity levels of white graduates of later decades.

In its admissions policy, Michigan Law School states that in choosing which students to admit, whether white or minority, it seeks those students "who have a strong likelihood of succeeding in the practice of law and contributing in diverse ways to the well-being of others." It desires to have alumni, white and minority, "who are esteemed legal practitioners, leaders of the American bar, significant contributors to legal scholarship and/or selfless contributors to the public interest." We see in the data we have presented on career choices and career success that students admitted under Michigan Law School's affirmative action admissions program meet the school's aspirations for all its applicants. 
TABLE 26

Community Involvement, by Minority Status and Graduation Decade

\begin{tabular}{rcc}
\hline & $\begin{array}{c}\text { Serves on At Least } \\
\text { One Nonprofit Board }\end{array}$ & $\begin{array}{c}\text { \% Involved in Electoral or } \\
\text { Nonelectoral Issue Politics }\end{array}$ \\
\hline 1970 s & $60.3 \% *$ & $40.4 * * *$ \\
MA & $(146)$ & $(146)$ \\
WA & $48.3 \%$ & $22.9 \%$ \\
& $(265)$ & $(266)$ \\
$1980 s$ & $47.6 \% *$ & $24.1 \%$ \\
MA & $(187)$ & $(191)$ \\
WA & $34.4 \%$ & $17.1 \%$ \\
& $(207)$ & $(209)$ \\
$1990 s$ & $29.1 \%$ & $24.5 \%$ \\
MA & $(206)$ & $(208)$ \\
& $19.2 \%$ & $20.8 \%$ \\
WA & $(103)$ & $(104)$ \\
\hline${ }^{2}<.05 * * * p<.001$ & & \\
\hline
\end{tabular}

TABLE 27

Average Hours Per Year of Pro Bono Legal Work, by Practice Sphere, Minority Status, and Graduation Decade

\begin{tabular}{|c|c|c|}
\hline & \multicolumn{2}{|c|}{ Pro Bono Hours Per Year } \\
\hline & In Private Practice & Not in Private Practice \\
\hline \multicolumn{3}{|l|}{ 1970s } \\
\hline MA & $\begin{array}{l}137+ \\
(48)\end{array}$ & $\begin{array}{l}94 * * * \\
(39)\end{array}$ \\
\hline WA & $\begin{array}{c}92 \\
(113)\end{array}$ & $\begin{array}{c}15 \\
(50)\end{array}$ \\
\hline \multicolumn{3}{|l|}{$1980 \mathrm{~s}$} \\
\hline MA & $\begin{array}{c}105 \\
(74)\end{array}$ & $\begin{array}{l}61^{*} \\
(48)\end{array}$ \\
\hline WA & $\begin{array}{l}126 \\
(76)\end{array}$ & $\begin{array}{c}17 \\
(52)\end{array}$ \\
\hline \multicolumn{3}{|l|}{$1990 \mathrm{~s}$} \\
\hline MA & $\begin{array}{c}98^{*} \\
(101)\end{array}$ & $\begin{array}{c}19 \\
(51)\end{array}$ \\
\hline WA & $\begin{array}{c}57 \\
(54)\end{array}$ & $\begin{array}{c}92 \\
(13)\end{array}$ \\
\hline
\end{tabular}




\section{PREDICTING PERFORMANCE}

\section{The LSAT and Undergraduate Grades}

In this section we turn to the significance of the Law School Admissions Test (LSAT) and undergraduate grade-point averages (UGPA) as indicators of future performance. We examine the relationship between these two measures and grades during law school and the relationship between these measures and achievement after law school. We also look at what the likely consequences would have been if admissions at Michigan had been based entirely on the LSAT and UGPA. What we find is a strong, statistically significant relationship between LSAT and UGPA, on the one hand, and grades at the end of three years of law school on the other. But we find no significant relationship between the LSAT or UGPA and what matters more-the achievement of students after graduation. Drawing on work done in connection with the affirmative action lawsuit against the University of Michigan Law School, we can also say that had the LSAT and the UGPA been the only criteria for admissions at Michigan, few of Michigan's minority graduates would have been admitted to the school, even though their career success since law school is similar to the career success of Michigan's white graduates and consistent with the aspirations Michigan has for all students it admits.

The University of Michigan Law School is a highly selective law school. It receives far more applications for admission than it has places to fill. In deciding who will succeed in the competition for admission, Michigan, like other highly selective law schools, considers such difficult-toquantify, or soft, indicators of ability as applicant essays and letters of recommendation, but it also pays attention to two so-called objective, or hard, indicators of ability: LSAT scores and undergraduate grade-point averages. Critics of minority admissions programs typically point to disparities in these hard indicators and not to disparities in softer indicators of ability, to justify claims that minority admissions programs admit people who are less competent academically, less able to benefit from their education, and less likely to succeed after school than many rejected white applicants.

A response sometimes made to the critics' claims is that the validity of LSAT scores and the UGPA as law school selection devices is typically determined only with respect to first-year law school grades. Studies done for law schools by the Law School Admissions Council (LSAC), the agency that administers the LSAT, indicate that across a wide range of law schools an index that combines LSAT scores and UGPA is a statistically significant predictor of the grades that first-year law students receive. The relationship between LSAT, UGPA, or an index that combines them, and graded performance over the full three years of law school is not routinely studied by the LSAC and has seldom been examined. In the few studies that have 
been done, however, the correlation between LSAT scores and cumulative GPA suggests that LSAT scores are significant predictors of final LSGPAs, although the studies differ on whether correlations are stronger than (Winterbottom, Pitcher, and Miller 1976), weaker than (Lin and Humphreys 1977), or about the same (Carlson and Werts 1976) as they are when first-year LSGPA is the criterion. A recent, more elaborate study by Linda Wightman involving students from 142 law schools confirms earlier work and suggests that LSAT and UGPA, alone or in combination, relate to final LSGPAs in much the same way as they relate to first-year LSGPAs (Wightman 1999). Thus, arguments for giving LSAT scores and UGPAs a privileged status in law school admissions are not defeated by LSAC's practice of ordinarily validating these measures only by reference to first-year law school grades. It seems safe to conclude from Wightman's findings, and from the consistency of her results with more limited earlier research, that LSAT scores and an index based on LSAT scores and UGPAs are significantly correlated with both first-year and final law school grade-point averages. But two reasons to be concerned about overweighting LSAT scores and UGPA in the law school admission process remain. The first is that whether the validating criterion is first or final LSGPA, a substantial portion of the variance in graded law school performance remains unexplained. The second and more important reason is that we know almost nothing about the relationship between these so-called hard admissions credentials and indicators of success or achievements in law practice. In this section, we look at these relationships.

In order to measure the relationship between the LSAT and UGPA and performance during and after law school, we combined each graduate's LSAT and UGPA by separately ranking those in our sample according to their LSAT scores translated to year-specific national percentile ranks and by their UGPAs on a 4.5-point scale. We then added their percentile rankings in our sample on these two dimensions, yielding an index with the potential range, after rounding, of from 0 to 200, where 0 would be scored if a graduate had both the lowest UGPA and the lowest LSAT percentile score in our sample, and 200 would be scored if the same person was highest on both these dimensions. We sometimes shall refer to this measure as the admissions index, although it is not the index that Michigan used to sort applications. ${ }^{46}$ Because this index correlates more highly with final law

46. We could not use the index scores Michigan used because the formula for constructing them and, indeed, the variables used in constructing them, changed over time in ways we could not always identify. The range and metric of LSAT scores has also changed several times since 1970. In our analyses we use national percentile equivalents provided to us by LSAC as our measure of LSAT. These percentiles were noted, along with test scores, on materials LSAC furnished the nation's law schools. Because the volume of test takers has changed over the years, the percentile rankings are not a time invariant measure of aptitude for law studies, but only a measure of how a test taker fared relative to others in a given year. Only if changes in the size of the law applicant pool over time are uncorrelated with the 
school GPA than either of its constituent measures, we use it as our measure of "hard" admissions credentials rather than LSAT scores and UGPAs taken separately. ${ }^{47}$

\section{Measures of Success}

Income is a common, if controversial, measure of career success. In preliminary analyses, we measured income in three ways: as actual income, as the $\log$ of actual income, and as a percentile ranking among national household incomes. Correlations involving the log of income and income as a percentile ranking were close and more likely to be statistically significant than correlations involving actual income. Hence, in the tables that follow we report only correlations involving the log of income. In our figures, we use the percentile ranking measure because it better portrays how Michigan graduates do relative to national norms.

We created additional indexes, which combine measures presented in prior tables, to investigate the relationship between our admissions index and other indicators of success. The career satisfaction index is the total of the satisfaction scores on the variables found in tables $22 \mathrm{~A}, \mathrm{~B}$, and $\mathrm{C}$, with the overall satisfaction score counting double. ${ }^{48}$ The service index gives re-

distribution of talent in the pool are these rankings strictly comparable. But these relative rankings are the best we can do, and they are validated by their high correlation over time with final LSGPA. Moreover, these correlations compare favorably with the correlations Professor Wightman (1999) reports between a combined LSAT/UGPA measure and final LSGPA in her national study. The median correlation between Wightman's combined index and final LSGPA among schools in her Cluster One (the cluster that contains the University of Michigan's peer schools) is .48. The correlations between our admissions index and final LSGPA for the three decade cohorts we have been examining are $.62, .66$, and .62 . The difference between the correlations in our data and the median correlations Wightman reports is not a spurious result of the fact that our correlations are for decade cohorts and Wightman's are for students entering law school in the same year. For our sample, the partial correlation between our index and final LSGPA controlling for years since graduation is .62 . The correlations we report for minority students considered separately are higher than those Wightman reports for black or Latino students, and the correlations we report for white students are comparable to those Wightman reports.

47. When we analyze our data by decade cohorts, our admissions index correlates more strongly than either LSAT scores or UGPAs with final law school GPAs in all cohorts of all respondents, in all cohorts of minority respondents, and in two of the three cohorts of white respondents. (Among white graduates of the 1990s, LSAT alone is a better predictor of final LSGPA than our admissions index.) Looking at the full sample, the index is a trifle better in explaining variance in both final- and first-year LSGPA than a linear combination of LSAT and untransformed UGPA. The fact that these alternative measures are almost identical in their ability to explain law school grades is what one would expect given the way our index is constructed.

48. In order to check on the appropriateness of using this summated scale, we used SPSS to factor analyze responses to our satisfaction questions using a principal components analysis. We used the six specific satisfaction measures in one analysis and these measures plus the general satisfaction measure in a second analysis. Two components were extracted, and as these seemed easily interpretable, we did not use any rotation. The first, which explained $45 \%$ of the variance in the six-measure analysis and $50 \%$ of the variance in the seven-measure 
spondents 1 point for their involvement in each of 8 service areas (electoral politics, nonelectoral issue-oriented politics, PTAs, alumni associations, charitable organizations, religious organizations, bar associations, and other similar involvements), up to 5 points for service on nonprofit boards ( 2 points for service on 1 board and an additional point for each additional board served on up to a maximum of 3 additional points), up to 3 points for mentoring younger attorneys ( 1 point for mentoring $1-4$ attorneys, 2 points for mentoring 5-8 attorneys, and 3 points for mentoring nine or more attorneys) and up to 10 points for pro bono legal activity ( 2 points for 1 to 25 hours of pro bono work and an additional point for each additional 25 -hour increment, up to a maximum of 10 points for 201 hours or more). ${ }^{49}$ Our success indexes were all specified before we began our analysis of the relationship of LSAT, UGPA, and LSGPA to measures of accomplishment.

model, is easily interpretable as an indicator of overall satisfaction. All satisfaction measures have loadings above .45 on this factor, with the overall-success item having a loading of .917 when it is included. The correlation between our satisfaction index and these factor scores is .974 for the six-variable model and .994 for the seven-variable case. When we use satisfaction as a dependent variable, the regression coefficients have a more natural interpretation if our index is used as the dependent measure of satisfaction, so we use the index score rather than factor scores in our analyses. The second factor extracted, which explained about $18 \%$ of the variance in the six variable model and $16 \%$ when overall satisfaction is included, is one on which scores for the balance between family and professional life have a high loading (above .6) in a positive direction and income scores have a high negative loading, with no other factor loading above .33 . We interpret this as a "get a life" factor, which we call "separate spheres satisfaction." We believe that those who score high on this measure do better than those who score low in separating their working and nonworking lives and in keeping the former from encroaching on the latter. When we regress respondents' factor scores on this secondary dimension of satisfaction on the variables we shall shortly use in an attempt to explain satisfaction, we find that we can explain considerably more variance than we can when our satisfaction index or primary-factor scores are dependent. This is in part because there is a far stronger relationship between practice sector and separate spheres satisfaction than between job sector and overall satisfaction. Graduates working in all sectors other than private practice score significantly higher in separate spheres satisfaction than graduates in private practice jobs. Also law school grades, which are not significantly related to overall satisfaction, are significantly related to separate spheres satisfaction. Those with higher grades in law school are, controlling for practice sector, less satisfied than those who had lower grades in law school $(p<.001)$ It appears that those who make themselves unhappy because they cannot let up in the race for good grades while in law school also cannot let up when the goals are such accepted markers of career success as income or being regarded by others as an essential employee. Those who score lowest on the sphere-separation variable are likely to be Michigan's "Type A" alumni and, it appears, they are also more likely to have gotten As while in law school.

49. This scale is admittedly arbitrary; it is our sense of appropriate relative weights with caps so that no sector is excessively influential. Factor scores are not a good alternative here because we are not seeking to identify people with different underlying propensities to do service but instead want to measure the time and effort actually put into service activities by our respondents. Because minorities generally have higher scores than whites on each of the individual components of this index, we do not believe that the scoring and relative weighting of these factors (imposed by the caps) meaningfully affect the degree of ethnic differences in the overall index. In constructing this index, we did not explore other possible scoring arrangements or caps. Bivariate data suggest that if we removed the caps, minority graduates would appear to be doing more service relative to white graduates than the index indicates. 


\section{TABLE 28A}

\section{Correlations between Achievement Predictors and Measures of Achievement for 1970-79 Alumni Respondents}

\begin{tabular}{|c|c|c|c|c|c|c|}
\hline & $\begin{array}{c}\text { LSAT } \\
\text { Percentile }\end{array}$ & $\begin{array}{c}\text { Undergrad } \\
\text { GPA } \\
\text { Percentile }\end{array}$ & $\begin{array}{l}\text { UMLS Final } \\
\text { GPA }\end{array}$ & $\begin{array}{l}\text { Log of } \\
\text { Income }\end{array}$ & $\begin{array}{c}\text { Career } \\
\text { Satisfaction } \\
\text { Index }\end{array}$ & $\begin{array}{c}\text { Service } \\
\text { Index }\end{array}$ \\
\hline \multicolumn{7}{|l|}{ Admissions index } \\
\hline Pearson correlation. & 823 & 815 & 623 & .043 & .036 & -.186 \\
\hline Sig. level (2-tailed) & .000 & 600 & 100 & .413 & .489 & .000 \\
\hline$N$ & 469 & 409 & 409 & 365 & 365 & 409 \\
\hline \multicolumn{7}{|l|}{ LSAT percentile } \\
\hline Pearson correlation & & 342 & 533 & .081 & .017 & -.184 \\
\hline Sig. level (2-tailed) & & 000 & 000 & .122 & .749 & .000 \\
\hline$N$ & & 409 & 409 & 365 & 365 & 409 \\
\hline \multicolumn{7}{|c|}{$\begin{array}{l}\text { Undergrad GPA percentile } \\
\text { rank }\end{array}$} \\
\hline Pearson correlation & & & 487 & -.011 & .043 & -.120 \\
\hline Sig. level (2-tailed) & & & 000 & .830 & .414 & .015 \\
\hline$N$ & & & $40 \%$. & 365 & 365 & 409 \\
\hline \multicolumn{7}{|l|}{ UMLS Bnal GPA } \\
\hline Pearson correlation & & & & .223 & .032 & -.146 \\
\hline Sig. level (2-tailed) & & & & .000 & .538 & .003 \\
\hline$N$ & & & & 365 & 365 & 409 \\
\hline \multicolumn{7}{|l|}{ Log of income } \\
\hline Pearson correlation & & & & & .272 & .105 \\
\hline Sig. level (2-tailed) & & & & & .000 & .045 \\
\hline$N$ & & & & & 332 & 368 \\
\hline \multicolumn{7}{|c|}{ Career Satisfaction Index } \\
\hline Pearson correlation & & & & & & .124 \\
\hline Sig. level (2-tailed) & & & & & & .018 \\
\hline$N$ & & & & & & 368 \\
\hline
\end{tabular}

Note Cases are unweighted.

\section{Predicting Law School Grades}

The shaded parts of tables $28 \mathrm{~A}-\mathrm{C}$ present the correlations between our admissions index, LSAT percentile scores, UGPA percentile rankings within our sample, and LSGPA by graduation decade for all our respondents regardless of ethnicity. ${ }^{50}$ When we look at tables $28 \mathrm{~A}-\mathrm{C}$, we see that the

50. The data in tables $28 \mathrm{~A}-\mathrm{C}$ are unweighted. Our weights are designed to reproduce within the group of white respondents the likely pattern of responses had we not oversampled, relative to other whites, whites with low grade point averages. Since all white students were sampled with sampling fractions substantially less than " 1 ," we would have had to use different weights to reproduce the likely patterns among Michigan's alumni taken as a whole, and this pattern, particularly in the earlier decades, would dominate the correlations because the school has had so many more white alumni than minority alumni. Although we have LSAT, UGPA, and LSGPA data for sample nonrespondents, we present the data just for those alumni who responded to our survey to keep the sample consistent across all correlations presented in tables 28-30. Response bias is not a problem here. The correlations between our admissions index and the final LSGPA are in the 1970-79 cohort, .63 for respondents and .62 
TABLE 28B

\section{Correlations Between Achievement Predictors and Measures of Achievement for 1980-89 Alumni Respondents}

\begin{tabular}{|c|c|c|c|c|c|c|}
\hline & $\begin{array}{c}\text { LSAT } \\
\text { Percentile }\end{array}$ & $\begin{array}{c}\text { Undergrad } \\
\text { GPA } \\
\text { Percentile }\end{array}$ & $\begin{array}{l}\text { UMLS Final } \\
\text { GP्PA }\end{array}$ & $\begin{array}{l}\text { Log of } \\
\text { Income }\end{array}$ & $\begin{array}{c}\text { Career } \\
\text { Satisfaction } \\
\text { Index }\end{array}$ & $\begin{array}{l}\text { Service } \\
\text { Index }\end{array}$ \\
\hline \multicolumn{7}{|l|}{ Admissions index } \\
\hline Pearson correlation & 846 & 816 & 657 & .081 & -.035 & -.087 \\
\hline Sig. level (2-tailed) & .000 & .00 & 1000 & .117 & .498 & .077 \\
\hline$N$ & 420 & .420 & 420 & 377 & 371 & 417 \\
\hline \multicolumn{7}{|l|}{ LSAT percentile } \\
\hline Pearson correlation & & 382 & 605 & .058 & .046 & -.122 \\
\hline Sig. level (2-tailed) & & 200 & 2000 & .259 & .378 & .012 \\
\hline$N$ & & 420 & 422 & 379 & 373 & 419 \\
\hline \multicolumn{7}{|c|}{$\begin{array}{l}\text { Undergrad GPA percentile } \\
\text { rank }\end{array}$} \\
\hline Pearson correlation & & & 484 & .073 & -.105 & -.016 \\
\hline Sig. level (2-tailed) & & & oot & .159 & .043 & .740 \\
\hline$N$ & & & 420 & 377 & 371 & 417 \\
\hline \multicolumn{7}{|l|}{ UMLS ßnal GPA } \\
\hline Pearson correlation & & & & .202 & -.004 & -.089 \\
\hline Sig. level (2-tailed) & & & & .000 & .942 & .070 \\
\hline$N$ & & & & 379 & 373 & 419 \\
\hline \multicolumn{7}{|l|}{ Log of income } \\
\hline Pearson correlation & & & & & .139 & .126 \\
\hline Sig. level (2-tailed) & & & & & .010 & .014 \\
\hline$N$ & & & & & 343 & 377 \\
\hline \multicolumn{7}{|c|}{ Career Satisfaction Index } \\
\hline Pearson correlation & & & & & & .155 \\
\hline Sig. level (2-tailed) & & & & & & .003 \\
\hline$N$ & & & & & & 373 \\
\hline
\end{tabular}

Note Cases are unweighted.

index we created does a reasonably good job in predicting final law school grade-point averages. The correlation coefficients for the decades we examine are all above .6, and the proportion of the variance in LSGPA explained by the index ranges from $38 \%$ to $43 \%$. We also see from tables $28 \mathrm{~A}-\mathrm{C}$ that LSAT scores are, by themselves, a better predictor of law school grades than UGPAs taken alone; the advantage of the LSAT over UGPA in explaining LSGPA increases over the decades.

The correlations of index scores with law school grades diminish when we look just at the group of minority students, but the correlations are still highly significant and relatively high. Tables $29 \mathrm{~A}-\mathrm{C}$ report these data. The correlations of interest range from .53 to .61 across the three decades, which

for everyone sampled; in the 1980-89 cohort, .66 for respondents and .65 for everyone sampled; and in the 1990-96 cohort, .62 for respondents and .60 for everyone sampled. In all cases the correlations are significant $(p<.001)$. 


\section{TABLE 28C}

\section{Correlations between Achievement Predictors and Measures of Achievement for 1990-96 Alumni Respondents}

\begin{tabular}{|c|c|c|c|c|c|c|}
\hline & $\begin{array}{c}\text { LSAT } \\
\text { Percentile }\end{array}$ & $\begin{array}{c}\text { Undergrad } \\
\text { GPA } \\
\text { Percentile }\end{array}$ & $\begin{array}{l}\text { UMLS Final } \\
\text { GPA }\end{array}$ & $\begin{array}{l}\text { Log of } \\
\text { Income }\end{array}$ & $\begin{array}{c}\text { Career } \\
\text { Satisfaction } \\
\text { Index }\end{array}$ & $\begin{array}{l}\text { Service } \\
\text { Index }\end{array}$ \\
\hline \multicolumn{7}{|l|}{ Admissions index } \\
\hline Pearson correlation & 1830 & 832 & 617 & .002 & .042 & -.221 \\
\hline Sig. level (2-tailed) & 1600 & 000 & 000 & .975 & .452 & .000 \\
\hline$N$ & 356 & 356 & 356 & 327 & 328 & 356 \\
\hline \multicolumn{7}{|l|}{ LSAT percentile } \\
\hline Pearson correlation & & 381 & .584 & .015 & .007 & -.194 \\
\hline Sig. level (2-tailed) & & .010: & 1000 & .790 & .901 & .000 \\
\hline$N$ & & 356 & $35 \%$ & 328 & 329 & 357 \\
\hline \multicolumn{7}{|c|}{$\begin{array}{l}\text { Undergrad GPA percentile } \\
\text { rank }\end{array}$} \\
\hline Pearson correlation & & & 444 & -.015 & .057 & -.173 \\
\hline Sig. level (2-tailed) & & & 1000 & .791 & .301 & .001 \\
\hline$N$ & & & 356. & 327 & 328 & 356 \\
\hline \multicolumn{7}{|l|}{ UMLS (Rnal GPA } \\
\hline Pearson correlation & & & & .139 & -.003 & -.132 \\
\hline Sig. level (2-tailed) & & & & .010 & .961 & .012 \\
\hline$N$ & & & & 339 & 339 & 368 \\
\hline \multicolumn{7}{|l|}{ Log of income } \\
\hline Pearson correlation & & & & & -.040 & .066 \\
\hline Sig. level (2-tailed) & & & & & .473 & .220 \\
\hline$N$ & & & & & 318 & 342 \\
\hline \multicolumn{7}{|c|}{ Career Satisfaction Index } \\
\hline Pearson correlation & & & & & & -.007 \\
\hline Sig. level (2-tailed) & & & & & & .894 \\
\hline$N$ & & & & & & 342 \\
\hline
\end{tabular}

NOTE Cases are unweighted.

means that among minority students, between about $28 \%$ and $37 \%$ of the variance in law school grades can be explained by our index's combination of the so-called objective admissions credentials. By themselves, LSAT scores and UGPAs do about equally well in explaining law school grades, but neither measure alone does nearly as well as their combination.

When we look only at white students, as tables $30 \mathrm{~A}-\mathrm{C}$ do, the picture changes, as the index's value in predicting law school grades diminishes dramatically. The correlations between LSGPA and index scores range from .22 to .35 , which means that in no decade does our index explain more than $12.3 \%$ of the variance in law school grades. LSAT scores and UGPA taken individually relate not too differently to explained variance in the 1970-79 cohort, but the LSAT score is a substantially better predictor in the two subsequent decades. Indeed, for whites in the 1990-96 cohort, UGPA had 
TABLE 29A

Correlations Between Achievement Predictors and Measures of Achievement for 1970-79 Minority Alumni Respondents

\begin{tabular}{|c|c|c|c|c|c|c|}
\hline & $\begin{array}{c}\text { LSAT } \\
\text { Percentile }\end{array}$ & $\begin{array}{c}\text { UGPA } \\
\text { Percentile }\end{array}$ & $\begin{array}{l}\text { UMLS Final } \\
\text { GPA }\end{array}$ & $\begin{array}{l}\text { Log of } \\
\text { Income }\end{array}$ & $\begin{array}{c}\text { Career } \\
\text { Satisfaction } \\
\text { Index }\end{array}$ & $\begin{array}{c}\text { Service } \\
\text { Index }\end{array}$ \\
\hline \multicolumn{7}{|l|}{ Admissions index } \\
\hline Pearson correlation & 303 & .819 & 536 & -.033 & .054 & -.074 \\
\hline Sig. level (2-tailed) & 000 & .000 & .000 & .711 & .546 & .377 \\
\hline$N$ & 143 & 10 & 143 & 130 & 127 & 143 \\
\hline \multicolumn{7}{|l|}{ LSAT percentile } \\
\hline Pearson correlation & & 1.064 & 360 & .038 & -.133 & -.054 \\
\hline Sig. level (2-tailed) & & .317 & 1000 & .672 & .135 & .522 \\
\hline$N$ & & .143 & 143 & 130 & 127 & 143 \\
\hline \multicolumn{7}{|l|}{ UGPA percentile rank } \\
\hline Pearson correlation & & & 379 & -.063 & .150 & -.050 \\
\hline Sig. level (2-tailed) & & & (200. & .473 & .093 & .554 \\
\hline$N$ & & & 143. & 130 & 127 & 143 \\
\hline \multicolumn{7}{|l|}{ UMLS ®nal GPA } \\
\hline Pearson correlation & & & & .207 & .010 & -.099 \\
\hline Sig. level (2-tailed) & & & & .018 & .915 & .239 \\
\hline$N$ & & & & 130 & 127 & 143 \\
\hline \multicolumn{7}{|l|}{ Log of income } \\
\hline Pearson correlation & & & & & .252 & .195 \\
\hline Sig. level (2-tailed) & & & & & .006 & .025 \\
\hline$N$ & & & & & 118 & 132 \\
\hline \multicolumn{7}{|c|}{ Career Satisfaction Index } \\
\hline Pearson correlation & & & & & & 134 \\
\hline Sig. level (2-tailed) & & & & & & .129 \\
\hline$N$ & & & & & & 129 \\
\hline
\end{tabular}

no significant relationship to law school grades, ${ }^{51}$ and the LSAT score alone did a better job of predicting grades than the index. ${ }^{52}$

Reading tables 28-30 together, it appears that an index composed of LSAT scores and UGPA is a moderately good predictor of final law school grade-point averages when incorporated in a linear model. Index scores are less effective in predicting which minority admittees will do well among the group of minority students attending Michigan than they are for all

51. Part of the declining significance of UGPA as a predictor flows from a constriction of range in the more recent decades. In the 1970s, the mean UGPA for whites was 3.41 with a standard deviation of .35. In the 1980s and 1990s, the mean UGPA was 3.57, and the standard deviation was 26.

52. With unweighted data, the relationships in tables 30A-C look somewhat different. Correlations of final LSGPA with index scores are .45, .41, and .29 for the 1970-79, 1980-89, and 1990-96 cohorts respectively. Correlations with LSAT scores are $.29, .33$, and .30 , while correlations with UGPA are $.39, .24$, and .14 across the three decades respectively. All correlations are statistically significant, except the correlations between UGPA and LSGPA for the 1990-96 cohort. 
TABLE 29B

Correlations between Achievement Predictors and Measures of Achievement for 1980-89 Minority Alumni Respondents

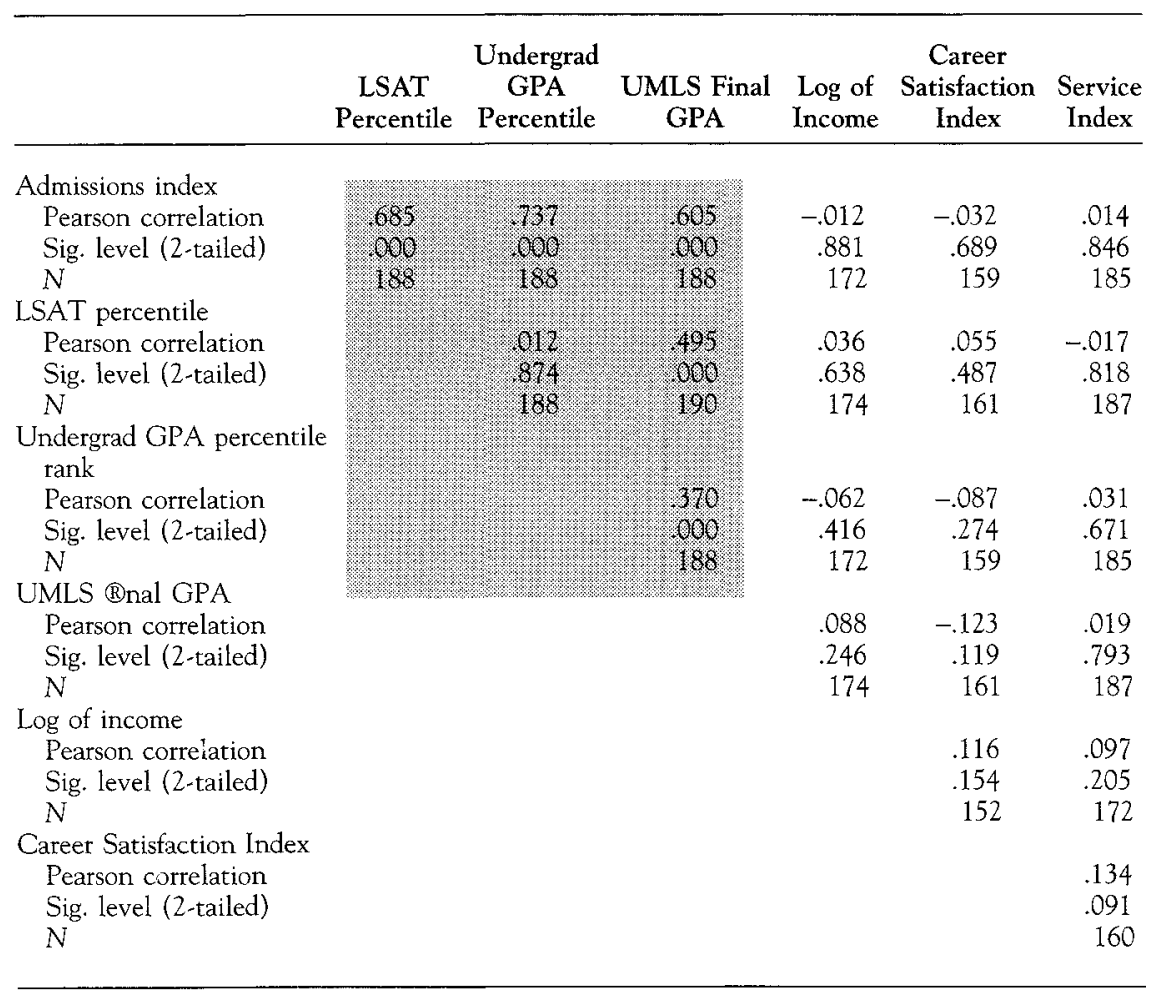

students, but the linear trend still seems pronounced. Among whites, index scores are still significantly correlated with LSGPA, but in each decade, the explained variance is less than half of what it is for minority students. ${ }^{53}$

53. Sometimes the failure of LSAT scores to predict substantial grade variance within law schools is attributed to a lack of substantial variation in test scores within particular schools. This might lead one to suspect that our index does a better job in predicting the grades of minority students than it does the grades of white students because the "hard" credentials of minority students who matriculated at Michigan span a wider range than the credentials of white students. We don't think this is the explanation, for the variance explained by LSAT scores alone, measured as national percentile equivalents, is no less for whites than for minority students even though the scores of whites tend to be confined to a narrower range. What appears to explain the different efficacy of the index in the two samples is that UGPA remains a strong predictor of graded law school performance for minority students across all three cohorts, but in the last two decades it loses much of its ability to predict the grades of white students. 
TABLE 29C

Correlations Between Achievement Predictors and Measures of Achievement for 1990-96 Minority Alumni Respondents

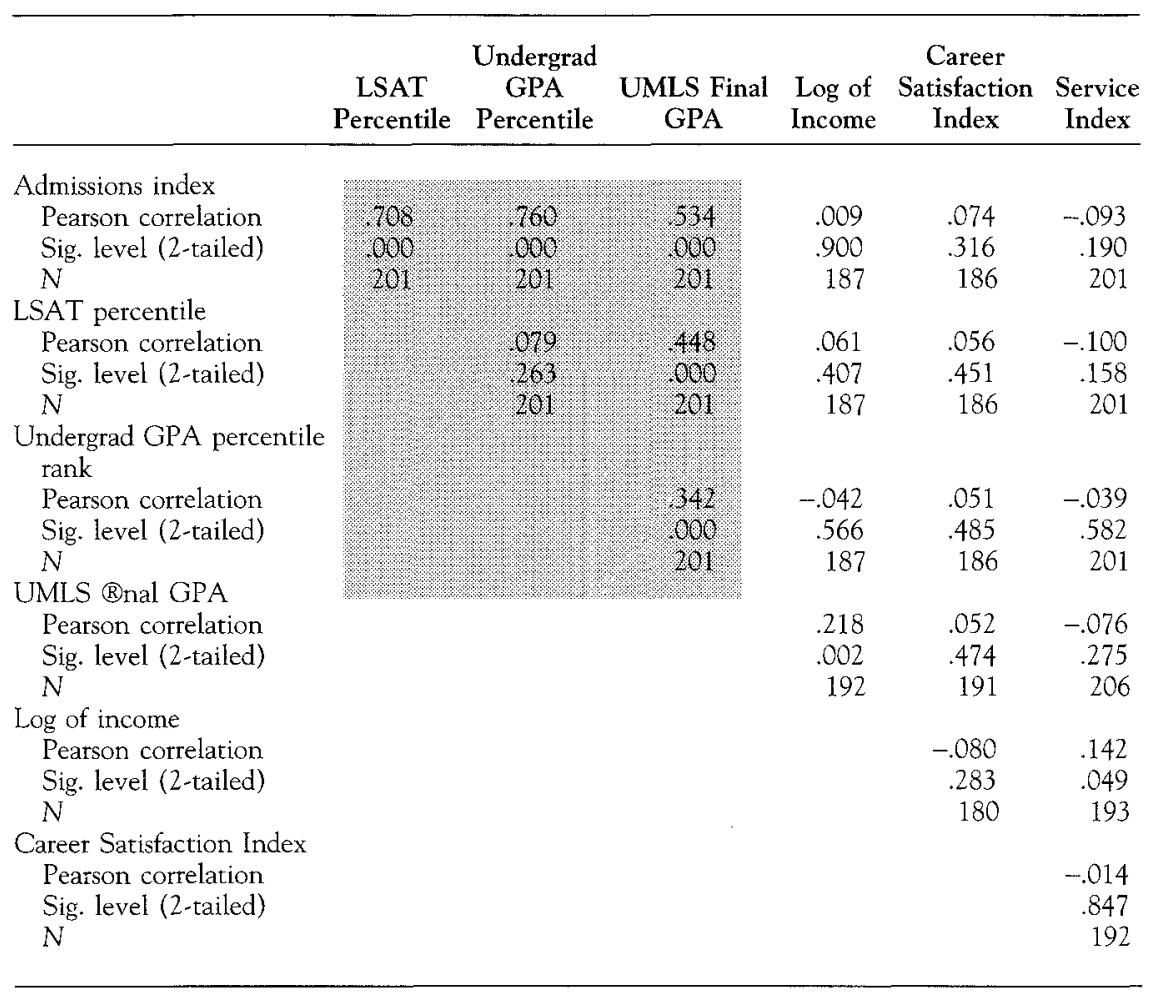

\section{Predicting Practice Success}

Given the linear relationship between the so-called hard law school admissions criteria as summarized in our admissions index and graded law school performance, one might expect that these admissions criteria would relate to success or achievements in practice. Our data, however, show no such a relationship. We see this when we return to tables $28 \mathrm{~A}-\mathrm{C}$, which present data for all alumni. In no decade is there a statistically significant relationship between the admissions index and either the log of income or our index of career satisfaction, although among 1980s graduates, there is a statistically significant negative relationship between UGPA and career satisfaction. In all decades, those with higher index scores tend to make fewer social contributions as measured by our service index (which excludes contributions through primary jobs) than those with lower index scores, and this negative relationship is statistically significant among graduates in the 
TABLE 30A

Correlations between Achievement Predictors and Measures of Achievement for 1970-79 White Alumni Respondents

\begin{tabular}{|c|c|c|c|c|c|c|}
\hline & $\begin{array}{c}\text { LSAT } \\
\text { Percentile }\end{array}$ & $\begin{array}{c}\text { Undergrad } \\
\text { GPA } \\
\text { Percentile }\end{array}$ & $\begin{array}{l}\text { UMLS Final } \\
\text { GPA }\end{array}$ & $\begin{array}{l}\text { Log of } \\
\text { Income }\end{array}$ & $\begin{array}{c}\text { Career } \\
\text { Satisfaction } \\
\text { Index }\end{array}$ & $\begin{array}{l}\text { Service } \\
\text { Index }\end{array}$ \\
\hline \multicolumn{7}{|l|}{ Admissions index } \\
\hline Pearson correlation & 710 & .835 & .324 & -.049 & .059 & -.024 \\
\hline Sig. level (2-tailed) & .000 & 000 & 000 & .475 & .386 & .710 \\
\hline$N$ & 244 & 244 & 24 & 217 & 218 & 244 \\
\hline \multicolumn{7}{|l|}{ LSAT percentile } \\
\hline Pearson cortelation & & .206 & 291. & .015 & .082 & -.042 \\
\hline Sig. level (2-tailed) & & Wol & 000 & .823 & .226 & .513 \\
\hline$N$ & & 2244 & 244 & 217 & 218 & 244 \\
\hline \multicolumn{7}{|c|}{$\begin{array}{l}\text { Undergrad GPA percentile } \\
\text { rank }\end{array}$} \\
\hline Pearson correlation & & & .224 & -.079 & .018 & .000 \\
\hline Sig. level (2-tailed) & & & 000 & .247 & .786 & .995 \\
\hline$N$ & & & 244 & 217 & 218 & 244 \\
\hline \multicolumn{7}{|l|}{ UMLS @nal GPA } \\
\hline Pearson correlation & & & & .244 & .015 & -.074 \\
\hline Sig. level (2-tailed) & & & & .000 & .823 & .253 \\
\hline$N$ & & & & 217 & 218 & 244 \\
\hline \multicolumn{7}{|l|}{ Log of income } \\
\hline Pearson correlation & & & & & .223 & .133 \\
\hline Sig. level (Z-tailed) & & & & & .002 & .050 \\
\hline$N$ & & & & & 197 & 218 \\
\hline \multicolumn{7}{|c|}{ Career Satisfaction Index } \\
\hline Pearson correlation & & & & & & .080 \\
\hline Sig. level (2-tailed) & & & & & & .238 \\
\hline$N$ & & & & & & 220 \\
\hline
\end{tabular}

1970-79 and 1990-96 cohorts. The same pattern holds for LSAT scores and UGPA when these index constituents are separately examined, except the negative relationship between LSAT scores and the service index is also statistically significant among 1980's graduates. However, in no decade does the relationship in the full sample between higher objective admissions credentials and less future service explain more than $4.9 \%$ of the variance. Moreover, when we look separately by cohorts at the minority and white subsamples, significant and marginally significant relationships are confined to the white sample. A possible explanation is that Michigan seeks to recruit students who will adhere to the legal profession's aspirational norms of service and to this end admits applicants who appear committed to serving others despite somewhat lower "hard" admissions criteria. If so, the negative relationship suggests the school has been successful in its efforts.

Figures 1-9 display by graduation decades the relationships between our admissions index and indexes of post-law school achievement. These figures display admissions index scores along the horizontal axis, with scores 
TABLE 30B

Correlations between Achievement Predictors and Measures of Achievement for 1980-89 White Alumni Respondents

\begin{tabular}{|c|c|c|c|c|c|c|}
\hline & $\begin{array}{c}\text { LSAT } \\
\text { Percentile }\end{array}$ & $\begin{array}{c}\text { Undergrad } \\
\text { GPA } \\
\text { Percentile }\end{array}$ & $\begin{array}{l}\text { UMLS Final } \\
\text { GPA }\end{array}$ & $\begin{array}{l}\text { Log of } \\
\text { Income }\end{array}$ & $\begin{array}{c}\text { Career } \\
\text { Satisfaction } \\
\text { Index }\end{array}$ & $\begin{array}{l}\text { Service } \\
\text { Index }\end{array}$ \\
\hline \multicolumn{7}{|l|}{ Admissions index } \\
\hline Pearson correlation & .628 & $.5 \%$ & 346 & .034 & -.004 & -.020 \\
\hline Sig. level (2-tailed) & 600 & 000 & 000 & .633 & .950 & .770 \\
\hline$N$ & 222 & 222 & .222 & 196 & 204 & 222 \\
\hline \multicolumn{7}{|l|}{ LSAT percentile } \\
\hline Pearson correlation & & -034 & 307 & -.084 & .051 & -.114 \\
\hline Sig. level (2-tailed) & & .619 & 000 & .242 & .472 & .089 \\
\hline$N$ & & 222 & 222 & 196 & 204 & 222 \\
\hline \multicolumn{7}{|c|}{$\begin{array}{l}\text { Undergrad GPA percentile } \\
\text { rank }\end{array}$} \\
\hline Pearson correlation & & & 186 & .114 & -.048 & .071 \\
\hline Sig. level (2-tailed) & & & 1005 & .112 & .495 & .294 \\
\hline$N$ & & & 222 & 196 & 204 & 222 \\
\hline \multicolumn{7}{|l|}{ UMLS (Bnal GPA } \\
\hline Pearson correlation & & & & .141 & .044 & -.114 \\
\hline Sig. level (2-tailed) & & & & .049 & .536 & .092 \\
\hline$N$ & & & & 196 & 204 & 222 \\
\hline \multicolumn{7}{|l|}{ Log of income } \\
\hline Pearson correlation & & & & & .104 & .119 \\
\hline Sig. level (2-tailed) & & & & & .161 & .098 \\
\hline$N$ & & & & & 184 & 196 \\
\hline \multicolumn{7}{|l|}{ Career Satisfaction Index } \\
\hline Pearson correlation & & & & & & .153 \\
\hline Sig. level (2-tailed) & & & & & & .029 \\
\hline$N$ & & & & & & 204 \\
\hline
\end{tabular}

increasing with movement toward the right. Dimensions of success are measured along the vertical axis with scores increasing with height. Minority students are indicated by dark triangles and white students by open circles. A "jittering" technique, which adds $2 \%$ random error to each case, is used to minimize completely overlapping cases. In figures $1-3$ income is the success measure, in figures 4-6 self-reported career satisfaction is the criterion and in figures 7-9 service activity is what we examine. The vertical line through each figure indicates the median admissions index score among all respondents. The horizontal line indicates the median score on the measure of accomplishment. In the figures involving income, income is not the log of actual income as it is in the tables but is where each respondent's individual income falls as a percentile of national household income. ${ }^{54}$

54. Using figures for national household income rather than figures for national personal income as a base conveys the income success of our respondents relative to national norms but allows for greater spread on the income graphs than if individual income had been used to locate our respondents' earnings, since the clustering at the high end is greater when individ- 
TABLE 30C

Correlations between Achievement Predictors and Measures of Achievement for 1990-96 White Alumni Respondents

\begin{tabular}{|c|c|c|c|c|c|c|}
\hline & $\begin{array}{c}\text { LSAT } \\
\text { Percentile }\end{array}$ & $\begin{array}{c}\text { Undergrad } \\
\text { GPA } \\
\text { Percentile }\end{array}$ & $\begin{array}{l}\text { UMLS Final } \\
\text { GPA }\end{array}$ & $\begin{array}{l}\text { Log of } \\
\text { Income }\end{array}$ & $\begin{array}{c}\text { Career } \\
\text { Satisfaction } \\
\text { Index }\end{array}$ & $\begin{array}{l}\text { Service } \\
\text { Index }\end{array}$ \\
\hline \multicolumn{7}{|l|}{ Admissions index } \\
\hline Pearson correlation & 527. & .812 & 210 & .028 & -.032 & -.166 \\
\hline Sig. level (2-tailed) & 000 & .006 & $=\sqrt{14} 7$ ? & .773 & .744 & .072 \\
\hline$N$ & 118 & 118 & 118 & 112 & 108 & 118 \\
\hline \multicolumn{7}{|l|}{ LSAT percentile } \\
\hline Pearson correlation & & -1067 & 362 & -.040 & -.072 & .029 \\
\hline Sig. level (2-tailed) & & 469 & .000 & .676 & .455 & .752 \\
\hline$N$ & & 118 & 120 & 114 & 109 & 120 \\
\hline \multicolumn{7}{|c|}{$\begin{array}{l}\text { Undergrad GPA percentile } \\
\text { rank }\end{array}$} \\
\hline Pearson correlation & & & .014 & .057 & .000 & -.211 \\
\hline Sig. level (2-tailed) & & & 877 & .548 & .999 & .021 \\
\hline$N$ & & & 118. & 112 & 108 & 118 \\
\hline \multicolumn{7}{|l|}{ UMLS $\mathbb{B}$ nal GPA } \\
\hline Pearson correlation & & & & .129 & -.060 & .001 \\
\hline Sig. level (2-tailed) & & & & .164 & .529 & .992 \\
\hline$N$ & & & & 118 & 113 & 124 \\
\hline \multicolumn{7}{|l|}{ Log of income } \\
\hline Pearson correlation & & & & & .034 & -.003 \\
\hline Sig. level (2-tailed) & & & & & .728 & .978 \\
\hline$N$ & & & & & 109 & 119 \\
\hline \multicolumn{7}{|c|}{ Career Satisfaction Index } \\
\hline Pearson correlation & & & & & & .047 \\
\hline Sig. level (2-tailed) & & & & & & .620 \\
\hline$N$ & & & & & & 115 \\
\hline
\end{tabular}

In each figure the index scores of white alumni fall, for the most part, substantially to the right of the scores of minority alumni. This pattern reflects the fact that white students who matriculate at Michigan tend to have higher LSAT scores and higher UGPAs than minority matriculants.

But a person's horizontal position has little to do with where that person will be located vertically. This is because among Michigan alumni, a matriculant's LSAT and UGPA have almost no implications for post-law school achievements, as we are able to measure them. Moreover, the vertical positions of minority graduates as a group are not easily distinguished, if they can be distinguished at all, from the vertical positions of white alumni as a group. This is because, as groups, minority and white alumni seem to enjoy almost equal success. 


\section{FIGURE 1}

Relationship between Admissions Index Scores and

Relationship of Personal Income to U.S. Household Income for 1970-79 Minority and White Alumni

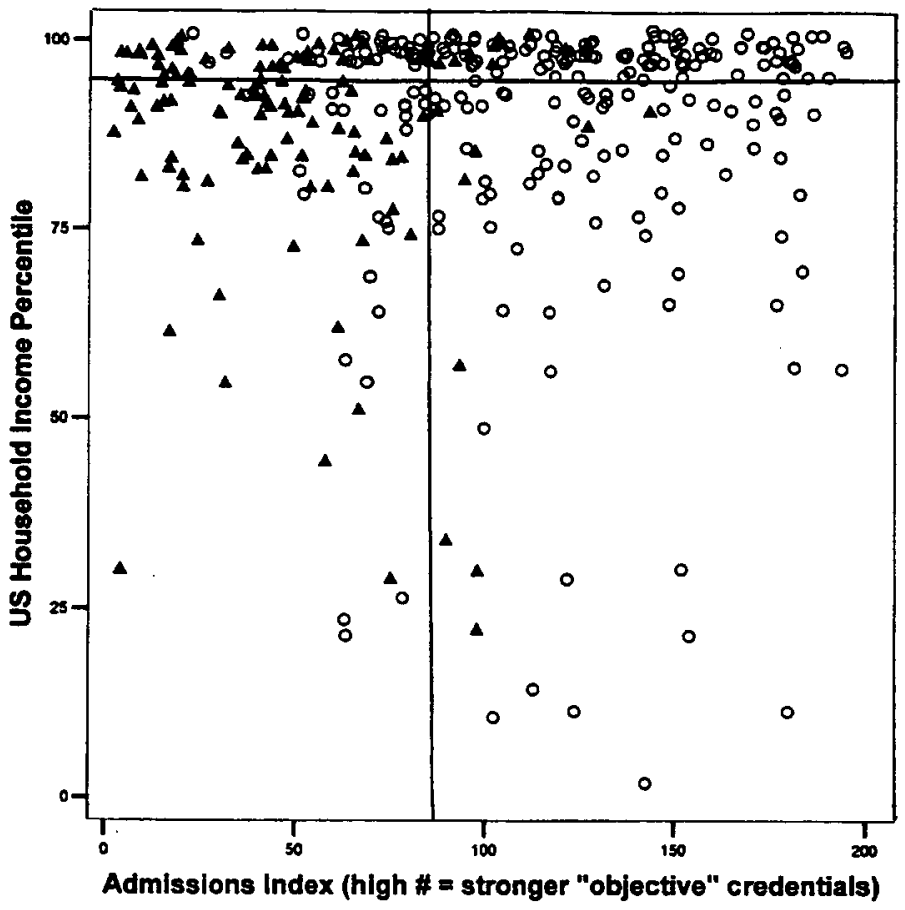

The figures for career satisfaction and service situate Michigan's alumni, both individually and as groups, relative to each other. While one might interpret these figures as indicating that most Michigan alumni are quite satisfied with their careers and engage in considerable service, no external standard defines considerable service or high career satisfaction. In contrast, the figures for income situate Michigan's graduates in relation to national norms. Here we see that Michigan's graduates, both white and minority, are very high earners compared to national norms.

\section{Regressions of Success Measures}

To check the patterns we see in figures $1-9$, we used ordinary least squares (OLS) regression to examine the sequential and simultaneous effects of various possible predictors on our three measures of accomplishment: logged income, the career satisfaction index, and the service index. The purpose of these regressions is not to do the best job we can in explaining post-law school success and accomplishments but rather to examine the implications of ethnicity and other factors known at admission to law 
FIGURE 2

Relationship between Admissions Index Scores and Relationship of Personal Income to U.S. Household Income for 1980-89 Minority and White Alumni
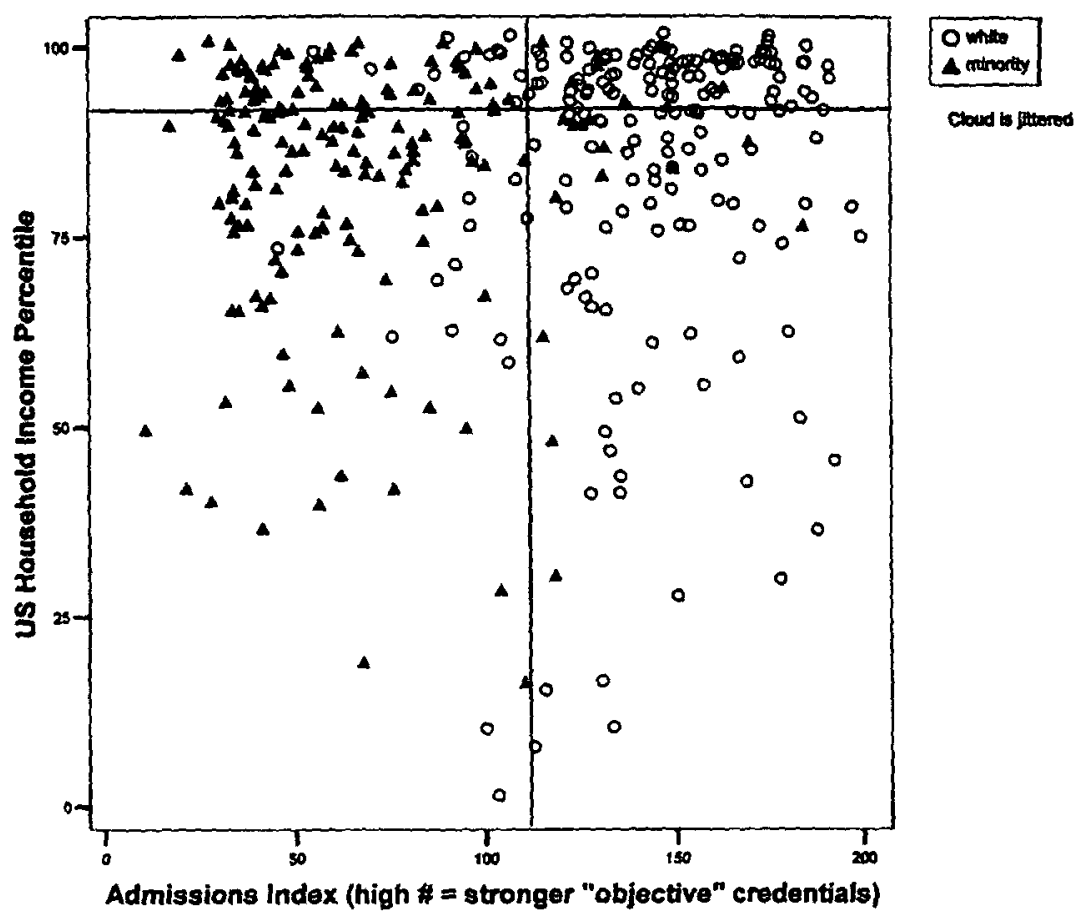

school for later accomplishments. We also wish to check whether the somewhat surprising failure of LSAT and UGPA to correlate with post-law school accomplishments and the lack of association between minority status and accomplishments that we see in tables 28-30 might be due to the suppression of true effects by other respondent characteristics that affect both admissions decisions and later accomplishments. In addition to examining characteristics an admissions officer might have observed, we look at how long a respondent has been out of law school and at two orher variables not known at admissions, final LSGPA and job sector, to see if the implications for achievement of our independent variables, especially minority status, change when these are controlled. Finally, we look not just at minority status but also at respondent ethnicity to see what effect including Asians in the analysis has and to see how members of the different ethnic groups compare to whites when they are looked at separately rather than as an aggregate group of minority alumni. Tables 31,33 , and 35 report the regression coefficients for the variables in our model; tables 32, 34, and 36 indicate the incremental variance explained by different variables or sets of variables entered sequentially. 


\section{FIGURE 3}

Relationship between Admissions Index Scores and

Relationship of Personal Income to U.S. Household Income for 1990-96 Minority and White Alumni
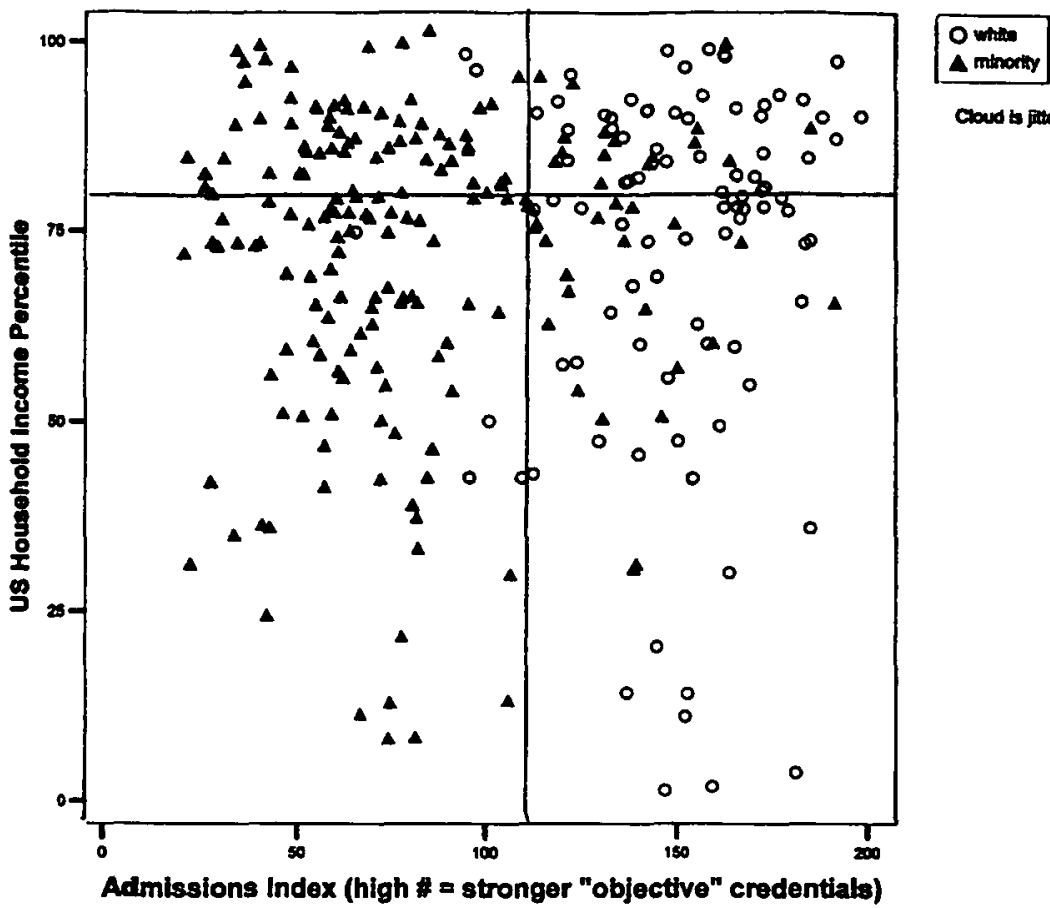

Coud b fillond

We constructed our models by first regressing each measure of achievement on a set of variables taken or constructed from our respondents' admissions files: gender, age at law school entry, ethnicity, a gender/ethnicity interaction term, our LSAT/UGPA admissions index, ${ }^{55}$ undergraduate college, undergraduate major, and whether the respondent had a nonlaw masters degree or doctorate as well as the additional control variables of time (in years) since graduation, time (in years) since graduation squared, marital status, final LSGPA, and job sector. We would like to have included several other variables but could not because of missing data. Beyond checking for missing data, we did no further exploratory model building. Undergraduate

55. We also ran all our regressions entering as a block respondents' LSAT scores and UGPA percentile rankings rather than the index we had constructed. In none of our equations was the coefficient on either variable significant, and when entered into our equations together, following only years since graduation and the basic demographic variables, the two variables together never added a statistically significant increment to the variance the model explained, nor did using LSAT and UGPA rather than the admissions index change the implications of other variables. Since the picrure painted when we use our admissions index is the same as when we use LSAT and UGPA together, we present models using only the former measure. 


\section{FIGURE 4}

\section{Relationship between Admissions Index Scores and}

Career Satisfaction Index Scores

for 1970-79 Minority and White Alumni

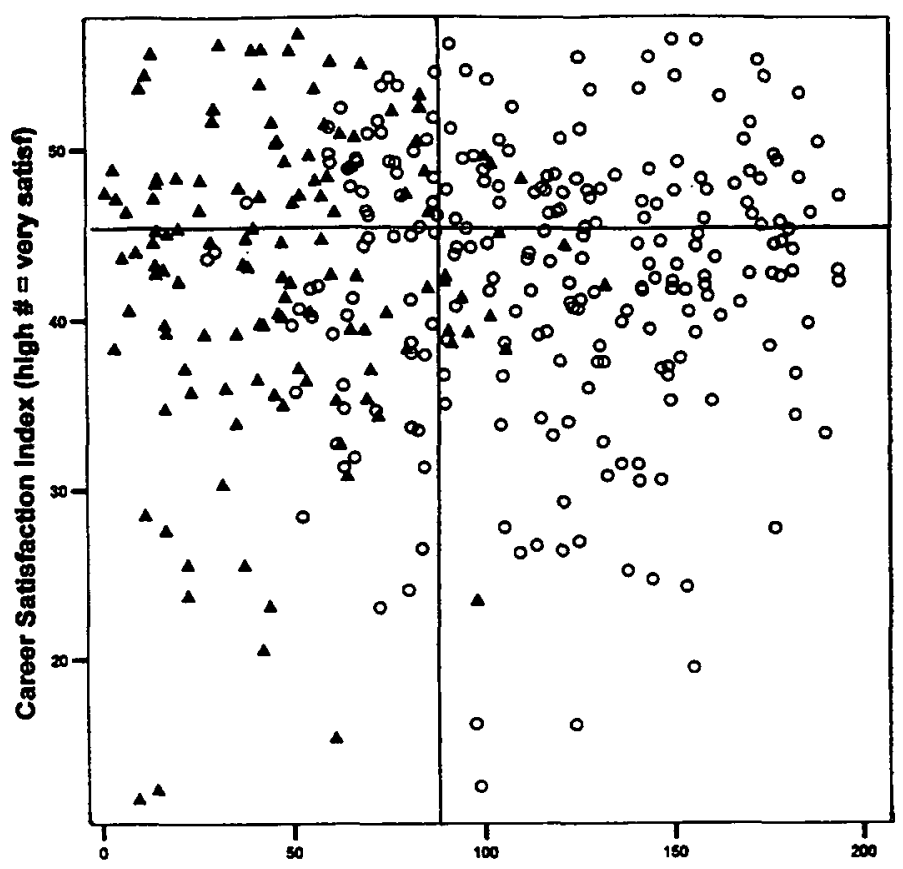

$O$ minge

$\Delta$ minerty

Cloud to futered

Admissions Index (high \# = stronger "objective" credentials)

college was entered as a series of zero-one dummy variables in which the University of Michigan was omitted and other colleges were coded by type (e.g., ivy league/seven sisters, other private, other Michigan public, other state schools); undergraduate major was entered as a series of zero-one dummy variables with social science the omitted category; and ethnicity was entered in the same way with whites the omitted category. We entered in our equation first, time since graduation and time since graduation squared; next the four demographic variables, gender and age at law school entry, as a block, and then ethnicity and the gender/ethnicity interaction term; then, the application form variables as separate blocks, with the LSAT/UGPA index the first variable entered; then, marital status and final LSGPA; and finally, current job sector. We dropped from our models information about undergraduate college attended, undergraduate major, and advanced degrees if the relevant dummy variables together did not make a statistically significant incremental contribution to explained variance and if none of the dummy coefficients was significantly different from the omitted category. These criteria resulted in the elimination of undergraduate college and advanced degrees from all models, and undergraduate major from one model. 


\section{FIGURE 5}

Relationship between Admissions Index Scores and Career Satisfaction Index Scores for 1980-89 Minority and White Alumni
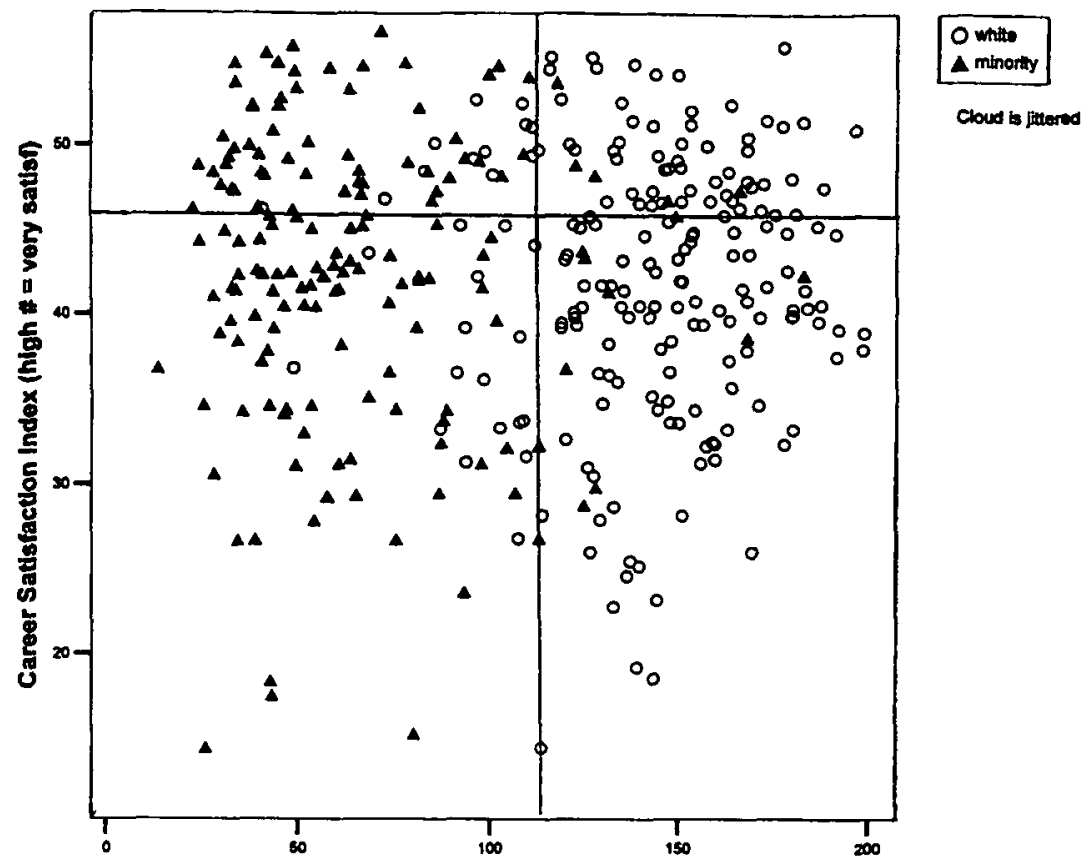

Admissions Index (high \# = stronger "objective" credentials)

We also omitted the gender/ethnicity interaction term and marital status from our final models because they were never significant in these screening regressions, and we omitted the time squared variable from the satisfaction and service models because it was not significant when these variables were dependent. In each regression we present results using two primary models; one that includes only time since graduation and information known at admissions and a second which includes these variables plus final LSGPA and job sector. ${ }^{56}$ The primary models use minority status as the measure of ethnicity, but we replicate these models using our five specific ethnic categories.

56. Social scientists differ on the appropriateness of using weighted data in multiple regression analyses. The data used in the models we present in tables 31-36 are unweighted, but as a check we ran models in which we weighted the data by the inverse of the sampling fraction (which in the case of minorities was always "1.") Our concern was particularly with model 1 in these tables, since among white graduates those with lower LSGPAs were oversampled, and it is reasonable to hypothesize a relationship between LSGPA and the variables we are seeking to explain. In the service and satisfaction regressions, weighting makes no difference in the significance of the impact of the admission index scores and minority status, which are the variables that most interest us in model 1 . With the log of income dependent, a marginally significant relationship between admission index scores and income in model 1 ( $p$ 


\section{Income}

Table 31 presents the regression results when logged income is dependent. And table 32 presents the incremental variance explained when each variable or, in some cases, set of variables is added to the analysis. Looking at model 1 , which includes the time since graduation variables and all variables known when the admissions decision was made, we see that time since graduation is the most important predictor of income. This is not surprising. Other things being equal, the longer people have been working, the more they earn. Time since graduation squared is also highly significant, but its coefficient is negative. It qualifies the story told by the linear time variable. Although income increases with time in the work force, the extra returns to

$=.099$ ) becomes insignificant when weighted data are used, a change that supports rather than undercuts our suggestion that admission index scores have little to do with future income.

Weighting occasionally changes the apparent significance of some other variables in these models. Most changes involve the tendency of graduates with different undergraduate majors to differ significantly from graduates who majored in social science. These are relationships that explain little variance despite their statistical significance, and that hardly figure in our discussion. The other differences between the weighted and unweighted regressions are that age entering law school is not significant in the weighted equation when log of income is dependent, though it is marginally significant when the regression is unweighted; age entering law school becomes significant in the weighted equation with the service index dependent ( $p$ $=.007$ ), and a tendency of women to be more satisfied than men becomes significant ( $\mathrm{p}=$ .032) when the satisfaction index is dependent.

Model 2 controls for LSGPA, so we are less concerned about theoretically relevant relationships that might be distorted due to sampling based on LSGPA strata. With log of income dependent, a marginally significant tendency of those with higher admissions indexes to have lower incomes becomes insignificant when the data are weighted, and a significant tendency of minorities to earn more than whites controlling for grades and practice sector disappears. Also those with jobs in the business/finance sector no longer earn significantly more than those in private practice. With the service index dependent, the significant tendency of minorities to do more service becomes only marginally significant in the full model $(p=.071)$, and attorneys in the public-interest sector score significantly lower on the service index than those in private practice $(\mathrm{p}=.044)$, but their jobs involve public service. The apparent influence of admissions index scores, LSGPA, and job sector remains the same in all equations, except that the tendency of those majoring in business and economics to earn more than those in the social sciences, which was significant with unweighted data $(\mathrm{p}=.002)$, becomes only marginally significant $(\mathrm{p}=.056)$ with weighted data, and the significant tendency of minority graduates to earn more than white graduates when LSGPA and job sector are controlled $(p=.011)$ becomes only marginally significant $(p=.073)$ when the data are weighted. A few differences exist in some equations in the statistical significance of undergraduate major and age at law school entry, but these variables explain little variance and do not figure prominently in our analyses. Weighting does not change the significance of any variables in the satisfaction equations.

After observing the limited effects of weighting on the crucial variables in models 1 and 2 , we saw no need to rerun models $1 \mathrm{~A}$ and $2 \mathrm{~A}$ with weighted data. We have also, as we noted, weighted all minority respondents as " 1, " since we sought to include all of Michigan's living minority graduates in our sample. We missed, however, at least one Latina graduate, but captured this person when she was inadvertently included in the white sample. Although as part of the white sample, this graduate had a probability of being in our sample that was less than one, she is included as a minority for analytic purposes and like other minorities has a weight of " 1. " 


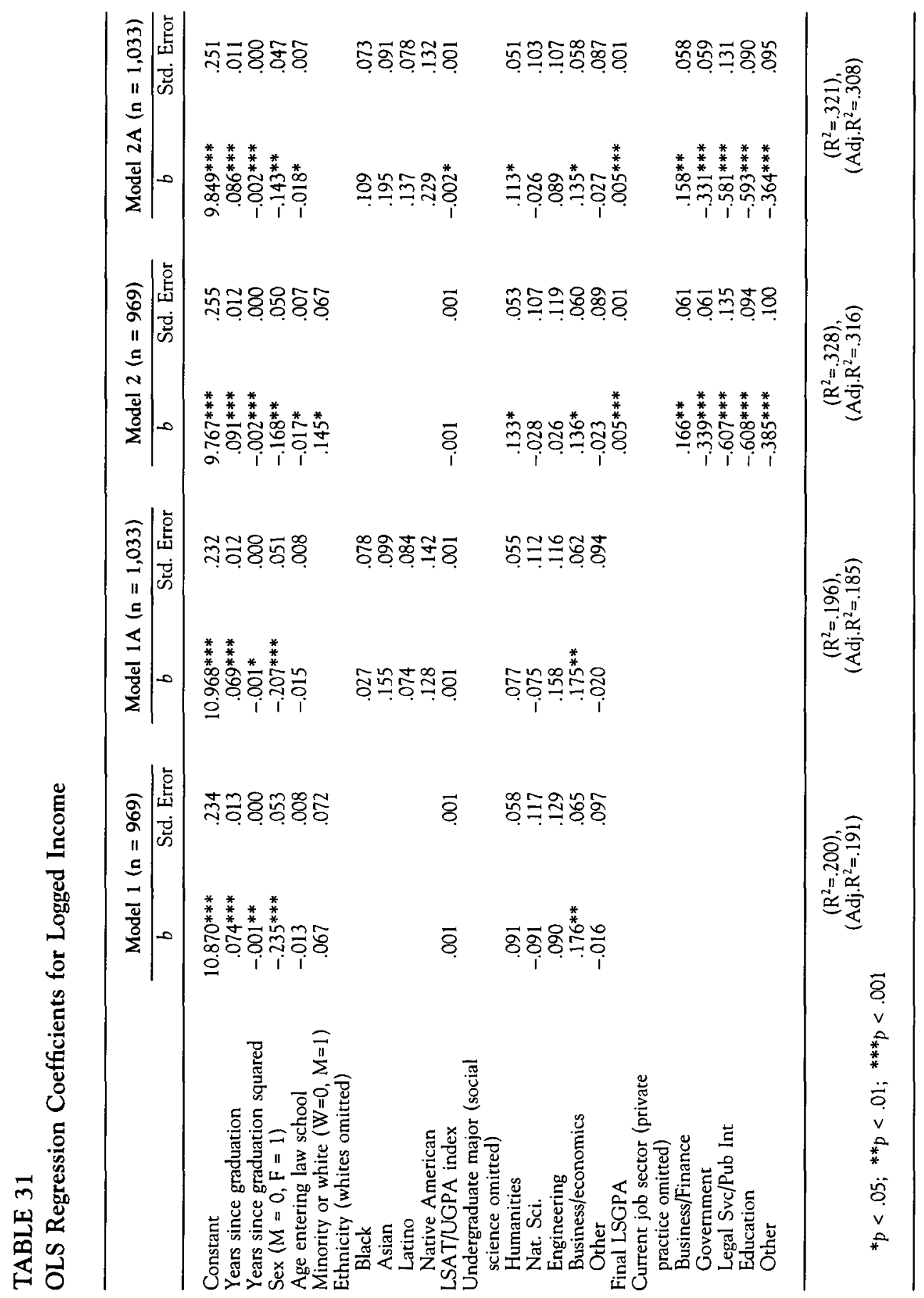


additional years of experience diminish over time. Looking at table 32 we see that when the two time variables are entered first in the equation, they explain together more than half the variance that we are eventually able to explain.

TABLE 32

Incremental Variance Explained by Logged Income Predictors

\begin{tabular}{lll}
\hline Order of Entry & Change in R Square & F Change \\
\hline $\begin{array}{l}\text { Years since graduation and } \\
\quad \text { (years since graduation) }\end{array}$ & .166 & $\begin{array}{l}96.452^{* * * *} \\
(2,967)\end{array}$ \\
Gender and age & .022 & $\begin{array}{l}13.171^{* * *} \\
(2,965)\end{array}$ \\
Minority status & .001 & .603 \\
& & $(1,964)$ \\
LSAT/UGPA index & .002 & 2.852 \\
& & $(1,963)$ \\
UG major & .009 & 2.112 \\
& & $(5,958)$ \\
Final LSGPA & .048 & $61.561^{* * *}$ \\
& & $(1,957)$ \\
Job sector & .079 & $22.400^{* * *}$ \\
& & $(5,952)$ \\
\hline
\end{tabular}

$* * * p<.001$

NOTE The numbers in parentheses are the degrees of freedom associated with the $F$ statistic for each variable when it is entered.

Gender also predicts income. Men earn more than women. Also there is a marginally significant tendency for students entering law school at an older age to earn less. But a graduate's ethnic status does not affect income. The coefficient on minority status is insignificant and when entered after time since graduation, gender, and age entering law school, it explains only $0.1 \%$ of the variance. The LSAT/UGPA index is also unimportant; its coefficient is only marginally significant (.099), and it explains only $0.2 \%$ of the variance. ${ }^{57}$ A respondent's undergraduate major also appears to have little effect on income, as the incremental contributions of this set of variables to explained variance is $0.9 \%$, but those majoring in business or economics, unlike those having other majors, earn significantly more than those majoring in a social science.

When we look at model $1 \mathrm{~A}$ we see that our decision to treat all minority students together and eliminate Asians from most analyses has not distorted our results. Controlling for the other variables in the models, no ethnic group differs significantly from whites in logged incomes.

57 . When entered immediately after years since graduation it explains $0.3 \%$ of the variation, so it is not a correlation with earlier entered variables that makes it unimportant. 
FIGURE 6

Relationship between Admissions Index Scores and

Career Satisfaction Index Scores

for 1990-96 Minority and White Alumni

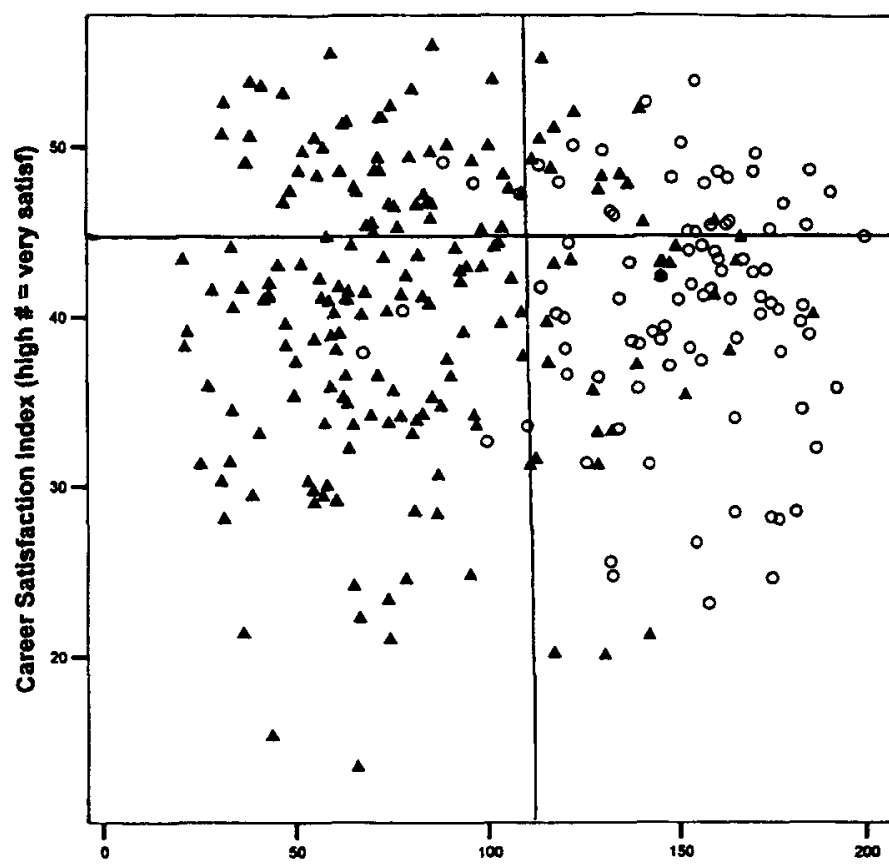

O whinorty

Cloud is jittered

Admissions Index (high \# = stronger "objective" credentials)

Model 2 adds factors known only at or after law school graduation. Both additional variables, final LSGPA and job sector, are significant predictors of future income. LSGPA adds $4.8 \%$ to the explained variance in income, and job sector adds $7.9 \%$. The importance of job sector is as expected. Those with government, legal services, public interest, education, and other jobs earn significantly less than those in the private practice of law. It is somewhat of a surprise that those in the business/finance sector earn significantly more. Our data indicate that this group of graduates contains both a somewhat lower proportion of low-income earners and a somewhat higher proportion of high-income earners than the group of private practitioners. ${ }^{58}$

The contribution of LSGPA makes the failure of the UGPA/LSAT index to predict earnings all the more puzzling, since there is a reasonably high and highly significant correlation between the LSAT/UGPA index and LSGPA, and in model 1 , as well as in tables $28-30$, the index does not

58. Only $8.2 \%$ of Michigan graduates in the business/finance sector earn less than $\$ 50,000$ per year compared to $11.6 \%$ of those in the private practice of law, and $32 \%$ of Michigan graduates in the business/finance sector earn more than $\$ 150,000$ per year compared to $24.2 \%$ of those in the private practice sector. 


\section{FIGURE 7}

Relationship between Admissions Index Scores and

Service Index Scores for 1970-79

Minority and White Alumni

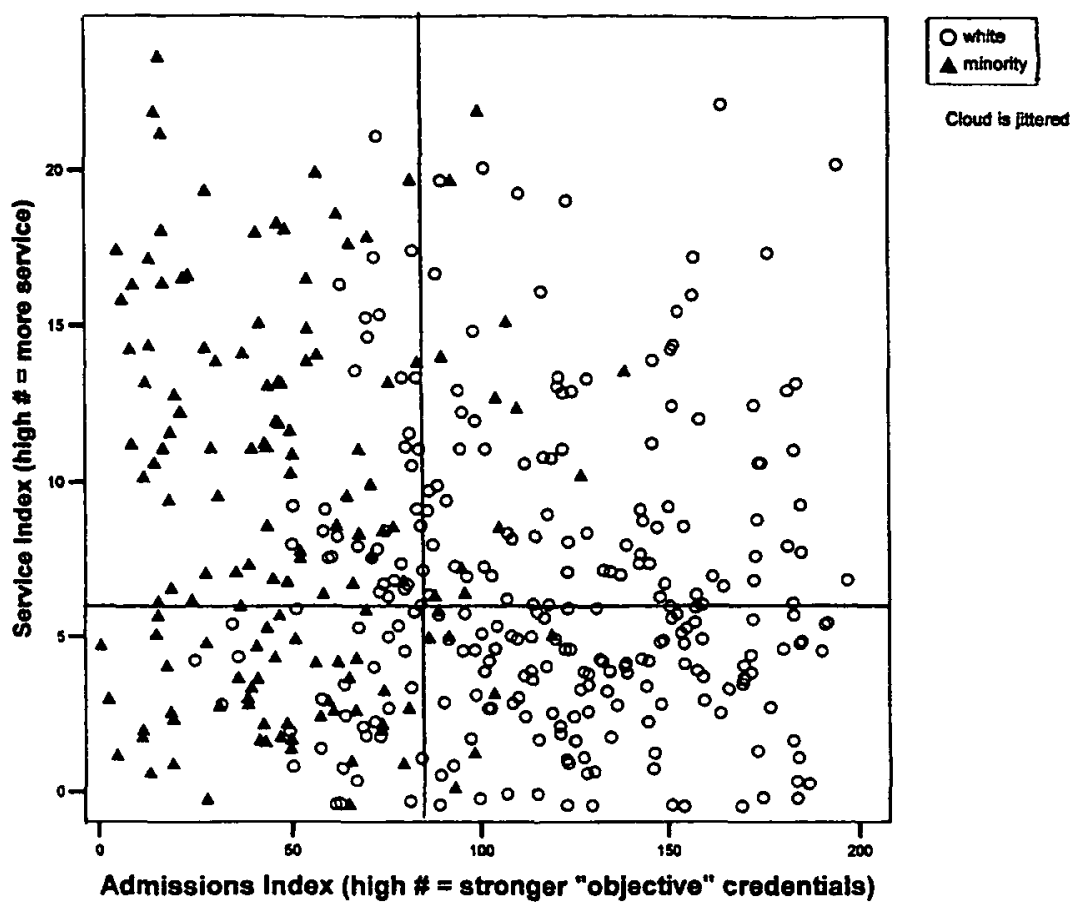

compete with LSGPA in explaining variance. Thus it appears that whatever it is about law school grades that predicts higher income has little to do with what the index tells us about a student's likely law school performance. Even if a high LSGPA predicts high income largely because it is a credential that leads to better-paying jobs, one would expect the UGPA/LSAT index, because of its correlation with LSGPA, to explain more of the variance in income than it does. But the index is not even a good proxy for that aspect of LSGPA which relates to future earnings. Instead, it appears from our results that a high LSGPA reflects something, perhaps an innate love for the law, or a sense of mission, or maybe a capacity for hard work under pressure, which relates to income success in practice. This capacity appears to be largely orthogonal to whatever it is that UGPA and LSAT measure.

These results do not necessarily mean that the traits that LSAT scores and UGPA measure have no relationship to the likelihood of later high incomes. They just indicate that there is no relationship among the students Michigan admitted. When we think about how the admissions process works, this may not be so surprising. First, at a school like Michigan, the difference between admittees with higher and lower index scores is not a 


\section{FIGURE 8}

Relationship between Admissions Index Scores and

Service Index Scores for 1980-89

Minority and White Alumni

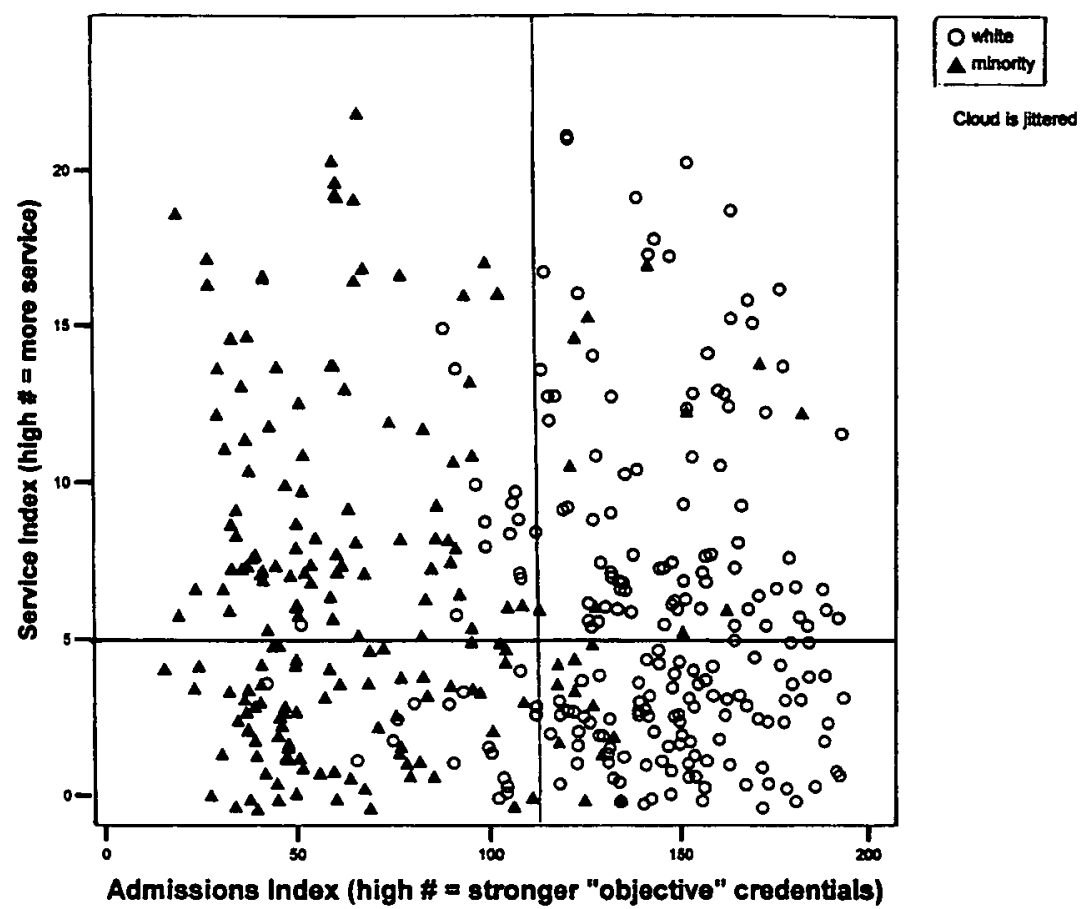

difference between likely competence and incompetence in doing law school or later legal work, but may be a distinction between competence and supercompetence. The marginal income returns to supercompetence may in practice be low. Second, when students have very high index scores, their files may not be perused for other evidence of their likely ability as lawyers. When students have relatively low index scores (which at Michigan are usually still high in national terms), the admissions officer is likely to examine files closely and admit only those who, on the basis of evidence other than the index score, seem likely to succeed. Thus a student admitted despite relatively low index scores may have, for example, exceptionally strong letters of recommendation, a record of leadership or accomplishment that bodes well for career success, or a personality or intellectual commitments that so impress the admissions officer in an interview that the officer will bet the applicant has what it takes to succeed. Similar characteristics might later impress potential employers and clients and contribute to career success.

For most of the graduating classes in our study, Michigan's regular admissions process was actually designed to ensure that for many students a 


\section{FIGURE 9}

Relationship between Admissions Index Scores and Service Index Scores for 1990-96

Minority and White Alumni

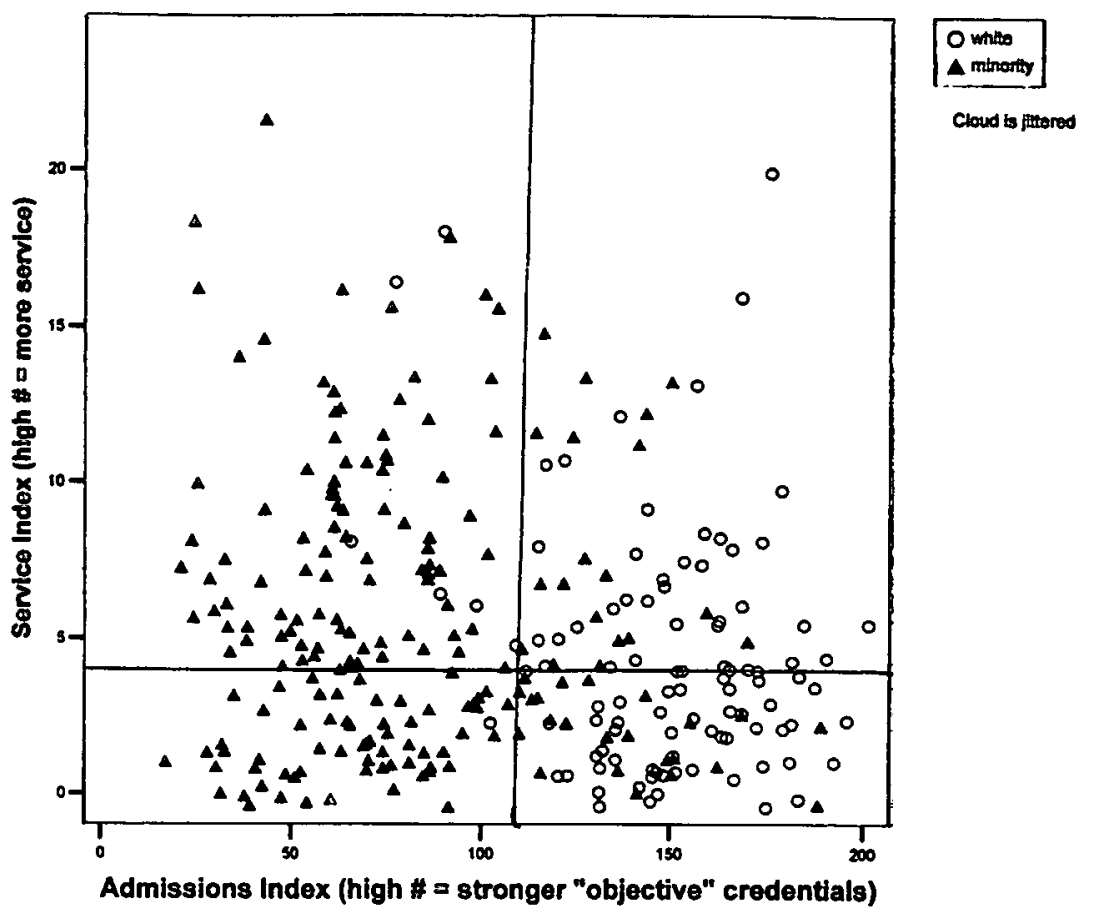

special emphasis was given to soft credentials. The school's policy was to admit half the class largely on the basis of index scores, and then to choose the other half from a group with the next highest index scores that was twice as large as it had to be to fill the class's remaining places. Within this group, index scores were not supposed to figure at all in the selection process. The admissions officer was instead instructed to look carefully at the "whole applicant," a type of inspection that since the beginning of affirmative action at Michigan has been given to minority applicants with relatively lower index scores. Proceeding in this way, a capable, experienced admissions officer might well make decisions that in large part negated any association between the skills that LSAT and UGPA measure and success in law practice. It is also not surprising that an association between these hard measures and LSGPA persisted despite the officer's desire to negate it. LSAT scores and UGPAs are more closely related in their nature or design to how a student performs on exams, while softer countervailing factors often relate far more strongly to accomplishments outside the classroom. Although we cannot show it to be the case, the lack of correlation between index scores and career accomplishments may be a sign that during the pe- 
riod we have studied, Michigan's admissions process, which called on its admissions officer to balance on a case-by-case basis an applicant's hard and soft credentials, worked well and as intended.

In most respects, models 1 and 2 are similar. The variables that were significant in model 1 remain significant in model 2 , and their directions remain the same. However, minority status, which had no significant effect on logged income in model 1 , is significantly related to income in model 2. Controlling for job sector and LSGPA, minority graduates tend to earn more than their white counterparts. ${ }^{59}$ The key control is job sector; in a model not presented, which includes the model 1 variables plus LSGPA but not job sector, the coefficient on minority status is not statistically significant $(\mathrm{p}=.238)$. Thus, minority graduates tend to earn more than their white counterparts with similar grades when they are in the same job sector. But the difference does not appear to be substantively important because minority status explains little of the variance in logged income.

Model 2A indicates that all groups that make up our minority alumni group, as well as Asians, tend to do better than white graduates once LSGPA and job sector are controlled. Although only the coefficient for Asians is significant $(p=.032)$, the coefficients for Latinos and Native Americans are marginally so, with p values of .078 and .083 respectively. In other respects, using specific ethnicity and including Asians in the sample does not change the pattern we saw when we looked at just white and minority students.

59. In fact, because we oversampled white graduates with low LSGPAs, this coefficient will be slightly biased in favor of white students if law school grades measure abilities that are also reflected in earned income. If we think of law school grades as a pretest that measures earnings-relevant abilities with some error, the ability scores of those whites we oversampled, who are at the extreme low end on this "test" should regress toward the white mean when they are remeasured on a different test, namely earned income. Empirically, this does not seem to be a great concern. LSGPA explains only $4.8 \%$ of the variance in earned income, suggesting that the abilities that high earnings reflect are, for the most part, not the abilities that law school tests measure. With just LSGPA in the model and not practice sector, minorities tend to earn more than whites other things being equal; but until practice sector is added the difference is not statistically significant. The same regression problem could, in theory, also bias the coefficient on the ethnicity variable when self-reported satisfaction or service are dependent, if law school grades measure abilities that are also reflected in how satisfied people feel about their careers and how much service they do. But LSGPA is not significant in the models for either of these variables, so we do not feel there is a problem here. The opposite problem could diminish the incremental variance explained by adding ethnic status to the model before LSGPA, since in these unweighted regressions the group of whites will have "too many" low LSGPA graduates who may earn less or otherwise do worse than those with higher grade-point averages. But the limited association between LSGPA and earnings, the lack of association between LSGPA and our other dependent variables, and the fact that controlling for grades, minorities tend to earn more than whites lead us to believe there is not a serious problem here. Moreover, in oversampling whites with low grades we were also oversampling whites who graduated longer ago, a factor far more strongly related to all our dependent variables than LSGPA. When a control for years since graduation is omitted, and ethnic status follows only age at law school entry and gender in our log income equation, the incremental variance that minority status explains increases to $1.2 \%$. 


\section{Satisfaction}

Tables 33 and 34 report data from regressions involving the satisfaction index. While the variables we used did a relatively good job explaining income, together they explain only $5.1 \%$ percent of the adjusted variance on the satisfaction index. And the little variance explained is largely attributable to practice sector, as the other variables that passed our screen for inclusion together explain only $1.5 \%$ of the adjusted variance in satisfaction scores. In model 1 we see that none of the variables known at the admission stage contributes significantly to an explanation for satisfaction, nor, we see from model 2, does final LSGPA. All that matters is time since graduation (those out longer are more satisfied) and job sector. ${ }^{60}$ Michigan graduates with jobs in government, legal-services/public-interest law, and education are significantly more satisfied than those working in the private practice of law even though, as we saw in table 31, they have significantly lower incomes. Graduates in the business/finance and other categories do not differ significantly from private practitioners in their reported career satisfaction. Models $1 \mathrm{~A}$ and 2A show that only Native Americans differ significantly from white graduates in career satisfaction as measured by our index. Because we have so few Native Americans in our sample, and as the block of ethnicity variables taken together do not explain a significant portion of the variation in satisfaction, we are not inclined to make much of this.

\section{Unremunerated Service}

Tables 35 and 36 report the results of regressions involving the service index. We see from model 1 that years since graduation continues to be an important predictor of behavior. The longer people are out, the more service they do. Of the other variables known at the time of the application, minority status is the most important. Minority graduates do more service

60. Time since graduation seems to matter only because it is a proxy for income. If we enter the $\log$ of current income as the last variable in the model, we lose about 70 cases because of missing data, but in the cases that remain, log of income is a highly significant predictor, time since graduation is no longer significant, and the adjusted variance explained in this subsample rises from .055 to .097 when logged income is entered. The significance of all other variables remains as it is in tables 33 and 34 except that those with current jobs in the "other" category are also significantly more satisfied than those with careers in private practice. Gender, ethnicity, the admissions index, and LSGPA still do not relate significantly to our career-satisfaction index. People are happier with their careers if, other things being equal, they earn more money and, except for those in business or finance, if they are in careers other than the private practice of law. There is a paradox here. High earnings figure importantly in career satisfaction, but those in the highest earning career sectors are less satisfied than those in careers that are on the average much less remunerative than the private practice of law. Thus, it appears that within job sectors, income is important to satisfaction, but across sectors job characteristics other than income, like a sense of balance between family and professional life, are more important than earnings to career satisfaction. 


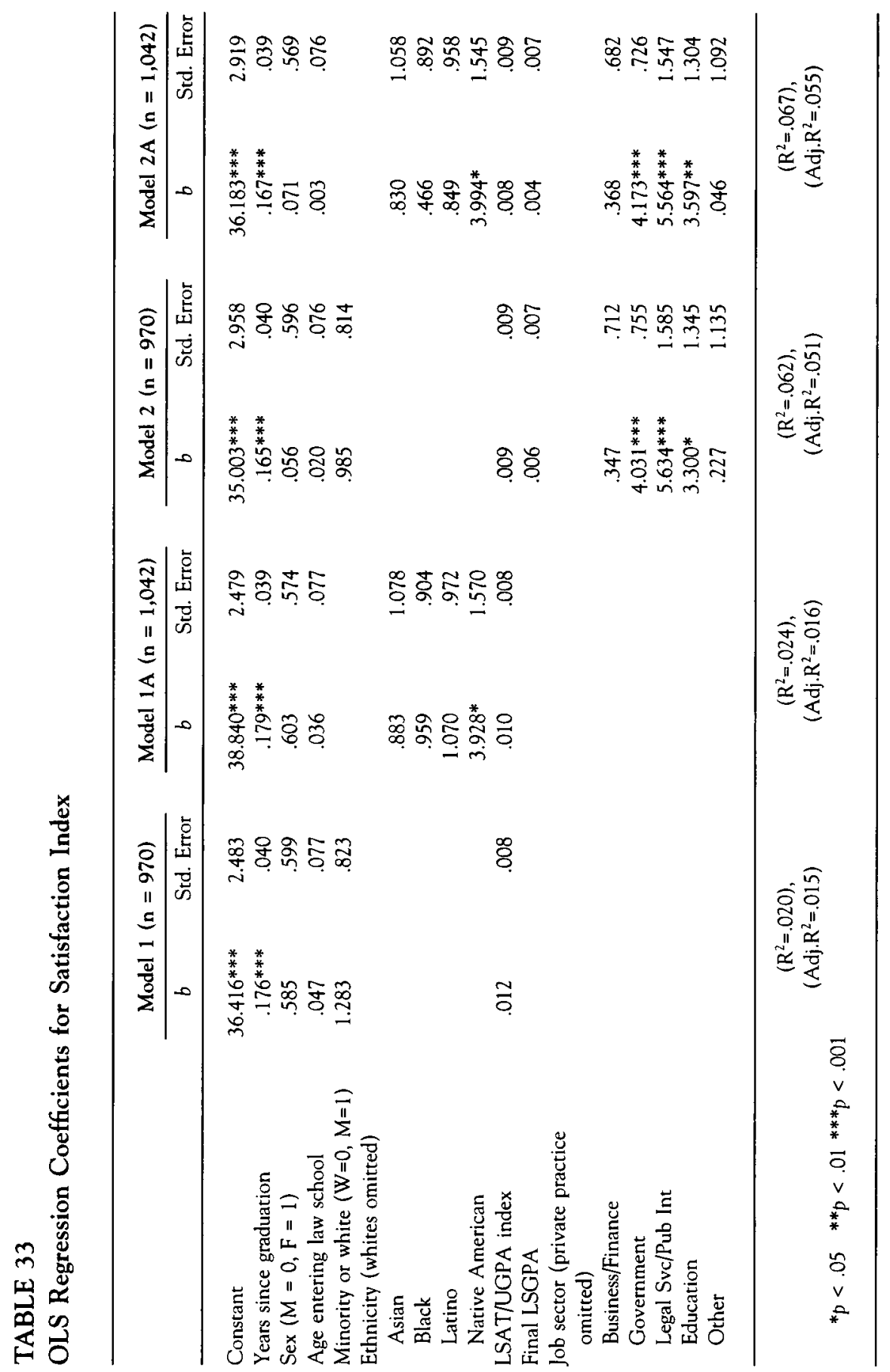


TABLE 34

Incremental Variance Explained by Satisfaction Predictors

\begin{tabular}{lcl}
\hline Order of Entry & Change in R Square & F Change \\
\hline Years since graduation & .016 & $\begin{array}{l}15.908^{* * *} \\
(1,969)\end{array}$ \\
Gender and age & .001 & .693 \\
& & $(2,967)$ \\
Minority status & .001 & .508 \\
& & $(1,966)$ \\
LSAT/UGPA index & .002 & 2.109 \\
Final LSGPA & .000 & $(1,965)$ \\
& & .343 \\
Job sector & .041 & $8.405^{* * *}$ \\
& & $(5,959)$
\end{tabular}

${ }^{* * *} p<.001$

NOTE The numbers in parentheses are the degrees of freedom associated with the $F$ statistic for each variable when it is entered.

than white graduates. The coefficient on the minority variable is significant, and when minority status is entered into our model, it adds $2.9 \%$ to the explained variance. As with satisfaction and income, the UGPA/LSAT index we constructed is statistically insignificant and explains only a minuscule portion of the variance. Undergraduate humanities majors are less likely to do substantial service than social science majors, but college major explains little variance, and we would not make much of this association.

Model 2 reveals a significant negative association between LSGPA and the amount of service done and a strong effect of job sector. Graduates working in all areas except legal-service/public-interest jobs are significantly less likely to do substantial service than those in private practice. The effect is so strong that adding job sector to the regression more than doubles the amount of variance the model explains. The controls for LSGPA and job sector do not, however, undercut the tendency of minority graduates to do more service than white graduates, for the strength of this association hardly varies when these controls are added.

Models 1A and 2A show an ethnicity effect that we did not see when we looked at our other two measures. The tendency of minority graduates to do more service than whites is largely driven by a tendency for black graduates to do more service than whites, although based on what is known at admission, Native Americans can also be predicted to do more service than 


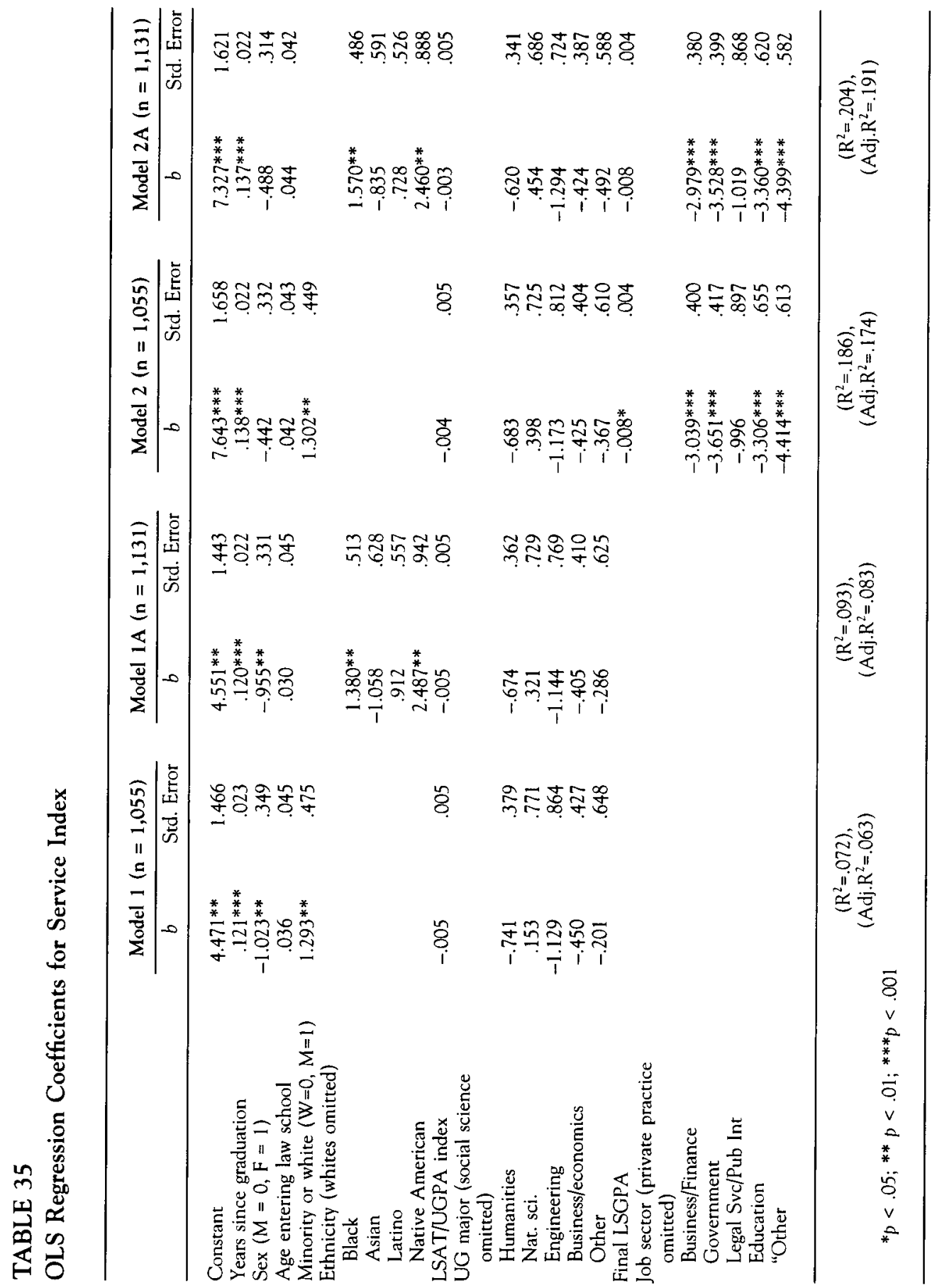


TABLE 36

Incremental Variance Explained by Service Predictors

\begin{tabular}{lcl}
\hline Order of Entry & Change in R Square & F Change \\
\hline Years since graduation & .030 & $\begin{array}{l}33.075^{* * *} \\
(1,1054)\end{array}$ \\
Gender and age & .007 & $3.888^{*}$ \\
& & $(2,1052)$ \\
Minority status & .029 & $32.083^{* * *}$ \\
& & $(1,051)$ \\
LSAT/UGPA index & .001 & 1.190 \\
& & $(1,1050)$ \\
UG major & .005 & 1.078 \\
& & $(1,045)$ \\
Final LSGPA & .002 & 1.803 \\
Job sector & & $(1,1044)$ \\
& .113 & $28.772 * * *$ \\
& & $(5,1039)$ \\
\hline
\end{tabular}

${ }^{*} p<.05{ }^{* * *} p<.001$

NOTE The numbers in parentheses are the degrees of freedom associated with the $F$ statistic for each variable when it is entered.

whites ( $p=.008)$, and Asians tend to do less ( $p=.093$ ). Model $2 \mathrm{~A}$ confirms the special propensity of black and Native American graduates to engage in substantial service, but Asian graduates no longer do significantly less service than whites. LSGPA and the job sectors variables behave as they did when just minority and white graduates were examined.

The tendency of those who earned higher grades in law school to do less service than those who earned lower grades is disquieting even if the effect is quite small in terms of explained variance. One explanation is that the law school in its admissions process accepts applicants with somewhat lower LSATs and UGPAs if they demonstrate a propensity for community service by a history of volunteer service during college. A related explanation may be that those prone to do service later will have done some in law school as well, at some cost to their grades. The relation of lower grades and greater service may also capture relative tendencies to prioritize assigned work. In law school an intense focus on assigned work probably leads to better grades; after law school, one of its consequences is that a person has little time for service. This is consistent with our observation in note 48 that LSGPA has a strong negative correlation with what we labeled the separate spheres dimension of satisfaction. Those likely to have concentrated most on getting good grades while in law school may be more likely than others to dedicate themselves to their jobs and to narrowly defined job responsibilities. The result is that they tend to earn more than others, but 
they also tend to do less service and to feel less satisfied because their jobs are so consuming.

The importance of job sector to service done is almost entirely a function of the opportunities for pro bono work that the private practice of law can furnish and encourage. When the job-service index is stripped of its pro bono component and the equations rerun (results not shown), the incremental proportion of the adjusted variance explained by job sector in model 2 diminishes from $11 \%$ to $.7 \%$, and minority status is second only to years since graduation in variance explained. ${ }^{61}$ Only those in government positions and our "other" job category have service scores that are significantly lower than those in private practice, but those in government have arguably chosen a career of public service and may face "Hatch Act" or other restrictions on their political or pro bono activities. Other relationships, including the significant tendency of those with higher LSGPAs to do less service, remain the same. The UGPA/LSAT index explains nothing $(\mathrm{p}=.585)$. Controlling for job sector, those majoring in the humanities or engineering $(p=.074)$ tend to do less service than those majoring in the social sciences, but the increment in adjusted variance explained when college major is added to the model is only $0.6 \%$. Looking at the specific ethnic groups when the service index is stripped of its pro bono component presents essentially the same picture that we get from model $2 \mathrm{~A}$, in table 35 , although the tendency of Asian graduates to do less service than white graduates is statistically significant.

\section{Summary of Regression Analyses}

These regressions confirm what we saw in our graphs and tables, and provide additional information as well. LSAT and UGPA, which in many law schools are the most prominent admissions screens, have almost nothing to do with our measures of achievement after law school despite their high correlation with LSGPA and the latter's relationship to earned income. The demographic categories of age when starting law school and gender affect future income regardless of job sector: Men earn more, and those who start law school at older ages earn less. But these categories bear no relationship to career satisfaction or to the amount of unremunerated service done by graduates. With respect to ethnicity, we see a different pattern. Neither minority status nor ethnic group affects future earnings or

61. Here our decision not to weight the regressions makes an important difference. A tendency for minorities to do more service than whites does not emerge in the weighted regression $(p=.420)$. Also, practice sector is more important as a block, explaining $2.7 \%$ of the variance in service, which is second only to time since graduation in this regard. The effects of other variables are similar in the weighted and unweighted models, except that those in business and finance do significantly less service than those in private practice. 
satisfaction, but they do relate to service by the school's graduates. Minority graduates do more service than white graduates, and among the minority graduates, the black and Native American graduates do the most service relative to whites. Time from graduation is universally important. The longer a person has been out, the more successful he or she is likely to be on all our achievement measures. Job sector is important in different ways. Private practitioners earn more than those in all fields except business and finance, but they are less satisfied than those in all sectors except business and finance and our "other" category. Private practitioners do considerably more service of the kinds we identify than do other graduates, with the exception of those in legal service and public-interest positions, but outside of their pro bono work, the tendency of private practitioners to do more to serve others is substantially diminished and seems largely to exist in relation to those working in government and a few miscellaneous occupations lumped together in our "other" category. The most important results are two:

- Controlling for variables known at admissions and for two key variables after admission, minority students are as successful as white students.

- An additive index that ranks students on their combined relative LSAT and UGPA performance does nothing to explain variance in future incomes, self-reported satisfaction, or service to others.

\section{What If Admissions Had Been Based Solely on Hard Criteria?}

LSAT scores and UGPAs drive the admissions process for most applicants at most law schools. Moreover, when opponents of affirmative action claim that law schools are admitting minority applicants who are "less qualified" than white applicants, they typically point to discrepancies in these measures both to justify this claim and to evidence impermissible attention to race in the admissions process. In the lawsuit against the University of Michigan Law School, for example, the plaintiff introduced as expert evidence a statistical report purporting to show that the odds that a minority applicant will be admitted to Michigan may be 500 times greater than the odds for a white student with a similar LSAT/UGPA index score. ${ }^{62}$ The model implicit in the plaintiff's expert's statistical analysis that yielded

62. Although no one disputes the fact that LSAT scores and UGPAs are important in the selection of both white and minority law students, analyses like those of the plaintiffs in the Michigan lawsuit do not necessarily show that this is the case. Even when the odds that a minority student with certain hard credentials will be admitted are hundreds of times what they are for a white student with similar credentials, the evidence does not necessarily mean race was the crucial factor, or even that it figured in the admissions decision. As to any given student, it may be the case that some factor other than race, such as leadership ability, was the crucial factor in the decision. 
these odds estimates is one in which only LSAT scores and UGPAs count in a law school's admissions process; in other analyses by the plaintiff's expert, resident status, gender, and application fee-waiver status are allowed to count as well.

We can draw on the work of Michigan Law School's statistical expert, Dr. Stephen Raudenbush (1999), a professor at the University of Michigan's School of Education, to estimate the effect that an admissions procedure which ignored minority status and turned largely on LSAT scores and UGPA would have on minority enrollments at the University of Michigan. ${ }^{63}$ Working with data from the applicant pools of 1995 and 1996 and using a mixed model for logistic regression that allows random effects, Dr. Raudenbush concludes that if LSAT scores, UGPA, residence status, and gender were the only factors that figured in Michigan's admissions decisions, $3.1 \%$ of the group offered admission to Michigan in 1995 would have been minority students compared to $18.3 \%$ in the group actually offered admission. This reflects a reduction from 182 to 29 in the number of minority students offered admission. In 1996 the expected change would be from a group offered admission that was $17.6 \%$ minority to one that was $4.7 \%$ minority, or a drop from 182 to 47 in the number of minority students offered admission. The actual number of minority students attending Michigan would be still smaller, for Michigan enrolls about $30 \%$ of its admitted applicants, and the minorities it would be offering admission to without an

A thought experiment can make this clear. Suppose, for example, that neither minority status nor an LSAT/UGPA index counted in Michigan's admissions process, but students were instead admitted based on a factor, say proven leadership potential, which was similarly distributed among white and minority applicants and orthogonal to or only weakly correlated with the LSAT/UGPA index. Because most minorities in Michigan's applicant pool have index scores that are below the index scores of most whites in Michigan's applicant pool, admitting students with no attention to ethnicity could be expected to yield groups of minority and white matriculants whose index scores, on average, would differ substantially. Of course, if Michigan ignored index scores and admitted applicants on apparent leadership potential, its white applicant pool would soon come to include many people with low index scores and strong evidence of leadership, and the gap between white and minority applicants on index scores probably would diminish. However, looking historically, differences in index scores do not necessarily tell us much about the degree to which ethnicity as opposed to letters of recommendation, a history of overcoming adversity, a history of outperforming standardized tests, leadership ability, impressions in a personal interview, or other factors dominated Michigan's admissions process or the admissions process in any law school.

63. In a part of this supplemental report and Professor Raudenbush's original report (which we don't draw on), the appropriateness of the plaintiff's expert's logistic analysis and the relative odds of admission that are derived therefrom are seriously called into question. Dr. Raudenbush points out, among other things, that the plaintiffs odds estimates purport to apply to all black and white applicants, but no single number can characterize the relative chances that white and minority applicants will be admitted. At some combined LSAT/ UGPA levels, virtually all applicants, white or minority, will be admitted, and at other levels none will be admitted; and in between these levels the relative odds of admission will vary. For the admissions years of 1995 through 1998, the net result of Michigan's admissions decisions is that approximately equal proportions of minority and white applicants were admitted. 
affirmative action program would all be likely to have attractive offers from other highly selective schools.

Using a different simulation method in which applicants are placed in cells on a grid based on the conjunction of LSAT scores and UGPAs and assuming that the proportion of admitted minorities in a cell would be the proportion of all applicants in the cell who are admitted, Dr. Raudenbush estimates that $6 \%$ of the 1995 offerees and $5 \%$ of the 1996 offerees would have been minority applicants. Again, the actual proportion of minority matriculants at Michigan might have been far lower than the proportion admitted. Dr. Raudenbush regards the results of his second method as "quite conservative" as an estimate of the likely detrimental effects of ignoring minority status in the admissions process, and he views his first method as "somewhat liberal" $(1999,10)$. But even the lower estimates of the first model are likely to overestimate the proportion of minority applicants who would have been admitted to Michigan through most of the period we have examined. This is because Michigan enrolled, and presumably was admitting, a smaller proportion of minority students during the 1970s and 1980s than during the middle years of the 1990s, and hard admissions credentials, particularly LSAT scores, have over the years increased more rapidly among minority applicants than among white ones, at least over the range where Michigan admits students.

We saw earlier that minority alumni who graduated in the 1990s look much like their white counterparts on most career-related variables. Indeed, 1990s minority alumni in private law firms tend to earn slightly more than white alumni, and in non-private practice settings they are more likely than their white counterparts to have risen already to supervisory and managing attorney positions. Minority graduates of earlier decades have careers that diverge more from the careers of white alumni, but they have very high earnings, are as satisfied with their careers as white alumni, and tend to do more service. If racial and ethnic diversity had been an impermissible consideration in admissions decisions, it is probable that only a handful of these students would have attended and graduated from Michigan. Raudenbush's study tells us that basing admissions decisions largely on the so-called hard credentials of LSAT scores and UGPA would have prevented most of Michigan's minority alumni from attending Michigan. On the other hand, if Michigan had ignored LSAT scores and UGPA, it might have admitted more minority students, but these students would probably not have performed as well in law school as the students it did admit because, as we have seen, the index scores of Michigan's minority students are moderately predictive of their law school grades, as are its constituent measures.

LSAT scores and UGPA can, in short, help a law school admit students who will perform well in their classes. But they also can be a mechanism for keeping most black, Native American, and Latino students from 
attending elite law schools like Michigan, even though, if what we have found holds generally for graduates of elite law schools, these credentials bear no clear relationship to success after law school and have, if anything, an inverse relationship with some kinds of valued achievements. Considering both the relationship of LSAT and UGPA to law school grades and their relationship to practice success, it makes sense for a law school like Michigan to select which minority and which white students it wants to admit partly on the basis of LSAT scores and UGPA, since schools want those they admit to perform well in class, but at least above a certain threshold $^{64}$ it makes little sense to use LSAT scores and UGPA to choose between minority and white applicants since Michigan's goals in admitting students focus far more on the kinds of lawyers they will be than on the grades they will receive while in law school.

\section{CONCLUSION}

The test of a school's admissions policy is whether it meets the school's goals with respect to overall class composition and the kinds of persons the school seeks to enroll. Throughout the period we have studied, the University of Michigan Law School's various admissions policies have sought to achieve diverse classes and to this end treated ethnicity as an element that might alter admission probabilities. The Law School's admissions policies appear to have succeeded well in enhancing diversity through increased minority enrollment. In 1967, shortly after the Law School started its minority admissions program, only two black students attended the law school, members of the class of 1968. Records do not reveal whether any Latino or Native American law students attended Michigan at that time, but if they did, there were very few of them. Largely because of its minority admissions program, during the decade of the 1970 s, $7.6 \%$ of Michigan's graduates, or 300 individuals, were black, Latino, or Native American. In the 1980s, the proportion of graduates with these backgrounds rose to $10.2 \%$, or 378 individuals. During the years from 1990 through 1996, 382 individuals, or $15.4 \%$ of the school's graduates, have been members of these groups. Had Michigan not considered ethnicity as an element in admissions decisions but relied largely on LSAT scores and UGPAs, it is likely that during the period we have studied only a handful of the students in each class, perhaps under $3 \%$ in the 1990s and even fewer in earlier decades, would have been of black, Latino, or Native American ethnicity.

64. Bowen and Bok $(1998,59,60)$ found in their study that there was an SAT threshold above which test score differences made little difference in graduation rates. The same could be true of law schools and LSATs. 
Our respondents' current recollections reveal that substantial proportions of minority group members and white women have long regarded ethnic diversity as contributing considerably to their classroom experience. Among white males the proportion of 1990 s graduates expressing this view is double the proportion of 1970 s and 1980 s white male graduates with similar opinions, and few white male students feel it made no contribution at all. We have suggested that this increase is related to the large proportion of minority students (including here Asians as a minority) in the graduating classes of the 1990s and perhaps to the fact that when gender is taken into account, white males in the 1990s found themselves in the minority. Regardless of the explanation, our data suggest that if the recollections of alumni can be trusted, increasing diversity has served Michigan's larger goal of increasing the quality of the education it offers all students.

According to its current admissions policy, the University of Michigan Law School seeks to admit students who will go on not just to successful careers as practitioners but also to careers that involve community leadership and service in the tradition of past generations of graduates from one of the nation's great law schools. If students admitted with diversity in mind did not succeed in these ways after law school, the school's admission policy would be working at cross-purposes with respect to major admission's goals. The data we have reviewed indicate that the purposes do not conflict. Not only has the consideration of ethnicity as a factor in admissions not detracted from achieving these admissions goals, but in some respects, such as community leadership and public service, the school's goals seem to have been better met than they would have been without a minority admissions program.

Although the University of Michigan's current minority admissions policy is motivated by the faculty's interest in realizing the academic benefits of classroom diversity, policies like Michigan's can have larger social ramifications. In a series of cases beginning in the 1940s and culminating in Brown v. Board of Education, the Supreme Court promoted the transformation of this country from a segregated to an integrated society. For many years after Brown, however, the bar, particularly its higher echelons, remained de facto segregated. Michigan's admissions policies during the past three decades, together with similar policies at Michigan's peer schools, have brought a degree of integration to the bar, and to the most elite firms within it, that otherwise could not have been achieved. Evidence in this study indicates that in doing so these policies have increased the availability of legal services to members of disadvantaged minorities. They have also, if we can judge by Michigan's minority alumni, created a group of African American, Latino, and Native American lawyers who are prospering in every sense of the word and are helping foster a degree of integration never before possible in the middle and upper reaches of American society. Had 
Michigan not considered ethnic diversity as one goal of admissions decisions, attention primarily to LSAT scores and UGPAs in admitting students would have meant that most of the minority graduates we have surveyed would not have attended Michigan, even though LSAT scores and UGPAs seem to bear little or no relationship to post-law school success among Michigan's graduates.

Current attacks on law school affirmative action programs ignore the costs both to legal education and to society that outlawing such programs would entail. Perhaps this is because until now no one has looked closely at the educational value that practicing lawyers, including whites, place on the diversity they encountered in law school classrooms, thanks in large measure to affirmative action; and no one has looked at how the beneficiaries of race-conscious law school admissions fare in practice, or at whom they serve, or how much they give back to their communities. This is also the first paper which indicates that LSAT scores and UGPAs, the admissions credentials that the opponents of law school affirmative action would privilege for their supposed bearing on "merit" and "fitness to practice law," bear for one school's graduates little if any relationship to measures of later practice success and societal contribution. Although we did not expect our research to question the place of these credentials in law school admissions decisions, our findings suggest that law schools might want to reconsider the weight they give them and to augment them with other instruments that are better predictors of practice success.

Our research uncovered other relationships that we also did not set out specifically to investigate. Our data indicate, for example, that those who make careers in the private practice of law are, except with respect to income, less satisfied with their careers than those who work in other settings. We also see in our data a strong tendency, particularly in the two most recent decades, for lawyers to move from early jobs in law firms to later jobs in other settings. This suggests that the relative ${ }^{65}$ dissatisfaction with the private practice of law is greater than our career-satisfaction data indicate, because one would expect those who are least happy with private practice jobs to be the most likely to leave them.

Perhaps the core finding of our study is that Michigan's minority alumni, who enter law school with lower LSAT scores and UGPAs than its white alumni and receive, on average, lower grades in law school than their white counterparts, appear highly successful-fully as successful as Michigan's white alumni-when success is measured by self-reported career satisfaction or contributions to the community. Controlling for gender and career length, they are also as successful when success is measured by in-

65. We emphasize the word relative because, on balance, the private practitioners in our sample are more satisfied than not with their careers, although they are somewhat less satisfied than those who are in careers other than the private practice of law. 
come. Some people we have told of this result suggest that it simply reflects the fact that minority graduates benefit from affirmative action throughout their careers. What they seem to mean by this is not just that minority graduates are advantaged by their race or ethnicity in securing jobs, but also that they do not perform as well in these jobs as whites would. Thus, they challenge the idea that our indicators of practice success reflect genuine accomplishment. Their view seems to be that because of their ethnicity, our minority respondents do better than one would expect given their skills and work habits and, in particular, that they get paid throughout their careers more than the market value of their skills, effort, and business-getting ability.

It may well be that at times in their careers some of our minority graduates have benefited from forms of affirmative action, but as a general matter we do not find this explanation to be a plausible one for the evidence of practice success that we have uncovered. As an initial matter, affirmative action is not a good explanation of why Michigan's minority alumni seem similar to its white alumni in career satisfaction and seem to do even more professional and community service. When we consider satisfaction, we see that as compared to white alumni, minority graduates are least satisfied with their incomes, although income satisfaction is the dimension where one might expect affirmative action to make the most difference. Minority alumni are, on the other hand, just as satisfied as white alumni with the intellectual challenge of their work, and many take great pleasure in it. If minority alumni were hired and retained by law firms and other employers because of their race, one might expect them to receive less challenging work and not only to sense this but also to resent it.

Affirmative action hiring also does not seem to explain well the relatively high incomes of Michigan's minority graduates. One would expect affirmative action hiring to be most important at the start of careers and to matter less in promotions and lateral moves, when a firm has a record of past job performance to scrutinize. Most respondents in our sample have been out of law school for many years, during which time they have changed jobs and even job sectors. Even if our minority graduates benefited from affirmative action when they were first hired, the benefits would likely have dissipated over time. Consider also the experience of minority lawyers who are on their own or in small firms, a group unlikely to benefit significantly in their current practice from affirmative action. The minority lawyers we surveyed from the 1970 s who are in solo practice or in small firms had average incomes in 1996 of $\$ 154,400$. Their median income was $\$ 95,000$. The minority graduates of the 1980 s in solo practice and in small firms averaged $\$ 78,500$, with a median of $\$ 76,000$. (White graduates from the 1970s in solo practice and small firms average somewhat less than their minority classmates; white graduates from the 1980s average somewhat 
more.) To be sure, all lawyers are hired from time to time for reasons other than their abilities or their reputations for ability-they are golf buddies of the client or are married to a client's cousin. But, on average, one would expect that most clients with a legal problem look for someone with a reputation for competence and that lawyers who do not develop such a reputation are likely to pay a heavy financial price. From an economic perspective, these solo and small-firm minority practitioners seem to have demonstrated their competence in the marketplace.

In addition, although the Professional Development Survey did not ask about summer clerkships, responses to our Alumni Survey indicate that minority graduates are very likely to have had either a prior job, other than a judicial clerkship, before being hired by their current law firm employer or a summer clerkship with the firm that employs them. Among minority graduates working in firms with more than 50 attorneys, this is true, for example, of $61.9 \%$ of 1970 s alumni, $83.6 \%$ of 1980 s alumni, and all responding minority graduates of the classes of 1990 and 1991.66 These data do not show that law firms are not giving some weight to race when they hire minority attorneys, but they do show that even if they are, they typically have considerable evidence, apart from law school grades, on which to base hiring decisions. The data also suggest that to the extent firm hiring involves any affirmative action, it is unlikely to lead to hiring lawyers who are unable to do the firm's work. Firms have no reason to want to hire incompetent attorneys, and when hiring minorities, they usually have a performance basis for judging professional competence. Moreover, as we discussed earlier, ${ }^{67}$ among those who have taken initial jobs in large firms, there is no statistically significant difference between the length of time that our minority graduates and our white graduates stay in their jobs.

If the benefits of continuing affirmative action cannot explain the high incomes, substantial career satisfaction, and considerable public service of Michigan's minority graduates, the question is how to explain them. ${ }^{68}$

66. Because attorneys more commonly move from larger to smaller firms, prior job experience is even more common among minority alumni working in firms with 50 or fewer attorneys. The data indicate that minority graduates are more likely than white graduates to have had either prior jobs or second-year summer clerkships with their current employers. Because the alumni survey data are not collected with as intense follow-ups as the PDS, and the same kind of bias checking is not done, we cannot be confident in the specific numbers we present, but we are confident of the accuracy of the general picture, which shows that when firms hire minority attorneys they usually can evaluate them based on how they have performed in a practice setting.

67. See text that follows shortly after note 37.

68. Arguably, all that needs to be explained is the service done by minority graduates since this is the only accomplishment measure on which there is a statistically significant difference between the accomplishments of minority and white graduates. But the fact that Michigan's minority alumni received significantly lower law school grades than its white alumni and entered a world where they might encounter discrimination both in their profes. sional ands extra-professional lives might reasonably lead one to believe that these minority 
Service is perhaps the easiest to explain. We believe that the service of minority graduates exceeds that of white graduates for several reasons. First, we expect that the typical minority attorney, either because of ethnic or experience-based identification with the less well off or because of family and community pressure not to forget one's origins, is more likely than the typical white attorney to feel an obligation to help the less fortunate, particularly those of his or her own race. ${ }^{69}$ Second, we expect that minority attorneys, because they are minorities in the practice of law, have on average, more requests for service made of them than are made of white attorneys. These two reasons can work in concert. Both might, for example, lead a senior black or Latino attorney in a largely white law firm to take a special interest in the progress of the young black or Latino attorneys the firm hires. White attorneys, on the other hand, are likely to feel a more diffuse sense of responsibility for mentoring young white attorneys, since many people are potentially available to perform the role. ${ }^{70}$

In addition, ethnicity is sometimes regarded as a criterion for service. Community organizations often feel a need for board members of varied ethnic backgrounds in order to maintain ties to and legitimacy in different constituent communities. An organization with this need may know of many possible white representatives but few minority representatives to choose from. Thus, a prominent white attorney may be asked to join one or two community boards, but a prominent black attorney may be asked to join five or six. In this way something akin to affirmative action may play a role in the higher levels of service that minority graduates exhibit. But this process should not lead to the selection of minority members who are less well qualified than whites who might serve. Rather it seeks out (and burdens) minority attorneys because in addition to desired skills, they have attributes, like ties to segments of a minority community, that are important to the success of the project or organization the board serves.

Our data do not allow a strong test of these suppositions, but consistent with them, the only one of seven specific activities we inquired about in which the proportion of participating white alumni exceeded the proportion

graduates would not be earning high incomes or be satisfied with their careers, either absolutely or relative to Michigan's white graduates.

69. Year after year on the law school's annual survey of its graduates five years after law school, Michigan's minority graduates report themselves as more liberal politically than its white graduates report themselves. They are also more likely than white graduates to recall that they started law school with a plan to work in government, politics, or public-interest work.

70. This diffusion-of-responsibility effect has been most commonly documented in the context of apparent emergencies, where numerous social psychological studies report that when responsibility is diffused there is a tendency for no one to act, even though most of those who could act would be likely to do so if they thought themselves the only help available. See, e.g., Darley and Latane (1968a, b). 
of participating minority alumni was PTAs and other school organizations. ${ }^{71}$ School organizations, among the activities we inquired about, are likely to be the ones where the racial pull to serve is least. Minority attorneys often will have their children in schools with numbers of children from their own ethnic background, meaning that many parents will be available to represent specific ethnic concerns or to help the school maintain ties to ethnic communities. Even when a minority attorney's children are in a largely white school, white parents will often be able to serve as effective advocates for the high-quality education the minority attorney values.

An additional possible explanation for the greater service done by Michigan's minority graduates is that Michigan Law School's admissions process gives students several opportunities to provide evidence of leadership experience and community service. If these factors are given more importance for minorities than for whites-perhaps because when LSAT scores and UGPAs are weaker the whole file is more closely scrutinizedand if they reflect enduring traits or commitments, minorities admitted to Michigan would be expected to do more community service than whites, even if the propensity to do community service is not associated with ethnicity in the applicant pool. The service difference could thus reflect not just structural factors that impinge on careers after graduation, but also an admissions process that sometimes, and proportionately more often for minorities than for whites, selects for service-related traits and commitments.

Finally, we note that Bowen and Bok in their study of the graduates of 28 colleges also found that minority-group members, particularly those with advanced degrees, tended to do more civic and social service than comparably educated whites $(1998,158-74)$. These corroborating results do not explain why minority-group members do more service, but they increase our confidence in what we found and suggest that features of the backgrounds or social positions of highly educated minority-group members, and not just of those who are lawyers, are in some way responsible.

The explanation for the high incomes and substantial career satisfaction of Michigan's minority alumni lies, we suspect, largely in the same factors that explain the high incomes and substantial career satisfaction of Michigan's white students: ambition, considerable intelligence, a capacity for hard work, the quality of a Michigan education, and the prestige and network benefits that go with a Michigan degree. The way in which social conditions affect how law is practiced also seems important. What seems most important is the continuing salience of race and ethnicity in society. We have seen that lawyers and clients of the same race tend to find each other. As blacks, Latinos, and members of other minorities achieve political

71. The activities were electoral politics; nonelectoral politics; PTAs, PTOs, and other school organizations; college or law school alumni organizations; charitable organizations; religious organizations; and bar organizations. 
power or positions of business responsibility, lawyers with similar backgrounds may develop a market value sufficient to offset any diminution in their market value that lingering discrimination by the white majority may entail. If law firms search out senior minority attorneys and treat them well, they likely do this not from an abstract desire to increase diversity but for the same reason they search out senior white attorneys-namely, the ability to bring in new business and to satisfy existing clients. Largely minority firms can also prosper when members of minority groups have a role in determining who gets a municipality's or business firm's legal business. This prosperity is not necessarily because minority group members seek to place their legal business with minority attorneys any more than the flow of white legal business to white attorneys necessarily reflects an intention to choose white attorneys because they are white. Rather, legal business often follows friendship lines or other patterns of personal contact. Given the pervasiveness of race and ethnicity as organizing dimensions of American society, minority attorneys are likely to have more informal contacts than white attorneys with minority business and political elites who are in a position to place substantial legal business. They are also more likely to have informal ties to people of their own race with lucrative one-time legal problems, such as serious personal injuries.

The idea that the success of Michigan's minority graduates, particularly their high incomes, is something that needs to be explained while the success of Michigan's white graduates requires no special explanation is probably rooted for most people in the assumption that law school grades are an important predictor of success as manifested in high income. ${ }^{72}$ The assumption is reasonable if one believes that high grades are closely associated with the kind of skills, intelligence and diligence needed to succeed in legal practice and/or if high grades are an essential entry credential in securing positions with the highest paying large law firms. The assumption is, however, easy to overweight. Controlling just for time out of law school and gender, the partial correlation of final LSGPA with logged income is .214 , which means that grades explain only about $4.6 \%$ of the variance in future income among those in our sample. Among minority students, the correlation is .205 (explained variance $=4.2 \%$ ) and among white students the correlation is .253 (explained variance $=6.4 \%$ ). Thus one need not resort to ideas like ongoing affirmative action to explain most of the income success of Michigan's minority graduates relative to that of its white ones. Nor does rejecting

72. Alternatively, it could be rooted in the expectation that Michigan's minority alumni would encounter discrimination after law school that would impede their earning ability. Our data suggest that discrimination in legal job markets is today not a great problem for most Michigan graduates, or at least not so great that most minority graduates cannot overcome it. It may have been a more serious problem for minority graduates of the 1970 s, who were much less likely than minority graduates of later decades to take first jobs in the private practice of law. 
the affirmative-action story mean that one must claim that LSGPA has no bearing on lawyer competence. There are, however, many aspects to lawyer competence, such as negotiation skill, a gift for rain making, and the ability to persuade juries. If LSGPA relates somewhat to some dimensions of lawyer competence, ${ }^{73}$ it is probably orthogonal to many others, and may even have a negative relationship to some.

If one accepts the view of affirmative action's critics, affirmative action after law school would presumably give minority lawyers opportunities on account of their race that more competent white lawyers are denied. Yet the only basis for assuming that Michigan's white alumni are more competent as a group than its minority alumni as a group is the former's higher mean LSGPA. Even among Michigan's white graduates, however, law school grades explain little of the differences in later income. Just as one does not need an affirmative-action story to explain why many of Michigan's white graduates now earn more than classmates who ranked higher on grades at graduation, so one does not need an affirmative-action story to explain why Michigan's minority graduates are mostly higher earners, with many now earning more than many of their white classmates.

What needs to be explained is the income success of all Michigan alumni, both white and minority. Surely an important shared ingredient in the job success of Michigan's alumni is graduation from Michigan. While we cannot determine the importance of a Michigan education for future income in a study that looks only at Michigan graduates, it appears that graduates of the nation's most prestigious law schools earn substantially higher starting salaries than graduates of less prestigious ones (U.S. News $\mathcal{E}$ World Report 1999). Moreover, students of the legal profession have shown that graduation from a so-called elite law school is associated with work in large law firms and with generally high status and lucrative legal specialties (Heinz and Laumann 1982; Nelson 1988). Also, the elite-school credential may help graduates who do not choose large-firm practice to find employment niches that are well suited to their particular skills and other incomeearning resources.

Because of the association between law school status and subsequent legal careers, we do not claim that our findings will generalize to the gradu-

73. The income/LSGPA correlation, though not great, is consistent with an association between LSGPA and lawyer competence. It could also, however, be explained in whole or in part by the role LSGPA plays in initial hiring. Those with high LSGPAs are more likely than those with lower LSGPAs to get the most lucrative initial positions. We hope to explore in a later paper the degree to which lucrative initial positions predict higher current incomes. Although one would expect a high correlation, it may be substantially attenuated by the tendency of lawyers to leave large, high-paying firms. This may also attenuate any relationship between LSGPA and income that reflects a joint relationship to lawyer competence. Regardless of relative competence, lawyers who, after a number of years, leave high-paying jobs in large firms for lower-paying jobs in smaller firms or government may for a while, or even throughout their careers, earn less than those who started and remained in such settings because of the sector- or employer-specific capital that the latter have acquired. 
ates of all law schools with admissions policies giving weight to diversity. ${ }^{74}$ But there is little reason to think that graduates of schools that are Michigan's peers on the prestige hierarchy have careers much different from the careers of graduates in our sample. However one measures success, attendance at an elite law school appears to attenuate the effects of substantial differences in the entry credentials of students entering law school. Michigan's minority admissions policies have produced lawyers who are for the most part high earners, satisfied with their careers, and through unremunerated service, giving back to their communities. This picture is consistent with what Bowen and Bok found when they looked at the careers of black students who graduated from elite undergraduate institutions. The congruence of Bowen and Bok's findings with our own gives us considerable confidence in our findings and supports the validity of their results.

Our study, together with Bowen and Bok's study, suggest that affirmative action programs in elite higher education are working much as their proponents hoped they would. ${ }^{75}$ It would be a tragedy if the current legal assault on affirmative action, which is fueled, in part, by the argument that these programs ignore "merit" and graduate people who are less competent than those whom they displace, were to succeed just when empirical research is telling us how successful the beneficiaries of affirmative action have been in their own lives and in giving back to society. Indeed, if future empirical research yields results like ours, a case can be made that without an affirmative action component, law school admissions policies that are heavily oriented toward LSAT scores and UGPAs discriminate against minorities.

Bowen and Bok use Mark Twain's portrait of the Mississippi River as a metaphor to describe the route minority students traverse at selective undergraduate schools and beyond. We now see a part of the "beyond" more clearly. There are, to be sure, shoals that exist when the river runs through

74. Indeed, we are confident that neither the white nor minority graduates of schools substantially less prestigious than Michigan will do as well financially as Michigan graduates, and we expect from the literature on the legal profession that they will be less satisfied with their careers. However, it may be that, just as at Michigan, minority graduates from these schools will be similar to their school's white graduates in post-law school career success. One cannot conclude from our results that this is either likely or unlikely.

75. The only other similar study we could find has results remarkably consistent with ours except it finds no special propensity of minority professionals to serve people of their own ethnicity. Davidson and Lewis (1997) looked at graduates of the University of California at Davis Medical School over a 20-year period. They find that students admitted under an affirmative-action program do worse than a matched control group of regularly admitted students on grades in key medical school courses, but the two groups do not differ significantly in the rates at which they completed their initially chosen residency; academic difficulty in residence programs; special honors as residents; most popular residency disciplines; later board certification; general practice characteristics; involvement in teaching; or satisfaction with their choice of medicine as a career, their choice of medical specialty, or their current practice. Minority respondents did, however, express significantly more satisfaction with life overall. 
law school, but most minority admittees get past them to sail proudly, and equally with their white counterparts, on the sea.

\section{REFERENCES}

Bowen, William, and Derek Box. 1998. The Shape of the River: Long-Term Consequences of Considering Race in College and University Admissions. Princeton, N.J.: Princeton University Press.

Carlson, A. B., and C. E. Werts. 1976. Relationships among Law School Predictors, Law School Performance, and Bar Examination Results. In Reports of LSAC-sponsored Research: Volume 1, 1949-1969, Report no. LSAC 76-1, pp. 264-69. Princeton, N.J.: Law School Admissions Council.

Darley, J. M., and B. Latane. 1968a. Bystander Intervention in Emergencies: Diffusion of Responsibility. Journal of Personality and Social Psychology 8:377-83.

- 1968b. The Unresponsive Bystander: Why Doesn't He Help? New York: Appleton-Century Crofts.

Davidson, Robert, and Ernest Lewis. 1997. Affirmative Action and Other Special Consideration Admissions at the University of California, Davis, School of Medicine. Journal of the American Medical Association 278:1153-1158.

Heinz, J. P., and E. O. Laumann. 1982. Chicago Lawyers: The Social Structure of the Bar. New York: Russell Sage Foundation; Chicago: American Bar Foundation.

Keith, Stephen, et al. 1986. Acts of Affirmative Action in Medical School: A Study of the Class of 1976. New England Journal of Medicine 313:1519-1525.

Komaromy, Miriam, et al. 1996. The Role of Black and Hispanic Physicians in Providing Health Care for Underserved Populations. New England Journal of Medicine 334:1305-1310.

Lin, P., and L. G. Humphreys. 1977. Predictions of Academic Performance in Graduate and Professional School. Applied Psychological Measurement 1(2):249-57.

Moy, Ernest, and Barbara A. Bartman. 1995. Physician Race and Care of Minority and Medically Indigent Patients. Joumal of the American Medical Association 273:1515-1520.

Nelson, R. L. 1988. Partners with Power. Berkeley and Los Angeles: University of California Press.

Orfield, Gary, and Dean Whitla. 1999. Diversity and Legal Education: Student Experiences in Leading Law Schools. Civil Rights Project, Harvard University.

Raudenbush, Stephen W. 1999. Supplemental Expert Witness Report, Grutter v. Bollinger et al. No. 97-75928 (E.D. Mich.), 3 March.

Rhode, Deborah. 1999. Cultures of Commitment: Pro Bono for Lawyers and Law Students. Fordham L. Rev. 67:2415.

Ross, A. S. 1971. Effect of Increased Responsibility on Bystander Intervention: The Presence of Children. Journal of Personality and Social Psychology 19:306-310.

Smigel, E. O. 1969. The Wall Street Lawyer: Professional Organization Man? Revised edition. Bloomington: Indiana University Press.

U.S. Bureau of the Census. 1997. Annual Demographic File of Current Population Survey. Public Use Microdata Sample; Bureau of the Census. Washington, D.C.

U.S. News $\&$ World Report. America's Best Graduate Schools, 29 March 1999, 74-115.

Wightman, L. 1999. Beyond FYA: Analysis of the Utility of LSAT Scores and UGPA for Predicting Academic Success in Law School. Report prepared for the Law School Admission Council, Princeton, N.J. 
Wilkins, David, and G. Mitu Gulati. 1996. Why Are There So Few Black Lawyers in Corporate Law Firms? An Institutional Analysis. California Law Review $84: 493-625$.

Winterbottom, J. A., B. Pitcher, and P. Van R. Miller. 1976. Report of the Readministration of the LSAT to Third-Year Students. In Reports of LSAC-sponsored Research: Volume 1, 1949-1969, pp. 255-66. Report No. LSAC 63-3. Princeton, N.J.: Law School Admission Council. 